Western\&Graduate\&PostdoctoralStudies

Western University

Scholarship@Western

Electronic Thesis and Dissertation Repository

8-15-2013 12:00 AM

\title{
Soft-Switching DC-DC Converters
}

Ahmad Mousavi, The University of Western Ontario

Supervisor: Dr. Gerry Moschopoulos, The University of Western Ontario

A thesis submitted in partial fulfillment of the requirements for the Doctor of Philosophy degree in Electrical and Computer Engineering

(c) Ahmad Mousavi 2013

Follow this and additional works at: https://ir.lib.uwo.ca/etd

Part of the Electrical and Electronics Commons, and the Electronic Devices and Semiconductor Manufacturing Commons

\section{Recommended Citation}

Mousavi, Ahmad, "Soft-Switching DC-DC Converters" (2013). Electronic Thesis and Dissertation Repository. 1435.

https://ir.lib.uwo.ca/etd/1435

This Dissertation/Thesis is brought to you for free and open access by Scholarship@Western. It has been accepted for inclusion in Electronic Thesis and Dissertation Repository by an authorized administrator of Scholarship@Western. For more information, please contactwlswadmin@uwo.ca. 


\title{
SOFT-SWITCHING DC-DC CONVERSTERS
}

(Thesis Format: Monograph)

\author{
by
}

Ahmad Mousavi

Graduate Program in Engineering Science

Department of Electrical and Computer Engineering
A Thesis Submitted in Partial Fulfillment
of the Requirements for the Degree of Doctor of Philosophy

The School of Graduate and Postdoctoral Studies

The University of Western Ontario

London, Ontario, Canada

(CAhmad Mousavi 2013 


\section{ABSTRACT}

Power electronics converters are implemented with switching devices that turn on and off while power is being converted from one form to another. They operate with high switching frequencies to reduce the size of the converters' inductors, transformers and capacitors. Such high switching frequency operation, however, increases the amount of power that is lost due to switching losses and thus reduces power converter efficiency.

Switching losses are caused by the overlap of switch voltage and switch current during a switching transition. If, however, either the voltage across or the current flowing through a switch is zero during a switching transition, then there is no overlap of switch voltage and switch current so in theory, there are no switching losses. Techniques that ensure that this happens are referred to as soft-switching techniques in the power electronics literature and there are two types: zero-voltage switching (ZVS) and zero-current switching (ZCS).

For pulse-width modulated (PWM) Dc-Dc converters, both ZVS and ZCS are typically implemented with auxiliary circuits that help the main power switches operate with softswitching. Although these auxiliary circuits do help improve the efficiency of the converters, they increase their cost. There is, therefore, motivation to try to make these auxiliary circuits as simple and as inexpensive as possible.

Three new soft-switching Dc-Dc PWM converters are proposed in this thesis. For each converter, a very simple auxiliary circuit that consists of only a single active switching device and a few passive components is used to reduce the switching losses in the main power switches. The outstanding feature of each converter is the simplicity of its auxiliary 
circuit, which unlike most other previously proposed converters of similar type, avoids the use of multiple active auxiliary switches.

In this thesis, the operation of each proposed converter is explained, analyzed, and the results of the analysis are used to develop a design procedure to select key component values. This design procedure is demonstrated with an example that was used in the implementation of an experimental prototype. The feasibility of each proposed converter is confirmed with experimental result obtained from a prototype converter. 


\section{Acknowledgements}

I would like to offer my sincere appreciation to Dr. Gerry Moschopoulos for his continuous guidance throughout my research, and his assistance in publishing several journal and conference papers in addition to this thesis. I am also thankful to the members of my examination committee.

I also appreciate the support given by Dr. Praveen Jain at EPEARL (Energy and Power Electronics Applied Research Laboratory) and all my friends including Dr. Pritam Das, Dr. Majid Pahlevaninezhad and Dr. Hamid Danesh at Queen's University, for their assistance during my research.

I would like to express my deepest gratitude to my parents Rezvan and Reza for their constant encouragement and support to continue my higher education and finish this research. I also like to express thanks to my brother Ali for his best wishes.

Finally I would like to thank my wife Donya. Her support, encouragement, patience and unwavering love, provided the foundation for this work. I also want to thank my in-laws, Nahid and Fereidoon, for their unconditional support.

Ahmad Mousavi

Aug 15, 2013 


\section{Table of Contents}

Abstract $\quad$ ii

Acknowledgments $\quad$ iv

Table of Contents $\quad \mathrm{V}$

List of Figures $\quad$ vii

List of Nomenclature $\quad$ ix

List of Abbreviation $\quad$ xi

Chapter 1 : Introduction $\quad 1$

1.1 Introduction 1

1.2 High Switching Frequency Operation in Power Electronic Converters 3

1.3 Losses in Semiconductor Switches 4

1.3.1 Conduction Losses $\quad 4$

1.3.2 Switching Losses $\quad 4$

1.4 Soft Switching 6

1.5 Dc-Dc Converters $\quad 8$

$\begin{array}{ll}\text { 1.5.1 Boost Converters } & 8\end{array}$

$\begin{array}{ll}\text { 1.5.2 Buck Converters } & 10\end{array}$

$\begin{array}{ll}\text { 1.5.3 Full-Bridge Boost Converters } & 11\end{array}$

1.6 Literature Review 11

1.6.1 Soft Switching in PWM Bidirectional Dc-Dc Converters 12

1.6.2 Soft Switching in PWM Full-Bridge Dc-Dc Converters 14

1.6.3 Soft Switching in Three-Phase Dc-Dc Converters 18

$\begin{array}{ll}1.7 \text { Thesis Objectives } & 20\end{array}$

1.8 Thesis Outline $\quad 21$

Chapter 2: A Novel Non-Isolated Bidirectional ZVS-PWM Dc-Dc Converter 23 with One Auxiliary Switch

2.1 Introduction 23

2.2 Converter Operation 24

2.2.1 Boost Mode of Operation 25

2.2.2 Buck Mode of Operation 30

2.3 Design Guidelines $\quad 35$ 
2.4 Design Example $\quad 38$

2.5 Experimental Results $\quad 39$

2.6 Conclusion $\quad 42$

Chapter 3: A new ZCS-PWM Full-Bridge Converter with Simple Auxiliary Circuits 44

3.1 Introduction 44

3.2 Converter Operation $\quad 44$

3.3 Converter Features $\quad 53$

3.4 Design Guidelines $\quad 56$

3.5 Experimental Results $\quad 65$

3.6 Conclusion $\quad 66$

Chapter 4: A Novel Three-Phase ZVS PWM Dc-Dc Boost Converter 70

4.1 Introduction $\quad 70$

4.2 Circuit Description and Modes of Operation 71

$\begin{array}{ll}4.3 \text { Converter Features } & 76\end{array}$

4.4 Design Procedure $\quad 80$

4.5 Experimental Results $\quad 85$

$\begin{array}{ll}4.6 \text { Conclusion } & 87\end{array}$

$\begin{array}{ll}\text { Chapter 5: Conclusion } & 88\end{array}$

5.1 Introduction $\quad 88$

$\begin{array}{ll}5.2 \text { Summary } & 88\end{array}$

5.3 Conclusion $\quad 92$

$\begin{array}{ll}5.4 \text { Contributions } & 94\end{array}$

5.5 Future Work 95

References $\quad 96$

$\begin{array}{ll}\text { Curriculum Vitae } & 101\end{array}$ 


\section{List of Figures}

Fig.1.1 (a) Diagram of an IGBT (b) Diagram of a power MOSFET 3

Fig.1.2 Loss of Power during hard switching. $\quad 5$

$\begin{array}{ll}\text { Fig 1.3 ZVS MOSFET implementation } & 7\end{array}$

Fig.1.4 ZCS IGBT implementation. $\quad 8$

Fig.1.5 (a) A Dc-Dc boost converter, (b) Ideal waveforms 9

$\begin{array}{ll}\text { Fig.1.6 Buck converter } & 10\end{array}$

Fig.1.7 Ideal waveforms $\quad 10$

Fig.1.8 Full-bridge boost Dc-Dc converter $\quad 12$

Fig.1.9 Proposed converter in [2] 14

Fig.1.10 Proposed converter in [8] 14

Fig.1.11a Proposed circuit in [22] with 2 primary side aux switches 16

Fig.1.11b Proposed circuit in [23] with 2 secondary side aux switches 16

Fig.1.12a ZVZCS circuit in [27] with secondary side auxiliary switch 17

Fig.1.12b ZVZCS circuit in [33] with secondary side passive circuit 17

Fig.1.13 Example three-phase Dc-Dc converters (a) Converter proposed in [47], 19

(b) Converter proposed in [50].

Fig. 2.1 Proposed bidirectional boost/buck converter 25

Fig. 2.2 Equivalent circuit for each mode of operation (boost mode) 27

Fig. 2.3 Typical converter waveforms for boost mode operation 29

Fig. 2.4 Equivalent circuit for each mode of operation (buck mode). 31

Fig. 2.5 Typical converter waveforms for buck mode operation. 33

Fig. 2.6 Current and voltage in S1 - Boost mode $\quad 41$

(V: 200V/div, I: $2.5 \mathrm{Amps} / \mathrm{div}, \mathrm{t}: 2.5 \mu \mathrm{s} / \mathrm{div}$ )

Fig. 2.7 Current and voltage in S2 - Buck mode $\quad 41$

(V: 200V/div, I: $2.5 \mathrm{Amps} / \mathrm{div}, \mathrm{t}: 2.5 \mu \mathrm{s} / \mathrm{div}$ )

Fig. 2.8 Efficiency comparison for boost mode operation. $\quad 42$

Fig. 2.9 Efficiency comparison for buck mode operation. $\quad 42$

Fig. 3.1 The proposed ZCS converter $\quad 45$

Fig. 3.2 Equivalent circuit for each mode of operation $\quad 50$

Fig. 3.3. Ideal waveforms $\quad 52$ 
Fig. 3.4. Equivalent circuit for (a) Mode 1 (b) Mode 2 (c) Mode 3

Fig. 3.5 Variation of $C_{a}$ peak voltage for different values of $Z_{0} \quad 60$

Fig. 3.6 Variation of peak current in auxiliary switch for different values of $Z_{1} \quad 62$

Fig. 3.7 Variation of the duration in which current in S1 reduces to zero and goes negative 64 during modes 1-2 for different values of $\mathrm{V}_{\mathrm{Ca}}$

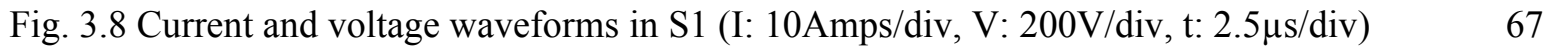

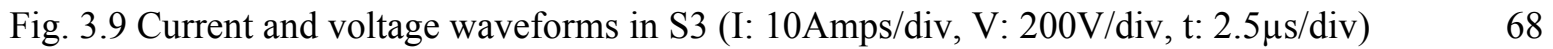

Fig. 3.10 Current and voltage waveforms in S2 (I: 10Amps/div, V: 200V/div, t: $2.5 \mu \mathrm{s} / \mathrm{div}) \quad 68$

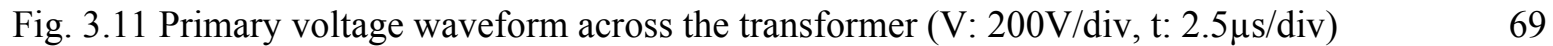

Fig. 3.12 Efficiency comparison results $\quad 69$

Fig. 4.1 Proposed three-phase ZVS boost converter 72

Fig. 4.2 Typical converter waveforms

Fig. 4.3 Equivalent circuit diagrams of modes of operation $\quad 78$

Fig. 4.4 Voltage across $C_{a}$ for different values of $Z_{o}$

Fig. 4.5 Current peak in the auxiliary switch versus different values of $Z_{o} \quad 84$

Fig. 4.6 Current and voltage waveforms in S1 (I: 10Amps/div, V: 30V/div, t: $2.5 \mu \mathrm{s} / \mathrm{div}) \quad 86$

Fig. 4.7 Current and voltage waveforms in S2 (I: 10Amps/div, V: 30V/div, t: $1 \mu \mathrm{s} / \mathrm{div}) \quad 86$

Fig. 4.8 Primary voltage waveform across the transformer (V: 20V/div, t: $5 \mu \mathrm{s} / \mathrm{div})$

Fig. 4.9 Efficiency results $\quad 87$ 


\section{List of Nomenclature}

\begin{tabular}{|c|c|}
\hline $\mathrm{C}_{\mathrm{a}}, \mathrm{C}_{\mathrm{r}}$ & Auxiliary Capacitor \\
\hline $\mathrm{C}_{\mathrm{o}}$ & Output Capacitor \\
\hline $\mathrm{C}_{\mathrm{ds}}$ & Capacitor Across Drain-Source of MOSFET \\
\hline $\mathrm{D}$ & Switch Duty Cycle \\
\hline $\mathrm{D}_{\mathrm{x}}$ & Diode \\
\hline $\mathrm{D}_{\mathrm{a}}$ & Auxiliary Diode \\
\hline$f, f_{\mathrm{s}}$ & Switching Frequency \\
\hline$f_{\mathrm{o}}$ & Resonant Frequency \\
\hline I & Current \\
\hline $\mathrm{I}_{\text {in }}$ & Input Current \\
\hline $\mathrm{I}_{\mathrm{o}}$ & Output Current \\
\hline $\mathrm{I}_{\text {prim }}$ & Primary Side Current \\
\hline $\mathrm{I}_{\text {peak }}$ & Peak Current \\
\hline $\mathrm{I}_{\mathrm{sec}}$ & Secondary Side Current \\
\hline $\mathrm{I}_{\mathrm{S}}$ & Current Flowing in a Switch \\
\hline $\mathrm{I}_{\mathrm{La}}$ & Current Flowing in Inductor $\mathrm{L}_{\mathrm{a}}$ \\
\hline $\mathrm{I}_{\mathrm{Ca}}$ & Current flowing in Capacitor $\mathrm{C}_{\mathrm{a}}$ \\
\hline $\mathrm{L}_{\text {in }}$ & Input Inductor \\
\hline $\mathrm{L}_{\mathrm{o}}$ & Output Inductor \\
\hline $\mathrm{L}_{\mathrm{a}}, \mathrm{L}_{\mathrm{r}}$ & Auxiliary Inductor \\
\hline $\mathrm{L}_{\mathrm{Ik}}$ & Leakage Inductance \\
\hline $\mathrm{N}$ & Transformer Turns Ratio \\
\hline $\mathrm{N}_{\text {prim }}$ & Number of Turns in the Primary Side of the Transformer \\
\hline $\mathrm{N}_{\mathrm{sec}}$ & Number of Turns in the Secondary Side of the Transformer \\
\hline$P_{\text {in }}$ & Input Power \\
\hline $\mathrm{P}_{\mathrm{o}}$ & Output Power \\
\hline$P_{o, \max }$ & Maximum Output Power \\
\hline $\mathrm{R}$ & Resistor, Load \\
\hline
\end{tabular}




$\begin{array}{ll}\mathrm{R}_{\mathrm{DS}, \text { on }} & \text { Resistance Between Drain-Source in MOSFET when Switch is On } \\ \mathrm{S} & \text { Switches (MOSFET/IGBT) } \\ \mathrm{S}_{\mathrm{a}}, \mathrm{S}_{\mathrm{aux}} & \text { Auxiliary Switch } \\ \mathrm{T} & \text { Transformer } \\ \mathrm{t}_{\mathrm{on}} & \text { Switch On-Time } \\ \mathrm{t} & \text { Time } \\ \mathrm{t}_{\mathrm{rr}} & \text { Diode Reverse Recovery Time } \\ \mathrm{V}_{\mathrm{Ca}} & \text { Voltage Across Capacitor } \mathrm{C}_{\mathrm{a}} \\ \mathrm{V}_{\text {peak }} & \text { Peak Voltage } \\ \mathrm{V}_{\text {in }} & \text { Input Voltage } \\ \mathrm{V}_{\mathrm{o}} & \text { Output Voltage } \\ \mathrm{V}_{\mathrm{S}} & \text { Voltage Across Switch S } \\ \mathrm{V}_{\text {prim }} & \text { Voltage Across Primary Side of Transformer } \\ \mathrm{V}_{\text {sec }} & \text { Voltage Across Secondary Side of Transformer } \\ \mathrm{V}_{\mathrm{g}} & \text { Gate Voltage } \\ \mathrm{V}_{\mathrm{CE}, \text { sat }} & \text { Equivalent Voltage Source Equal to Saturation Voltage Between } \\ & \text { Collector and Emitter in IGBT } \\ \mathrm{Z}_{\mathrm{o}}, \mathrm{Z}_{1} & \text { Resonant Impedance }\end{array}$




\section{List of Abbreviation}

$\mathrm{AC}$

BJT

DC

EMI

EMC

IGBT

PFC

MOSFET

ZCS

ZVS

ZVZCS
Alternating Current

Bipolar Junction Transistor

Direct Current

Electro Magnetic Interference

Electro Magnetic Compatibility

Insulated Gate Bipolar Transistor

Power Factor Correction

Metal Oxide Silicon Field Effect Transistor

Zero-Current Switching

Zero-Voltage Switching

Zero-Voltage Zero-Current Switching 


\section{Chapter 1}

\section{Introduction}

\subsection{Introduction}

It is generally the task of power electronics to convert the electric power available from a power source to the form best suited for the user loads. Some sort of power processor or converter is required to serve as an interface between power source and load. The load may be ac or dc, single-phase or three-phase, and may or may not require transformer isolation from the power source. The power source could be a single-phase or three-phase ac source with line frequency of 50 or $60 \mathrm{~Hz}$; it can be an electric battery, a solar panel or a commercial power supply. This source feeds the input of the power converter, which converts the power to the required form. The converter can be an ac-dc converter, a Dc-Dc converter, a dc-ac converter or an ac-ac converter.

Power converters typically consist of semiconductor devices such as transistors and diodes, energy storage elements such as inductors and capacitors, and some sort of controller to regulate the output voltage. Transistor type devices like BJTs (Bipolar Junctions Transistors), MOSFETs (Metal Oxide Silicon Field Effect Transistors) and IGBTs (Insulated Gate Bipolar Transistors) are used as switches in power electronic converters and are made to operate as switches that are either fully on or fully off at any given moment in time. These devices can be operated at higher switching frequencies than thyristor based devices, which helps reduce converter size. While BJTs and MOSFETs are 
basic devices, IGBTs are hybrid devices that have an insulated gate like a MOSFET but a conduction region that is the same as a BJT.

BJTs were used as switches in SMPS (Switch Mode Power Supplies) in the late 1970'searly 1980's, but since they are current-controlled devices, they are no longer used in SMPS where switches need to be turned on and off at very high frequencies in the $\mathrm{kHz}$ range. The MOSFET, being a charge controlled device, is faster than a BJT. When turned on, a MOSFET is equivalent to a resistance between its source and drain $\left(\mathrm{R}_{\mathrm{DS} \text {,on }}\right)$, while the BJT when fully on is equivalent to a voltage source equal to the saturation voltage between collector and emitter $\left(\mathrm{V}_{\mathrm{CE}, \mathrm{sat}}\right)$. Thus the conduction losses in MOSFETs are proportional to the square of the on-state current that it is conducting while these losses in a BJT is proportional to the on-state current it is conducting.

The IGBT is a hybrid device that incorporates an insulated gate so that it turns on like a MOSFET and conducts like a BJT in saturation, hence the name IGBT. The IGBT undergoes a MOSFET type turn, faster than a conventional BJT but its turn off is dependent on the minority carriers present in it during its on state (i.e it undergoes a turn off similar to that of a BJT and has a current tail during its turn off). The IGBT is therefore faster than a conventional BJT but slower than a MOSFET.

MOSFETs are used for lower power applications (typically a few kilowatts) and have lower current and lower voltage ratings (typically a few hundreds of volts) but higher frequency well in a range of hundreds of $\mathrm{kHz}$ while the IGBT is used in higher power applications, they have high voltage and current ratings, but operate at lower frequencies (up to $100 \mathrm{kHz}$ ). 
IGBTs and MOSFETs are widely used in power electronic applications such as high frequency inverters used at the front ends of high efficiency AC motor drives, high and very high frequency Dc-Dc converters, power factor correction modules etc. Diagrams of a N-P-N IGBT and a N-channel MOSFET are shown in Fig.1.1.

\subsection{High Switching Frequency Operation in Power Electronic Converters}

The size of the energy storage components of a power electronic converter, such as inductors (L) and capacitors (C), accounts for much of the overall size of the converter. These components are needed to store and transfer energy from the input power supply to the output load in the converter. Their values depend on the frequency that the converter switch is turned on and off. As the switching frequency is increased, the values of the inductors and capacitors decrease and so do their physical size and weight; therefore the higher the converter switching frequency, the smaller is the converter size.

Higher switching frequency operation, however, results in increased switching losses and EMI noise emissions, which are described in the next section. Problems associated with

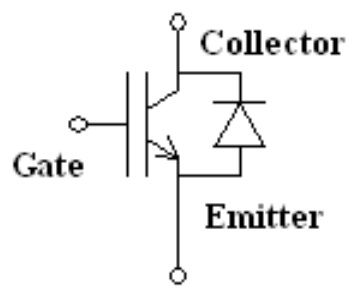

(a)

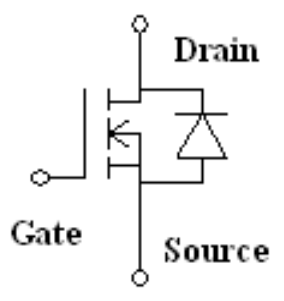

(b)

Fig.1.1 (a) Diagram of an IGBT (b) Diagram of a power MOSFET 
switching losses and EMI caused by sudden switching transitions can offset the advantages achieved by operating a converter with a high switching frequency.

\subsection{Losses in Semiconductor Switches}

The semiconductor switches used in power converters are not ideal and are a source of energy losses. The main losses that are associated with these switches are conduction losses and switches losses, which will be described in more detail below.

\subsubsection{Conduction Losses}

The conduction losses of a MOSFETs are due to its behaving as a resistor when fully on - the resistance being equal to $R_{D S, o n}$, the on state drain to source resistance. The conduction losses of an IGBT are related to the amount of current flowing in the device and $\mathrm{V}_{\mathrm{CE}, \text { sat }}$, the saturation voltage between collector and emitter.

\subsubsection{Switching Losses}

In a real semiconductor switch, the switch voltage or switch current do not go to zero instantaneously at the instant of turn-on or turn-off. There is a duration of time during any switching transition (i.e. switch turn-on and turn-off) when there is both voltage across and current through the switch. The corresponding power loss during each switching instant is the overlapped area of the switch current and voltage waveforms at the instant of turn-on or turn-off of the switch. Since the average power is energy divided by the period, higher switching frequencies lead to higher switching losses. Sharp and sudden switching 
transitions are also sources of electromagnetic interference (EMI) noise that can affect the performance of a converter and/or other surrounding electrical equipment.

Both the IGBT and MOSFET have anti-parallel body diodes. A MOSFET has a much higher output capacitance between its drain and source than that between collector and emitter of an IGBT. This output capacitance charges up to the off state voltage that the MOSFET is subjected to while the IGBT has a current tailing after it is actually turned off.

In a MOSFET, the main switching losses are caused by the charging and discharging of the output capacitance to and from the off state voltage that the MOSFET is subjected to, while the tailing of current is the primary cause of switching losses in IGBTs. Turning on and turning off the power electronic switches with such switching losses is known as "hard switching".

Fig. 1.2 shows the typical current and voltage and current graphs of the switch $\mathrm{S}_{1}$ during a whole switching cycle. At $t_{0}$, the driving pulse of $S_{1}$ is removed so that it gets turned off. $S_{1}$ takes time $t_{\text {off }}$ to turn off fully. During this time, due to the overlap of the current and voltage waveforms, there occurs a turn off loss represented by the area under the graph $P_{\text {off }}$. At $t_{1}$, the driving pulse is applied to the switch $S_{1}$ so that it gets turned on.

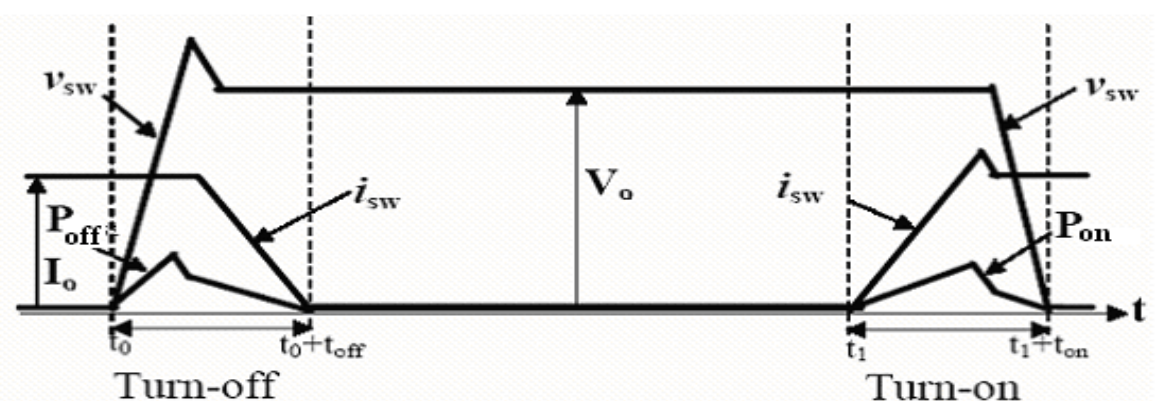

Fig.1.2 Loss of Power during hard switching. 
The switch $\mathrm{S}_{1}$ takes time $\mathrm{t}_{\mathrm{on}}$ to get turned on. During this time, due to overlap of the current and voltage waveforms of $\mathrm{S}_{1}$, a turn-on loss occurs.

\subsection{Soft Switching}

The problems of switching losses and EMI associated with hard-switching converter operation can be reduced by using soft-switching. The term "soft-switching" in power electronics refers to various techniques where the switching transitions are made to be more gradual to force either the voltage or current to be zero while the switching transition is being made. EMI is reduced by soft-switching because the switching transitions from on to off and vice versa are gradual and not sudden. Switching losses are reduced since the power dissipated in a switch while a switching transition made is proportional to the overlap of the voltage across the switch and the current flowing through it.

Soft-switching forces either the voltage or the current to be zero during the time of transition; therefore there is no overlap between voltage and current and (ideally) no switching loss. There are two types of soft-switching: zero-voltage switching (ZVS) and zero-current switching (ZCS). Although there are many ZVS and ZCS techniques, there are general principles associated with each type.

The circuit symbol for a MOSFET is shown in Fig.1.3, along with an anti-parallel diode (which is the body diode that is internal to the device) and a capacitor $\mathrm{C}_{\mathrm{ds}}$ that is across the device's drain and source. $\mathrm{C}_{\mathrm{ds}}$ usually consists of an internal capacitance associated with the device and an additional external capacitor. The MOSFET can turn on with ZVS if it is somehow ensured that current is flowing through the body diode to clamp the drain-source 


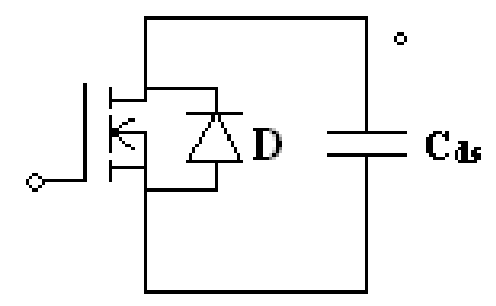

Fig 1.3 ZVS MOSFET implementation

voltage to zero just before turn-on. The MOSFET can turn off with ZVS because $\mathrm{C}_{\mathrm{ds}}$ prevents the voltage from rising abruptly as the device is turned off.

A switch can be made to operate with ZCS if an inductor is added in series to it as shown in Fig. 1.4 for a MOSFET. The MOSFET can turn on with ZCS because the inductor limits the rise in current so that the current flowing through the MOSFET is almost zero as the device is being turned on. The MOSFET can turn off with ZCS if a negative voltage is somehow impressed across the inductor-MOSFET combination so that current falls to zero at a gradual rate due to the inductor.

Although both ZVS and ZCS operations can reduce the switching losses of either a MOSFET or an IGBT, ZVS is preferred over ZCS for MOSFETs and ZCS is preferred over ZVS for IGBTs. In the case of MOSFETs, ZVS can substantially reduce the losses caused by the discharging of $\mathrm{C}_{\mathrm{ds}}$ into the device when it is turned on whereas ZCS cannot. In the case of IGBTs, since their output capacitances are lower than those of MOSFETs, the main source of switching losses are not the turn-on losses but the turn-off losses. This is especially true when it is considered that IGBTs have a current tail when they are turned off, which means that there is significant overlap between voltage and current during turnoff. This current tail can be eliminated if current is gradually removed from an IGBT using 


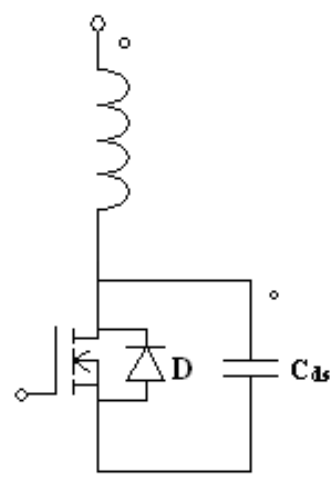

Fig.1.4 ZCS IGBT implementation.

some ZCS method before it is actually turned off; therefore switching losses can be reduced as there is no overlap between voltage and current during turn-off.

It should be noted that although soft-switching can reduce switching losses, conduction losses that exist when current flows through a MOSFET/IGBT/ Diode will still exist.

\subsection{Dc-Dc Converters}

\subsubsection{Boost Converters}

Dc-Dc converters convert an available unregulated dc input voltage into a regulated dc output voltage of a different magnitude and/or polarity as required by a particular load. Most Dc-Dc converters are switch-mode converters that operate with active semiconductor devices like MOSFETs and IGBTs, acting as on-off switches. These switches are required to undergo repetitive and periodic turn on and turn off. The output de voltage in such converters are dependent on the duty cycle $\mathrm{D}(<1)$ which is defined as the length of time that the switch is on $\left(t_{o n}\right)$ over the duration of the switching cycle $\left(T_{\mathrm{sw}}=1 / \mathrm{f}_{\mathrm{sw}}\right)$. " $\mathrm{D}=\mathrm{t}_{\mathrm{on}} / \mathrm{T}_{\mathrm{S}}$ " 
The two most basic types of Dc-Dc converters are the buck converter (output voltage is a stepped down value of the input voltage) and boost converter (output voltage is a stepped up value of the input voltage). Other types of Dc-Dc converters are buck-boost, Cuk, Sepic and Zeta etc. The circuit diagram of a boost converter is shown in Fig.1.5 (a) and the ideal waveforms are shown in Fig. 1.5 (b).

In steady state, after the switch is turned on, the whole input voltage is applied across the input inductor $\mathrm{L}_{\text {in }}$ and it stores energy. When the switches are turned off, a negative voltage equal to $\left(\mathrm{V}_{\text {in }}-\mathrm{V}_{\mathrm{o}}\right)$ is applied across the inductor and the energy stored in the inductor is delivered to the output capacitance $\mathrm{C}_{\mathrm{o}}$. The steady state output voltage of the boost inductor must always be greater than the input voltage as the ratio of the output to input voltage is: $\frac{V_{o}}{V_{i n}}=\frac{1}{1-D}$

In order to operate the switch in a boost converter (which is typically a MOSFET or IGBT), a periodic pulse $\left(\mathrm{V}_{\mathrm{ge}}\right)$ must be applied between the gate $(\mathrm{G})$ and the emitter $(\mathrm{E})$ of

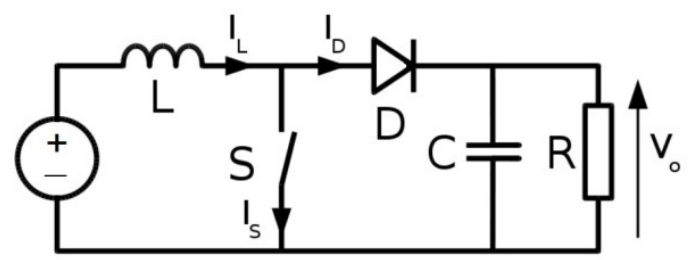

Fig.1.5(a) A Dc-Dc boost converter

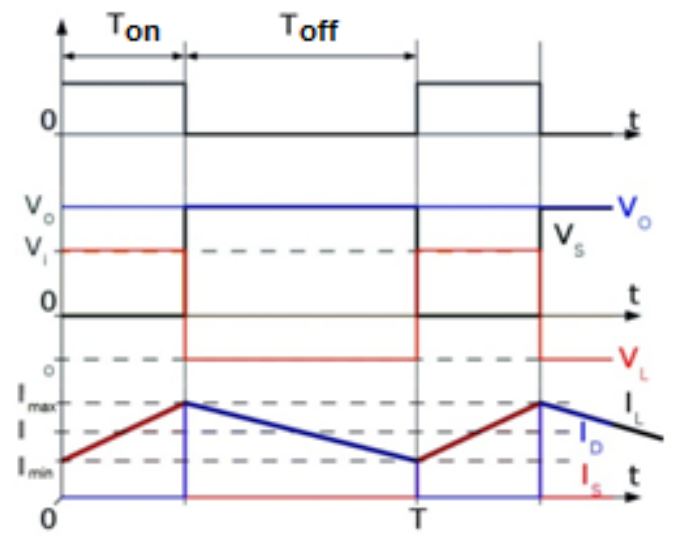

Fig.1.5(b) Ideal waveforms 
the device through a drive circuit. The MOSFET is on when the pulse $\mathrm{V}_{\mathrm{ge}}$ is high and off when it is low. Since $\mathrm{T}_{\mathrm{on}}=\mathrm{DT}_{\mathrm{sw}}$, the duty cycle of the converter, hence the ratio of the output to input voltage, is determined by the width of the pulse $\mathrm{V}_{\mathrm{ge}}$ so that it is the pulse width that is ultimately used to control and regulate the output voltage. This method of controlling the converter output, which is frequently used, is known as pulse width modulation control or PWM control.

\subsubsection{Buck Converters}

A buck converter is a step-down de to de switched-mode power supply converter that uses a transistor, a diode, an inductor and a capacitor. Buck converters are mainly used in regulated dc power supplies and dc motor speed control.

The output voltage of the converter varies linearly with the duty cycle for a given input voltage $\left(V_{o}=D V_{\text {in }}\right)$. Since the duty cycle $\mathrm{D}$ is equal to the ratio between $\mathrm{t}_{\mathrm{on}}$ and the period

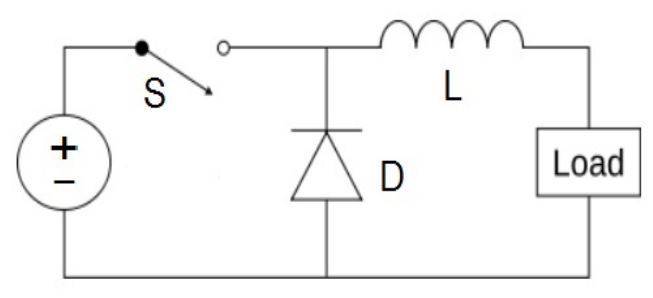

Fig. 1.6 Buck converter

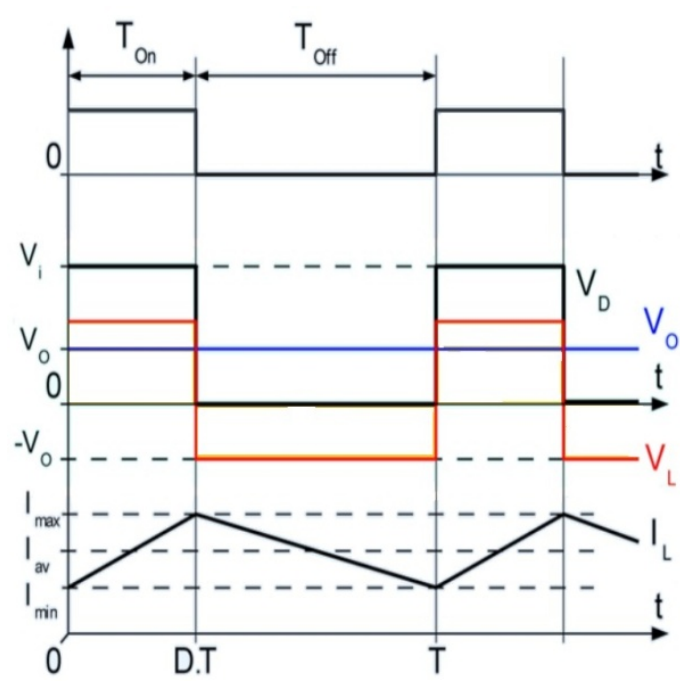

Fig.1.7 Ideal waveforms 
$\mathrm{T}$, it cannot be more than 1 , so $\mathrm{V}_{\mathrm{o}} \leq \mathrm{V}_{\text {in }}$ and this is why this converter is referred to as stepdown converter. Fig.1.6 and 1.7 shows the typical buck converter and the waveforms (in the continuous mode).

\subsubsection{Full-Bridge Boost Converters}

Full-bridge boost converters like the one shown in Fig.1.8 are very attractive for applications where an output dc voltage that is considerably larger than the input voltage is needed. Such applications include fuel cell power conversion, medical power supplies, and power supplies for electrostatic applications. These converters are essentially boost converters that contain a step-up transformer so that they can do additional voltage "boosting" without the very large duty ratios (D) needed with the boost converter shown in Fig.1.8.

The converter operates like a boost converter as the current in inductor $\mathrm{L}_{\text {in }}$ is increased whenever switches from the same leg are on and it is decreased whenever a pair of diagonally opposed switches is on as energy is transferred to the output through the transformer and the output diodes. It should be noted that there must always be a path for the input inductor current to flow through the full bridge switches at all times.

\subsection{Literature Review}

The main focus of this thesis is on certain problems that are related to soft-switching. The following problems are covered in this thesis:

- Making the switches in PWM converters that can operate with a bidirectional power flow operate with soft-switching. 
- $\quad$ Making the switches in PWM full-bridge converters operate with ZCS.

- Making the switches in three-phase Dc-Dc converters operate with soft-switching.

These three problems are interrelated with respect to each other, and the nature of this interrelation will be explained at the end of this thesis, in Chapter 5.

\subsubsection{Soft-Switching in PWM Bidirectional Dc-Dc Converters}

Bidirectional Dc-Dc converters allow transfer of power between two dc sources in either direction. In recent years the use of these converters has increased in fuel-cell applications, photovoltaic applications, uninterruptable power supplies (UPS) and hybridelectric vehicles. In order to reduce the size and weight of the converter, higher switching frequencies are used to operate these converters so as to decrease the size of the filtering components. When the switching frequency increases, switching losses and EMI (electromagnetic interference) rise in the circuit, which deteriorates the efficiency of the converter, so soft switching techniques are applied to high frequency converters.

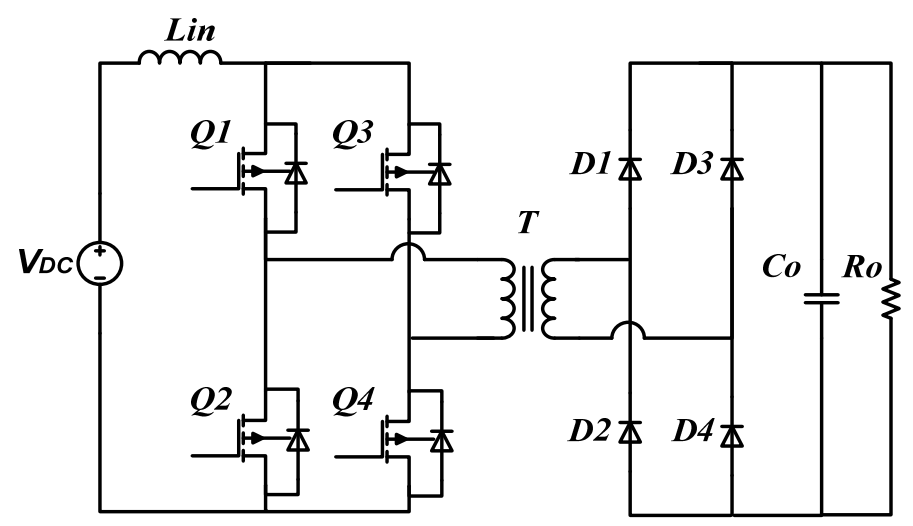

Fig.1.8 Full-bridge boost Dc-Dc converter 
Zero voltage switching (ZVS) or zero current switching (ZCS) is used to create soft switching in conventional PWM converters using auxiliary circuits. In [1] the auxiliary circuit used could achieve ZCS for the main switch in one direction and ZVS in the other direction, but forced the use of different types of switches for each direction of power flow. Due to the complexity of power flow in bidirectional converters, it is more challenging to develop soft switching techniques in these circuits; therefore it is desirable to use an auxiliary circuit to provide soft switching in both power flow directions (buck and boost mode). In some of the previously proposed bidirectional converters [2]-[6] two auxiliary circuits are employed to achieve soft switching when the power flows in both directions (Fig. 1.9).

The additional number of components can cause more conduction losses, along with increased complexity, cost, weight and size of the converter, and is thus considered to be a drawback. In [8] (Fig. 1.10), two auxiliary switches have been applied and the number of inductors was reduced to one. This causes the auxiliary switches to operate under hard switching conditions, thus reducing the gain in overall efficiency achieved by the soft switching of the main switches. A ZVS buck-boost converter with ZVS for all converter switches has been proposed in [9], but the converter still needs two auxiliary switches. 


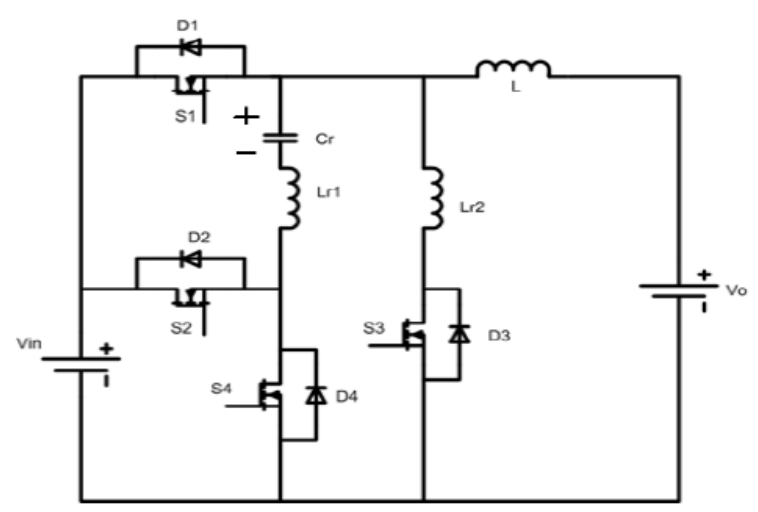

Fig. 1.9 Proposed converter in [2]

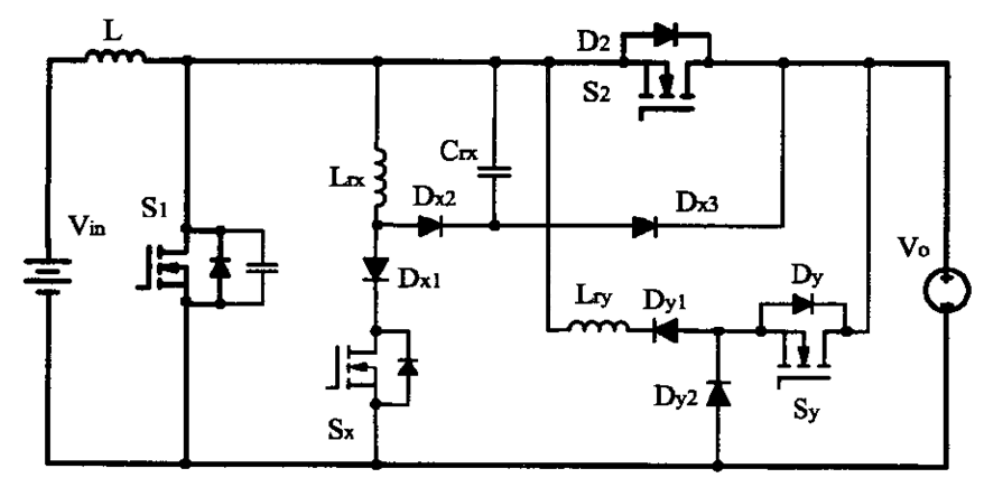

Fig. 1.10 Proposed converter in [8]

\subsubsection{Soft-Switching in PWM Full-Bridge Dc-Dc Converters}

Pulse-width modulated (PWM) Dc-Dc full-bridge converters with soft-switching are widely used in industry. For lower power applications, where the converters tend be to implemented with MOSFETs, zero-voltage-switching (ZVS) techniques are used to improve the efficiency of the full-bridge converter [13]-[20]. For higher power applications, where IGBTs are the preferred devices as they have lower conduction losses than MOSFETs due to their fixed collector-emitter voltage drop, zero-current-switching 
(ZCS) techniques are preferred. This is because ZCS methods can significantly reduce the tail in the IGBT device current that appears when the device is turned off. Reducing this current tail helps an IGBT operate with fewer turn-off losses and allows it to operate at higher switching frequencies.

Researchers have proposed various zero-current-switching (ZCS) techniques for higher power PWM full-bridge converters to allow their IGBT switches to operate at higher switching frequencies without unduly compromising converter efficiency. Some of these techniques use complicated auxiliary circuits to remove current from the main switches to turn off the main switches with ZCS. For example, auxiliary circuits with two auxiliary switches are proposed in [21]-[26] (Fig. 1.11a, b) to achieve ZCS for the main switches, but the increased cost of having two auxiliary circuits is a key drawback of these converters.

The use of active auxiliary circuits is avoided in converters such as the one proposed in [27] (Fig.1.12a), where passive auxiliary snubber circuits with integrated magnetics are added to provide a soft turn-off for the main power switches. Although the use of multiple auxiliary switches is avoided with these converters, the passive circuits themselves can be quite sophisticated and the overall converter efficiency is lower than that of the abovementioned converters that use multiple auxiliary switches.

Another approach that has been used to improve the efficiency of Dc-Dc PWM fullbridge converters is to implement them with auxiliary circuits that cause them to operate with zero-voltage-zero-current-switching (ZVZCS). These converters either use a secondary-side auxiliary switch [28]-[32] or a secondary-side passive circuit [33]-[37] (Fig.1.12b) to create a counter voltage in the converter primary that helps extinguish the 


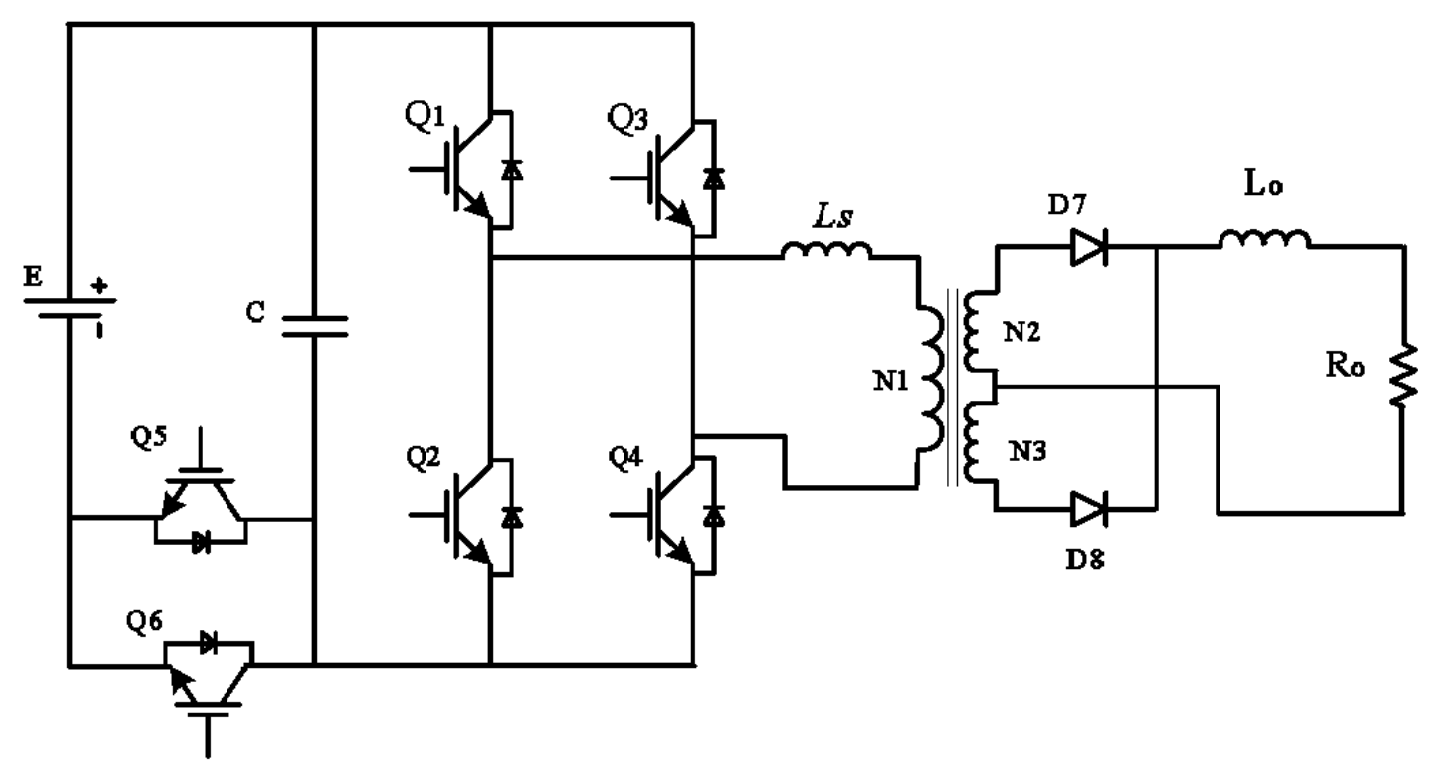

Fig.1.11a Proposed circuit in [22] with 2 primary side aux switches

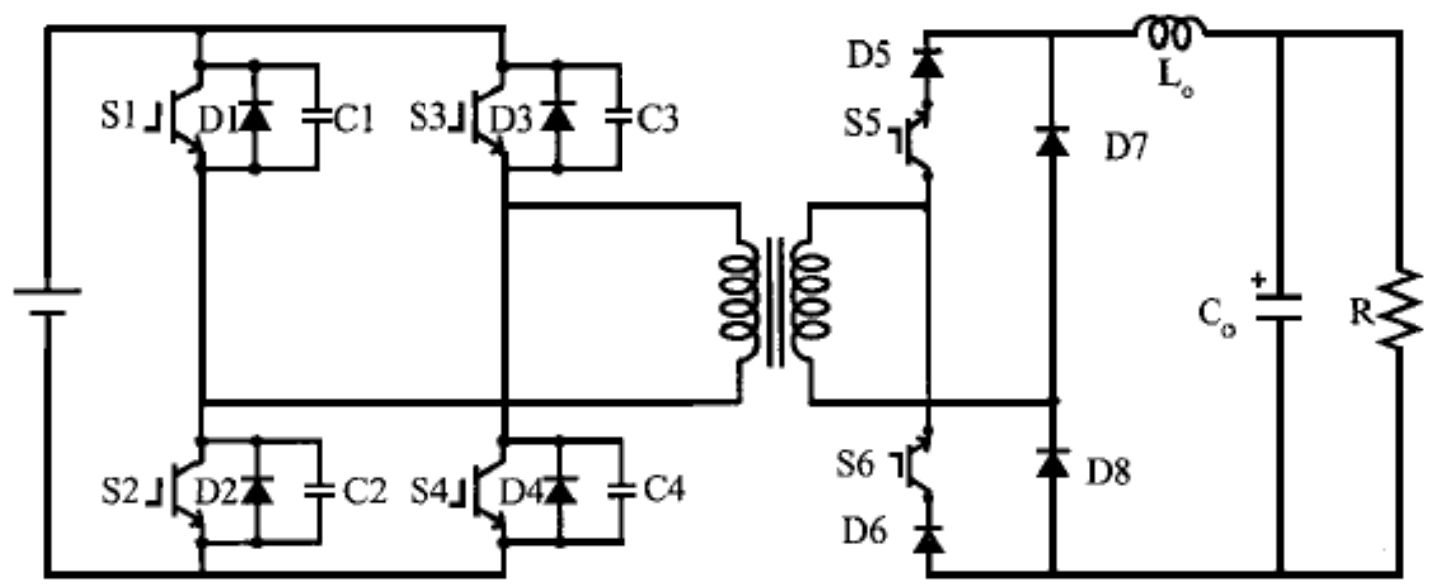

Fig.1.11b Proposed circuit in [23] with 2 secondary side aux switches 


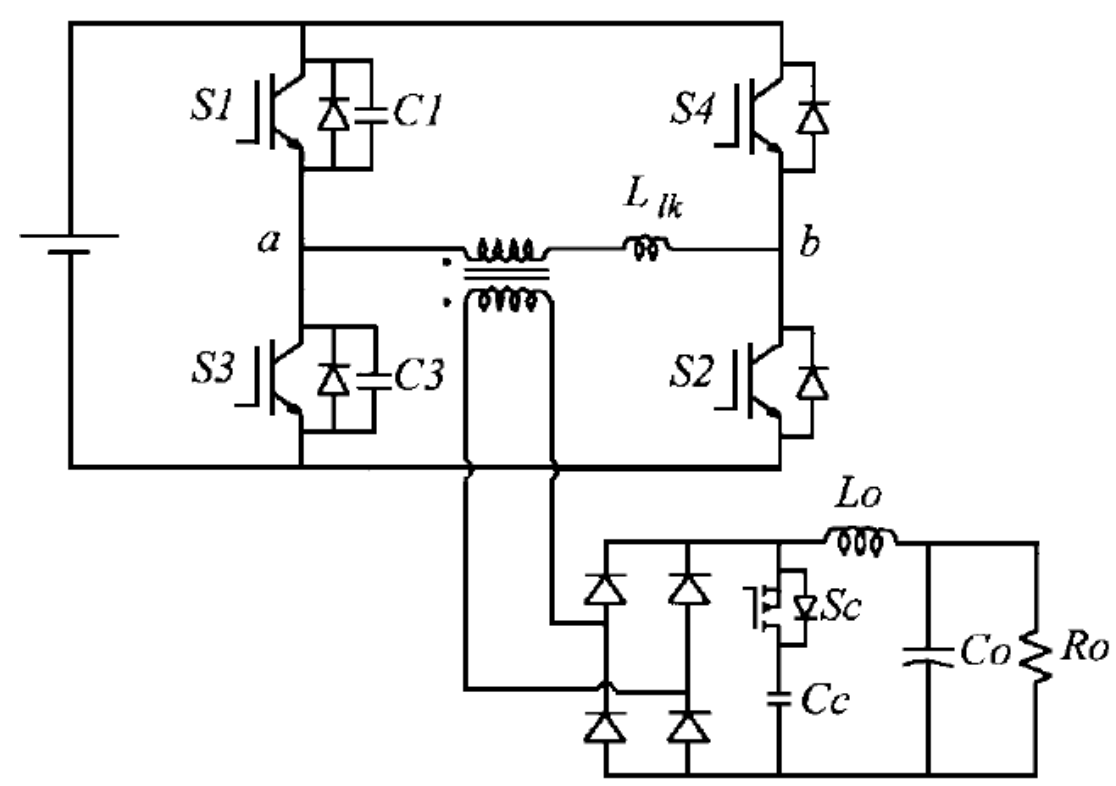

Fig.1.12a ZVZCS circuit in [27] with secondary side auxiliary switch

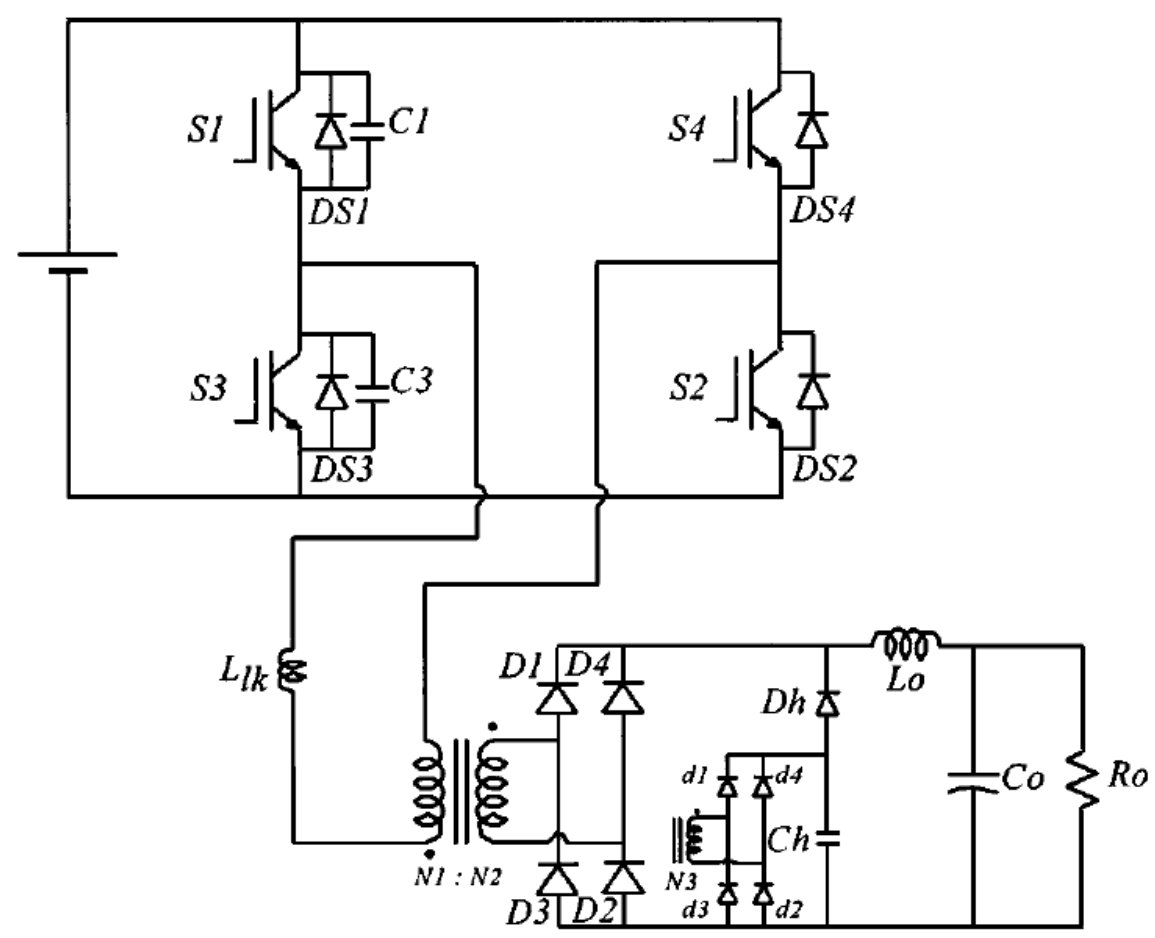

Fig.1.12b ZVZCS circuit in [33] with secondary side passive circuit 
current that would otherwise circulate in the full-bridge whenever the converter is in a freewheeling mode and do nothing but create conduction losses

- Regardless of what method is used to extinguish the freewheeling current, ZVZCS converters allow only their lagging leg switches to operate with ZCS so that IGBTs cannot be used in their leading leg.

This forces the use of MOSFETs in this leg instead of IGBTs to avoid high current losses at turn-off. As a result, not only does this increase the price of these converters as two different types of devices must be used as the main power switches in the converter, but the converter is limited to lower power applications due to the specifications of MOSFETs.

\subsubsection{Soft-Switching in Three-Phase Dc-Dc Converters}

Dc-Dc converters with transformer isolation that convert low input de voltages into high output dc voltages (i.e photovoltaic converters, fuel cell converters, etc.) are typically implemented with MOSFETs and use zero-voltage switching (ZVS) techniques to improve efficiency [39]-[45]. Most of these converters are single-phase boost-type converters with

just one input inductor. These converters, however, are unsuitable for higher power levels due to high switch stresses and high input current ripple. For such applications, three-phase Dc-Dc converters are more attractive because:

(i) They have more switches available to carry current so that switch current stresses are distributed over several switches instead of just a single switch.

(ii) They have less input current ripple and less output voltage ripple as the equivalent converter frequency is increased by a factor of three. 
(iii) They have higher power density due to the need for smaller filter components to filter the smaller input current ripple and output voltage ripple.

The first three-phase structure Dc-Dc converter was introduced in [46]. Researchers have since proposed various ZVS techniques for three-phase boost-type converter to allow the converter switches to operate at higher switching frequencies without unduly compromising converter efficiency [47]-[52]. Two examples are shown in Fig.1.13.

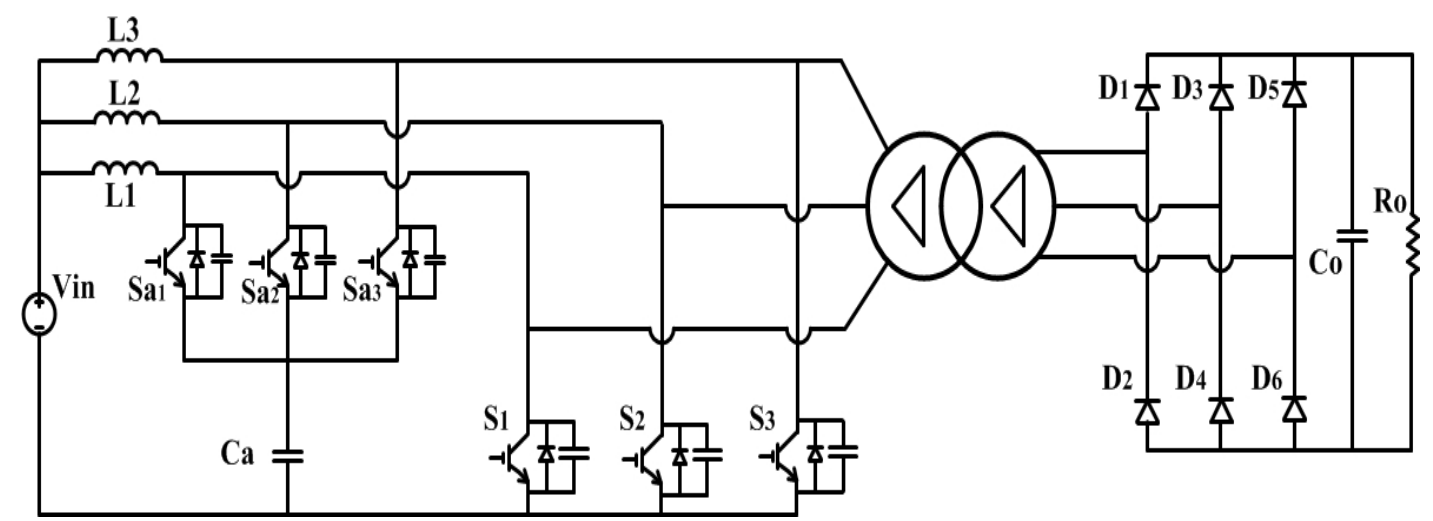

(a)

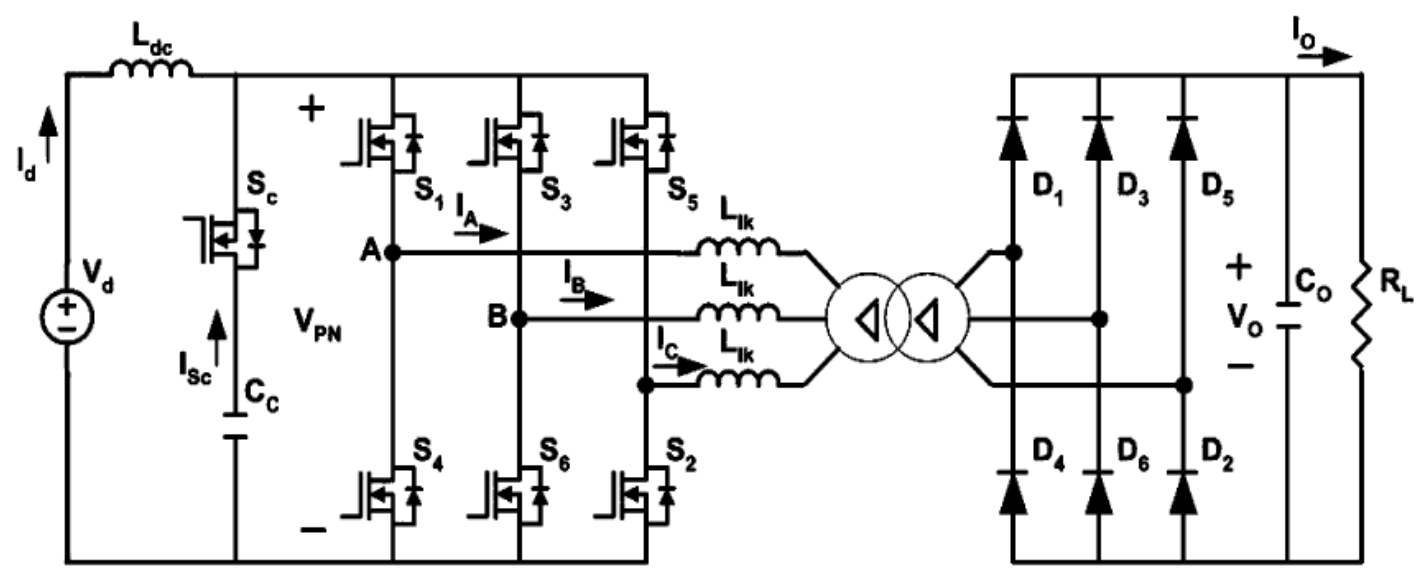

(b)

Fig.1.13 Example three-phase Dc-Dc converters

(a) Converter proposed in [47], (b) Converter proposed in [50]. 
Previously proposed three-phase Dc-Dc converters have at least one of the following drawbacks:

- Converters based on buck-type topologies have high input ripple as they do not have any inductor connected between the source and the three-phase converter.

- They are pulse-width modulated (PWM) converters that require costly and complicated auxiliary circuits to achieve ZVS operation. For example, the converter shown in Fig. 1.13(a) requires an auxiliary circuit that consists of three active switches to achieve ZVS operation.

\subsection{Thesis Objectives}

The main objectives of this thesis are as follows:

- To propose a new soft-switching PWM converter that can operate with a bidirectional power flow and with ZCS for its main power switches, using as simple an auxiliary circuit as possible.

- $\quad$ To propose a new ZCS-PWM full-bridge converter that allows its main power switches to operate with ZCS in as simple a manner as possible, without adding new components in the main power path that can increase conduction losses.

- To propose a new three-phase Dc-Dc converter that can be used for low input voltage applications and that can be implemented with soft-switching in a low cost manner.

- To determine the properties and steady-state characteristics of these new converters by mathematical analysis. 
- To develop a design procedure for each new converter that can be used in the selection of critical converter components

- To confirm the feasibility of each new converter with experimental results obtained from proof-of-concept prototype converters.

\subsection{Thesis Outline}

The outline of the thesis is as follows:

Chapter 2: The main focus of this chapter is a new bidirectional ZCS-PWM converter that allows its main power switches to operate with ZCS. In the chapter, the operation of the proposed converter is explained in detail, guidelines for the design of the converter are given and experimental results that confirm its feasibility are presented.

Chapter 3: A new ZCS-PWM full-bridge converter is proposed in this chapter. The main power switches of this converter can turn on and off with ZCS due to a novel and simple combination of active and passive auxiliary circuits. In this chapter, the operation of the converter is explained in detail, its modes of operation are analyzed and the results of the analysis are used to develop a design procedure for the selection of key converter components. The design procedure is demonstrated with an example that was used to implement an experimental prototype. The feasibility of the converter is confirmed with results that were obtained from the prototype converter.

Chapter 4: A new ZVS-PWM three-phase Dc-Dc converter is proposed in this chapter. Similar to Chapter 4, the operation of this new converter is explained and analyzed and a 
design procedure is developed and demonstrated with an example. Experimental results that confirm the feasibility of the converter are also presented.

Chapter 5: In this chapter, the contents of the thesis are summarized, the conclusions that have been reached as a result of the work performed are presented, and the main contributions of the thesis are stated. The chapter concludes by suggesting potential future research that can be performed, based on the thesis work. 


\section{Chapter 2}

\section{A Novel Non-Isolated Bidirectional ZVS-PWM DC-DC Converter with One Auxiliary Switch}

\subsection{Introduction}

A bidirectional Dc-Dc converter allows the transfer of power between two dc sources in either direction. The converter can be considered to be operating in buck or voltage stepdown mode if power is being transferred from a higher voltage level source to a lower voltage level source. It can be considered to be operating in boost or voltage step-up mode if power is being transferred from a lower voltage level source to a higher voltage level source.

A very commonly used bidirectional Dc-Dc converter is the boost and buck converter that has two main power switches. When the converter is operating in boost mode, the converter is made to operate like a basic boost converter, as described in Section 1.5.1. One of the switches acts like the boost converter switch and the other switch acts like the boost converter diode as it is never turned on and current is made to flow through the body diode of the switching device. Similarly, when the converter is operating in buck mode, the converter is made to operate like a basic buck converter, as described in Section 1.5.2. One of the switches acts like the buck converter switch and the other switch acts like the buck converter diode as it is never turned on and current is made to flow through the body diode of the switching device. 
If the converter is implemented with IGBTs, then ZCS is the preferred method of softswitching since it reduces or eliminates fully the current tailing effect during turn-off. For PWM bidirectional converters, ZCS methods are typically implemented with one auxiliary switch for each main power switch and each auxiliary switch helps just one main power switch operate with ZCS.

A new ZCS PWM bidirectional Dc-Dc converter is proposed in this chapter. The converter consists of only one auxiliary switch that can provide soft switching for both main switches in buck and boost mode. Other than the switch, the auxiliary circuit consists of a capacitor and an inductor that provides a bidirectional current path to achieve soft switching for both modes of operation. In this chapter, the operation of the new converter is explained for both boost and buck modes of operation, guidelines for the design of the converter are given and the design of the converter is demonstrated with an example. Experimental results obtained from a 500W, $80 \mathrm{kHz}$ prototype that was implemented and operated in both buck and boost modes of operation are presented to validate the feasibility of the proposed converter.

\subsection{Converter Operation}

The proposed converter is shown in Fig. 2.1. It consists of two main switches (IGBTs) $\mathrm{S}_{1}$ and $\mathrm{S}_{2}$, one auxiliary switch $\mathrm{S}_{\mathrm{aux}}$, two resonant inductors $\mathrm{L}_{\mathrm{r} 1}$ and $\mathrm{L}_{\mathrm{r} 2}$, the input inductor $\mathrm{L}_{\text {in }}$ and a resonant capacitor $\mathrm{C}_{\mathrm{r}}$. The modes of operation for both buck and boost type of operation are presented in this section. It has been assumed that the components are ideal and that the input inductor $\mathrm{L}_{\text {in }}$ is large enough so the input current ripple can be considered as negligible. 


\subsubsection{Boost Mode of Operation}

In the boost mode, $S_{1}$ is the main operating switch and $S_{2}$ is never turned on and acts like a diode. An equivalent circuit diagrams for each mode of operation is shown in Fig. 2.2 and typical converter waveforms are shown in Fig. 2.3. The converter goes through the following modes of operation during each switching cycle.

Mode $0\left(t_{0}<t<t_{1}\right) \quad$ (Fig.2.4a): Before time $\mathrm{t}=\mathrm{t}_{0}, \mathrm{~S}_{1}$ and $\mathrm{S}_{\mathrm{aux}}$ are off and power is transferred to $\mathrm{V}_{\text {in2 }}$ through the body diode of $\mathrm{S}_{2}$. At $\mathrm{t}=\mathrm{t}_{0}, \mathrm{~S}_{1}$ is turned on with ZCS as the presence of inductor $\mathrm{L}_{\mathrm{r} 1}$ in series with the switch makes the rise of switch current gradual and soft. Current is gradually diverted away from $\mathrm{D}_{\mathrm{S} 2}$ (body diode of $\mathrm{S}_{2}$ ) to $\mathrm{S}_{1}$ and this is done gradually due to the presence of $\mathrm{L}_{\mathrm{r} 2}$. Since the transfer of current away from $\mathrm{D}_{\mathrm{S} 2}$ is gradual, it does not have reverse recovery current. This current transfer can be expressed as

$$
I_{S 2}=\frac{V_{i n 2}}{L_{r 1}+L_{r 2}}\left(t-t_{0}\right)
$$

Mode $1\left(\mathrm{t}_{1}<\mathrm{t}<\mathrm{t}_{2}\right)$ (Fiq.2.4b): At $\mathrm{t}=\mathrm{t}_{1}$, current has stopped flowing through $\mathrm{D}_{\mathrm{s} 2}$ and the

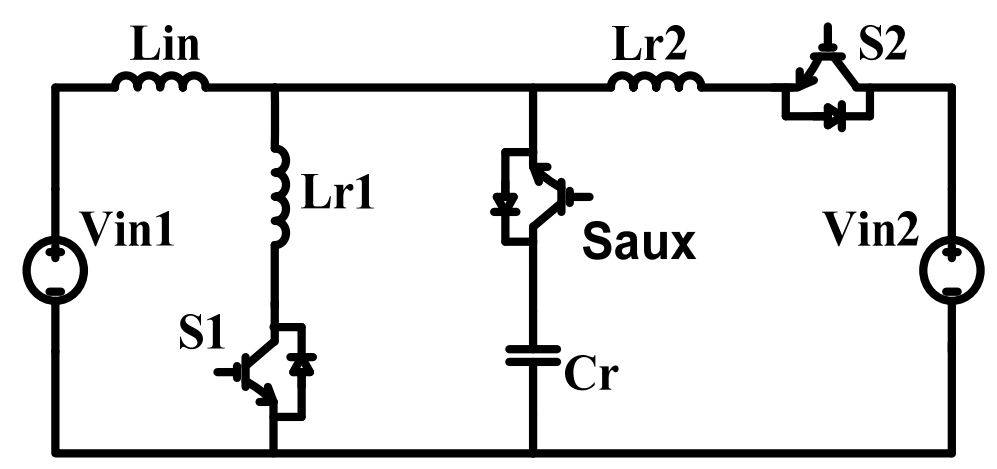

Fig. 2.1 Proposed bidirectional boost/buck converter 
full input current is flowing through $\mathrm{S}_{1}$.

Mode $2\left(\mathrm{t}_{2}<t<\mathrm{t}_{3}\right)$ (Fiq.2.4c): At $\mathrm{t}=\mathrm{t}_{2}$, the auxiliary switch $\mathrm{S}_{\text {aux }}$ is turned on to prepare for the ZCS turn-off of $\mathrm{S}_{1}$. The turn-on of $\mathrm{S}_{\mathrm{aux}}$ is soft due to the presence of $\mathrm{L}_{\mathrm{r} 1}$ and $\mathrm{L}_{\mathrm{r} 2}$, which help limit the rate of current rise in the auxiliary circuit. Current from the auxiliary circuit flows through $\mathrm{S}_{1}$ and $\mathrm{D}_{\mathrm{s} 2}$ during this mode and the mode ends when $\mathrm{D}_{\mathrm{s} 2}$ stops conducting. The voltage across $\mathrm{C}_{\mathrm{r}}$ is $\mathrm{V}_{\mathrm{Cr}}$ at the end of this mode and can be expressed as:

$$
V_{C r}=\left(V_{\text {in } 2}-V_{0}\right) \operatorname{Cos}\left(\omega_{0}\left(t-t_{2}\right)\right)
$$

Where $V_{\mathrm{o}}$ is the reflected output voltage, and the current flowing through $\mathrm{I}_{\mathrm{S} 1}$ and $\mathrm{I}_{\mathrm{S} 2}$ can be expressed as

$$
\begin{gathered}
I_{S 1}=I_{i n}+\frac{V_{o}}{2 L_{r 1}}-\frac{V_{o}}{2 Z_{o}} \operatorname{Sin}\left(\omega_{o}\left(t-t_{2}\right)\right) \\
I_{S 2}=\frac{V_{o}}{2 L_{r 1}}-\frac{2 V_{C r}-V_{o}}{2 Z_{o}} \operatorname{Sin}\left(\omega_{o}\left(t-t_{2}\right)\right)
\end{gathered}
$$

where:

$$
\omega_{0}=\sqrt{\frac{L_{r 1}+L_{r 2}}{L_{r 1} \times L_{r 2} \times C_{r}}}
$$

Mode $3\left(\mathbf{t}_{3}<t<t_{4}\right)$ (Fig.2.4d): At the beginning of this mode, $\mathrm{D}_{\mathrm{s} 2}$ has stopped conducting and current starts decreasing in the auxiliary switch $S_{\text {aux }}$. The current in $S_{\text {aux }}$ continues to decrease during this mode and current stops flowing through $\mathrm{S}_{\mathrm{aux}}$ at the end of this mode. 


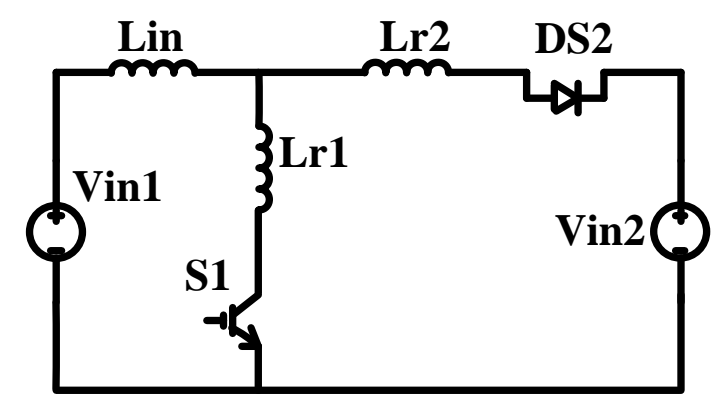

(a)

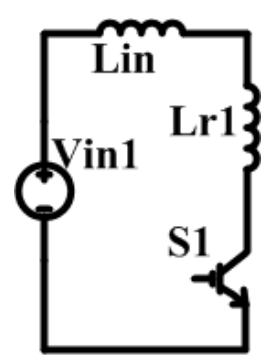

(b)

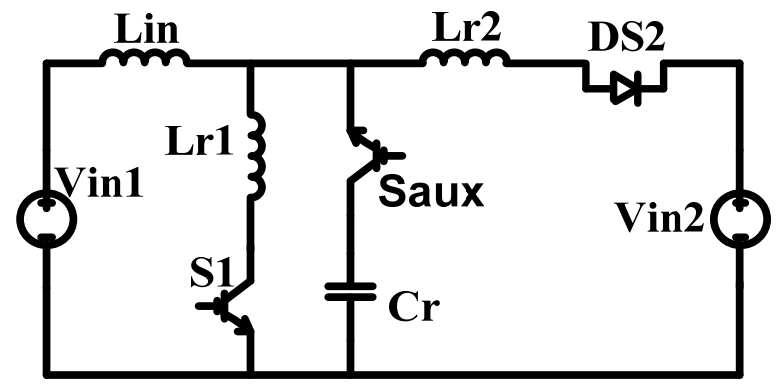

(c)

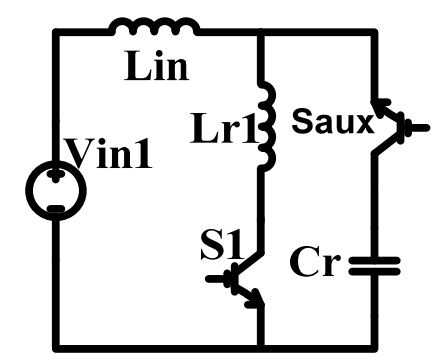

(d)

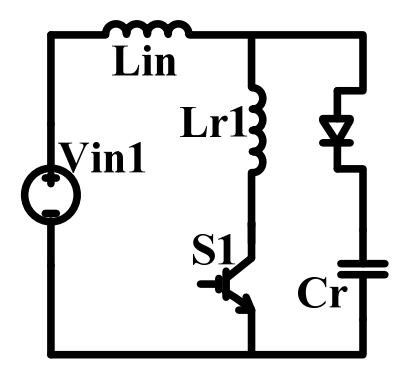

(e)

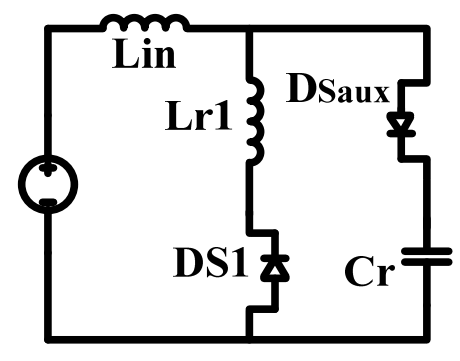

(f)

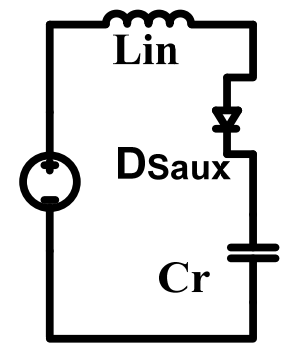

(g)

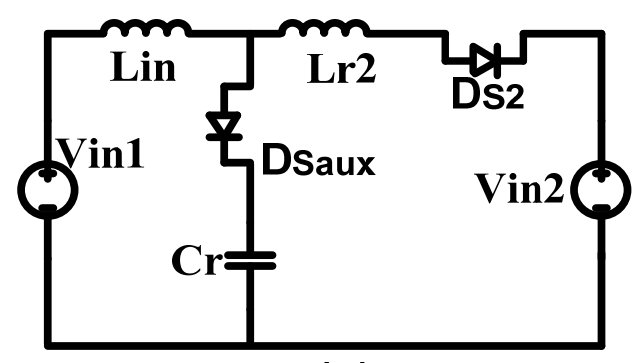

(h)

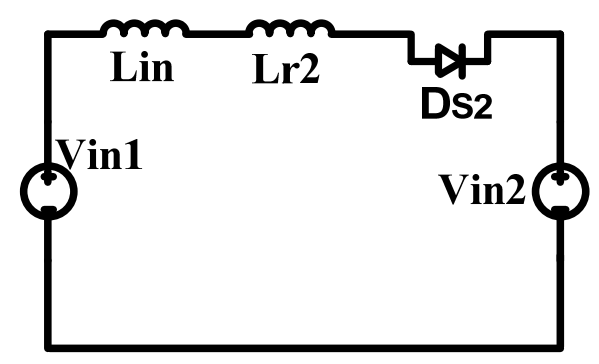

(i)

Fig. 2.2 Equivalent circuit for each mode of operation (boost mode) 
Mode $4\left(\mathrm{t}_{4} \leq \mathrm{t}<\mathrm{t}_{5}\right)$ (Fiq.2.4e): At $\mathrm{t}=\mathrm{t}_{4}$, the body diode of the auxiliary switch, $\mathrm{D}_{\text {Saux }}$, starts conducting and since current is no longer flowing through this switch, it can be turned off with ZCS. During this mode, current is gradually diverted away from $\mathrm{S}_{1}$ so that it is zero at the end of this mode. The current in $\mathrm{S}_{1}$ during this mode and the voltage across $\mathrm{C}_{\mathrm{r}}$ can be expressed as:

$$
\begin{gathered}
I_{S 1}=I_{i n}-\frac{V_{C r}}{Z_{0}} \operatorname{Sin}\left(\omega_{0}\left(t-t_{4}\right)\right) \\
V_{C r}=V_{\text {in }} \operatorname{Cos}\left(\omega_{0}\left(t-t_{4}\right)\right) \\
Z_{0}=\sqrt{\frac{L_{r 1}+L_{r 2}}{C_{r}}}
\end{gathered}
$$$$
\text { where }
$$

Mode 5 ( $\left.\underline{\mathbf{t}}_{5} \leq \boldsymbol{t}<\underline{t}_{6}\right) \quad$ (Fiq.2.4f): The continuing resonance between $\mathrm{L}_{\mathrm{r} 1}$ and $\mathrm{C}_{\mathrm{r}}$ causes current to flow through the anti-parallel diodes of $\mathrm{S}_{1}$ and $\mathrm{S}_{\text {aux }}$ during this mode. $\mathrm{S}_{1}$ can be turned off with ZCS at the end of this mode. The voltage across $\mathrm{C}_{\mathrm{r}}$ during this mode can be expressed as

$$
V_{C r}=I_{i n} Z_{o} \operatorname{Cos}\left(\omega_{0}\left(t-t_{5}\right)\right)-V_{o} \operatorname{Sin}\left(\omega_{0}\left(t-t_{5}\right)\right)
$$

Mode 6 ( $\left.\underline{t}_{6} \leq t<t_{7}\right)$ (Fig.2.4q): With $\mathrm{S}_{1}$ turned off, the full input current is flowing through the body diode of $\mathrm{S}_{\text {aux }}$ during this mode. The auxiliary capacitor will be charged up to the output voltage at the end of this mode. The voltage across $C_{r}$ during this mode can be expressed as 


$$
V_{C r}=V_{o}-\frac{I_{i n} Z_{o}}{C_{r}} \operatorname{Cos}\left(\omega_{0}\left(t-t_{6}\right)\right)
$$

Mode $7\left(\underline{t}_{7}<t<t_{g}\right)$ (Fig.2.4h): The body diode of $\mathrm{S}_{2}$ starts conducting at the beginning of this mode and current flows through it, as $\mathrm{L}_{\mathrm{r} 2}$ resonates with $\mathrm{C}_{\mathrm{r}}$. The current in $\mathrm{C}_{\mathrm{r}}$ decreases and reaches zero at the end of this mode. $\mathrm{I}_{\mathrm{S} 2}$ and $\mathrm{V}_{\mathrm{Cr}}$ during this mode can be expressed as follows:

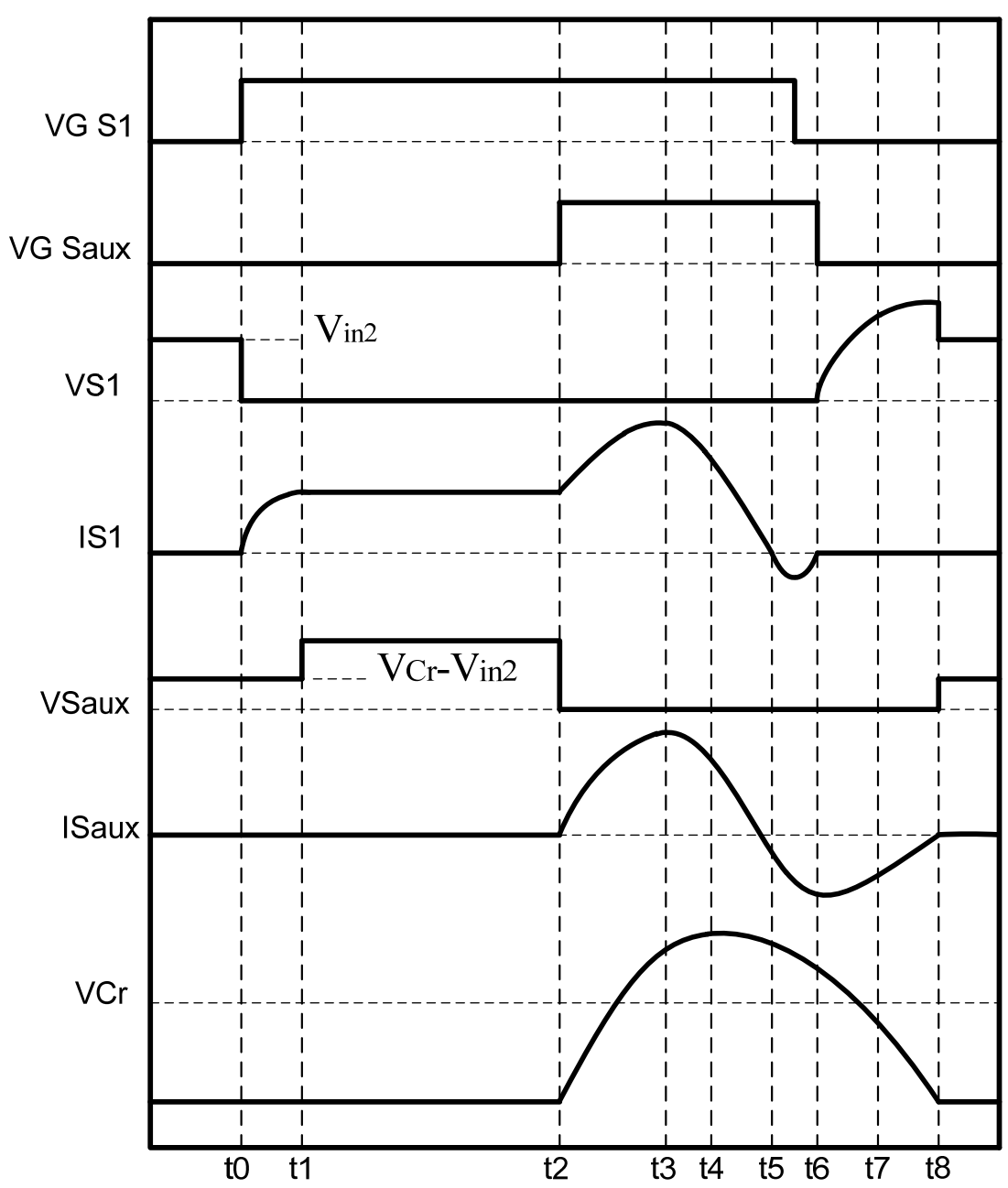

Fig. 2.3 Typical converter waveforms for boost mode operation 


$$
\begin{gathered}
I_{S 2}=I_{\text {in }} \operatorname{Cos}\left(\omega_{0}\left(t-t_{7}\right)\right)-I_{\text {in }} \\
V_{C r}=Z_{0} I_{\text {in }} \operatorname{Sin}\left(\omega_{0}\left(t-t_{7}\right)\right)-V_{\text {in }}
\end{gathered}
$$

Mode 8 ( $\underline{t}_{\underline{g}} \leq$ T) (Fiq.2.4i): The input current is transferred to the output through the body diode of $\mathrm{S}_{2}$ at the start of this mode and continues to flow until the end of the switching cycle at time $\mathrm{t}=\mathrm{T}$.

\subsubsection{Buck Mode of Operation}

In the buck mode, $S_{2}$ is the main operating switch and $S_{1}$ is never turned on and acts like a diode. An equivalent circuit diagrams for each mode of operation is shown in Fig. 2.4 and typical converter waveforms are shown in Fig. 2.5. The converter goes through the following modes of operation during each switching cycle.

Mode $0\left(\mathbf{t}_{0} \leq t<t_{1}\right)$ (Fiq.2.6a): At time $\mathrm{t}=\mathrm{t}_{0}, \mathrm{~S}_{2}$ is turned on with ZCS as $\mathrm{L}_{\mathrm{r} 2}$ limits the rate of switch current rise and current decreases in the body diode of $\mathrm{S}_{1}$. Currents $\mathrm{I}_{\mathrm{S} 1}$ and $\mathrm{I}_{\mathrm{S} 2}$ and the voltage across $\mathrm{C}_{\mathrm{r}}, \mathrm{V}_{\mathrm{Cr}}$, can be expressed as follows:

$$
\begin{gathered}
I_{S 1}=\frac{V_{i n 2}}{2\left(L_{r 1}+L_{r 2}\right)}\left(t-t_{0}\right)-\frac{V_{i n 2}}{2 Z_{0}} \operatorname{Cos}\left(\omega_{0}\left(t-t_{0}\right)\right)-I_{o} \\
I_{S 2}=\frac{V_{i n 2}}{2\left(L_{r 1}+L_{r 2}\right)}\left(t-t_{0}\right)+\frac{V_{i n 2}}{2 Z_{0}} \operatorname{Cos}\left(\omega_{0}\left(t-t_{0}\right)\right) \\
V_{C r}=-V_{i n 2} \operatorname{Cos}\left(\omega_{0}\left(t-t_{0}\right)\right)
\end{gathered}
$$




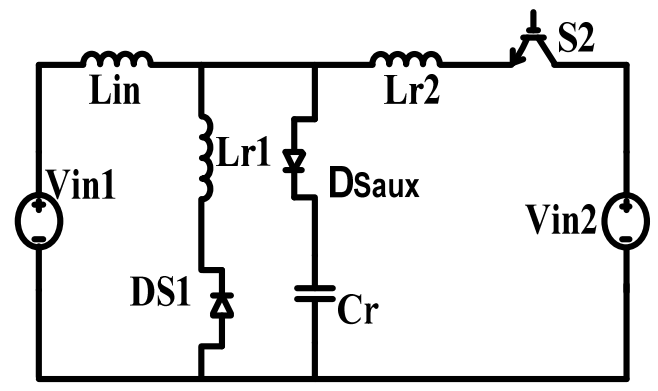

(a)

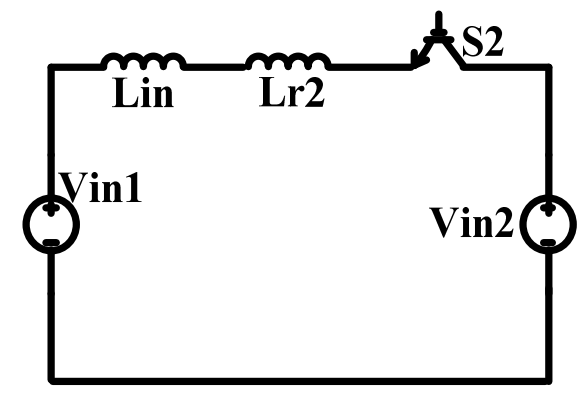

(c)

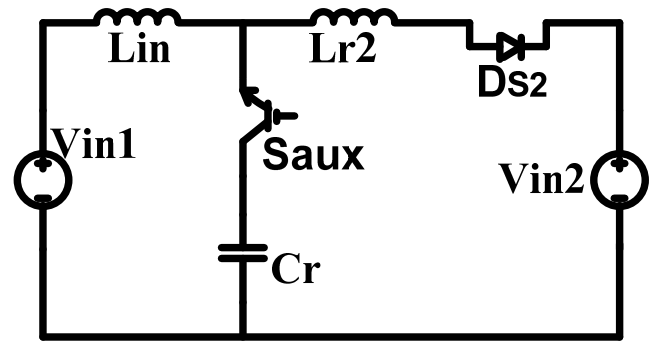

(e)

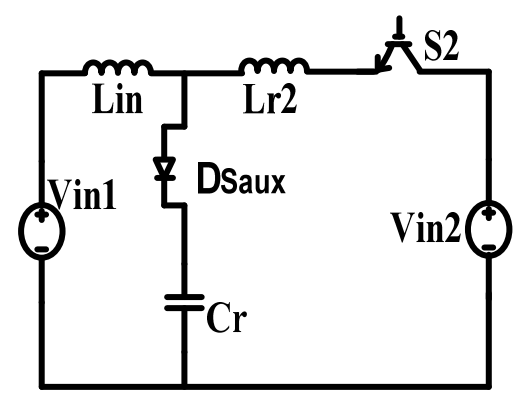

(b)

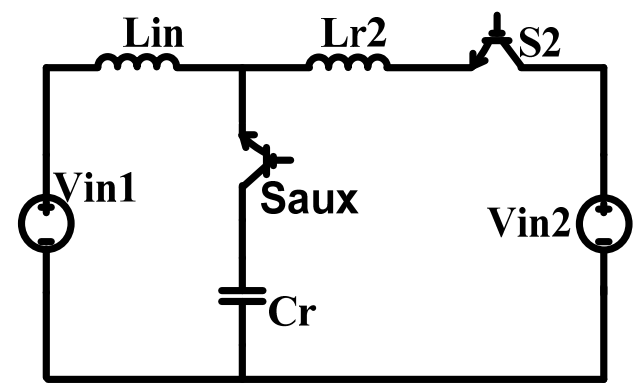

(d)

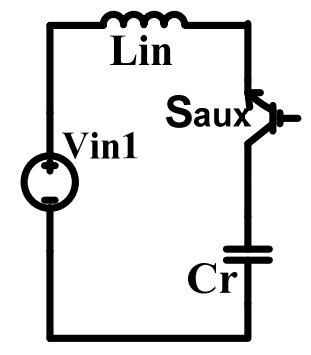

(f)

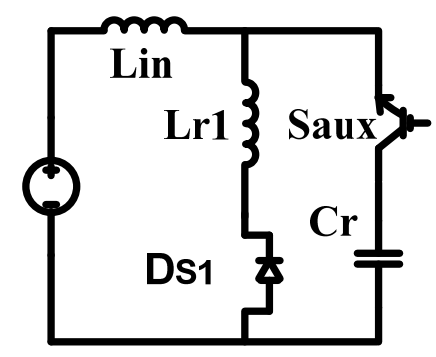

(g)

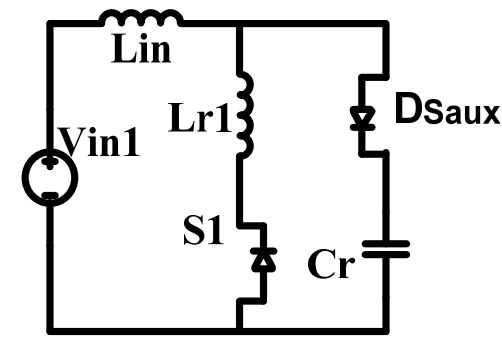

(h)

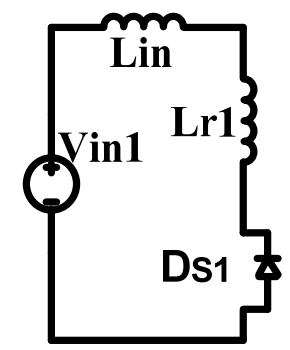

(i)

Fig. 2.4 Equivalent circuit for each mode of operation (buck mode) 
Mode 1 ( $\left.\mathbf{t}_{1} \leq t<t_{2}\right)$ (Fiq.2.6b): In this mode, the current through the body diode of $\mathrm{S}_{1}$ has reached zero and current continues to flow through $\mathrm{C}_{\mathrm{r}}$. The current through $\mathrm{S}_{2}$ and $\mathrm{C}_{\mathrm{r}}$ (also the body diode of $\mathrm{S}_{\mathrm{aux}}$ ) during this mode can be expressed as

$$
\begin{gathered}
I_{S 2}=I_{\text {in }} \operatorname{Cos}\left(\omega_{0}\left(t-t_{1}\right)\right)-\frac{V_{C r}}{Z_{o}} \operatorname{Sin}\left(\omega_{0}\left(t-t_{1}\right)\right) \\
I_{\text {Saux }}=-I_{\text {in }} \operatorname{Cos}\left(\omega_{0}\left(t-t_{1}\right)\right)-\frac{V_{o}-V_{C r}}{Z_{o}} \operatorname{Sin}\left(\omega_{0}\left(t-t_{1}\right)\right)
\end{gathered}
$$

Mode 2 ( $\left.t_{2}<t<t_{3}\right)$ (Fiq.2.6c): At the start of this mode, the body diode of $\mathrm{S}_{\text {aux }}, \mathrm{D}_{\text {Saux }}$, has stopped conducting and all the current flows through $\mathrm{S}_{2}$.

Mode $3\left(\mathbf{t}_{3}<t<t_{4}\right)$ (Fiq.2.6d): At the beginning of this mode $\mathrm{S}_{\text {aux }}$ is turned on with ZCS and the current in $\mathrm{S}_{2}$ starts to decrease. This action is in preparation for the ZCS turn-off of $S_{2}$. The current flowing through $S_{2}$ and voltage across $C_{r}$ can expressed as follows:

$$
\begin{array}{r}
I_{S 2}=I_{o}-\frac{V_{\text {in2 } 2}}{Z_{0}}\left(t-t_{3}\right) \operatorname{Cos}\left(\omega_{0}\left(t-t_{3}\right)\right) \\
V_{\text {Cr }}=-V_{\text {in } 2} \operatorname{Cos}\left(\omega_{0}\left(t-t_{3}\right)\right)
\end{array}
$$

Mode $4\left(\mathrm{t}_{4}<t<\mathrm{t}_{5}\right)$ (Fig.2.6e): At $\mathrm{t}=\mathrm{t}_{4}$, the current in $\mathrm{S}_{2}$ is zero and begins to change direction and start to flow through the body diode of the device. $S_{2}$ can be turned off with soft switching sometime during this mode while this is happening. The current in $\mathrm{S}_{2}$ can be expressed as

$$
I_{S 2}=I_{o}-I_{o} \operatorname{Cos}\left(\omega_{0}\left(t-t_{4}\right)\right)-\frac{V_{C a}-V_{o}}{Z_{o}} \operatorname{Sin}\left(\omega_{0}\left(t-t_{4}\right)\right)
$$


Mode $5\left(t_{5}<t^{-1} t_{6}\right)$ (Fiq.2.6f): At $\mathrm{t}=\mathrm{t}_{5}$, current ceases to flow through the body diode of $\mathrm{S}_{2}$ and continues to flow in the auxiliary branch. The voltage across $\mathrm{C}_{\mathrm{r}}$ can be expressed as:

$$
V_{C r}=-V_{o}+\frac{I_{o}}{C_{r}} \operatorname{Cos}\left(\omega_{0}\left(t-t_{5}\right)\right)
$$

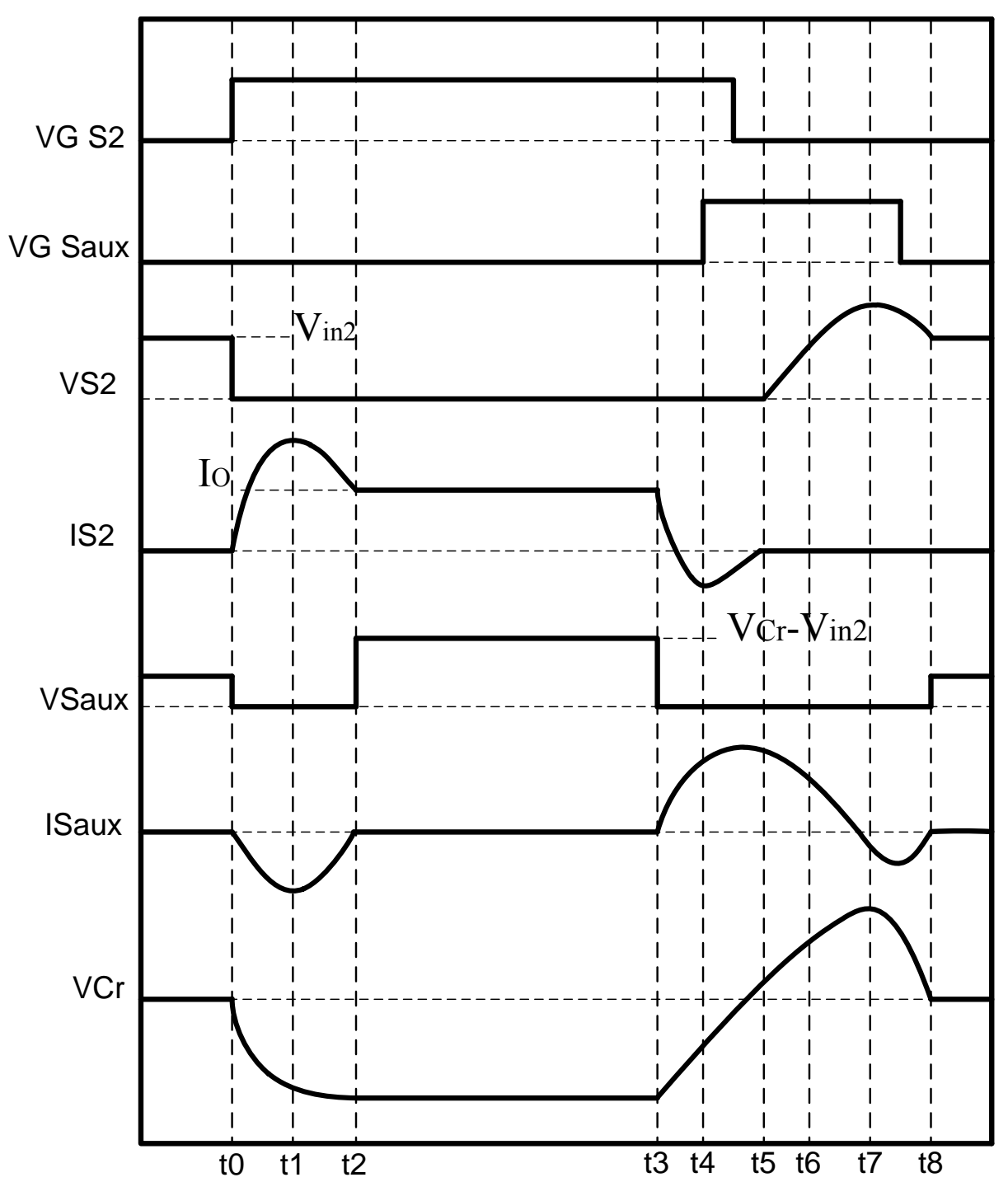

Fig. 2.5 Typical converter waveforms for buck mode operation. 
Mode $6\left(t_{6} \leq \underline{1}<t_{7}\right)$ (Fig.2.6q): The body diode of $S_{1}$ starts to conduct at the start of this mode. During this mode, current through the auxiliary switch and the voltage across the auxiliary capacitor during this mode can be expressed as follows

$$
\begin{aligned}
& V_{C r}=Z_{o} I_{o} \operatorname{Cos}\left(\omega_{0}\left(t-t_{6}\right)\right) \\
& I_{\text {Saux }}=I_{o} \operatorname{Cos}\left(\omega_{0}\left(t-t_{6}\right)\right)
\end{aligned}
$$

$\left.\underline{\text { Mode } 7\left(\mathbf{t}_{7}\right.} \leq \underline{t_{1}} \underline{t}_{8}\right)$ (Fiq.2.6h): The auxiliary switch can turn off with ZCS as current start to flow through its body diode at the start of this mode. The current through the auxiliary switch body diode and the voltage across the auxiliary capacitor during this mode can be expressed as follows

$$
\begin{gathered}
I_{\text {DSaux }}=\frac{V_{C r}}{Z_{o}} \operatorname{Cos}\left(\omega_{0}\left(t-t_{7}\right)\right) \\
V_{\text {Cr }}=V_{o}-Z_{o} I_{o} \operatorname{Cos}\left(\omega_{0}\left(t-t_{6}\right)\right)
\end{gathered}
$$

Mode 8 (t ${ }_{8}<t$ ) (Fig.2.6i): The circuit is equivalent to a buck converter in this mode and current flows through body diode of $\mathrm{S}_{1}$ until the end of the switching cycle at time $\mathrm{t}=\mathrm{T}$.

It should be noted that all the switches in the proposed converter, even the auxiliary switch can turn on and off with ZCS, regardless of whether the converter is operating in boost mode or in buck mode. 


\subsection{Design Guidelines}

Guidelines for the design of the proposed bidirectional converter are presented in this section. The auxiliary circuit must be designed so that it can create a ZCS turn-off for the main power switches regardless of the direction of power flow in the converter. The key components values in the design of the converter are $\mathrm{C}_{\mathrm{r}}, \mathrm{L}_{\mathrm{r} 1}$ and $\mathrm{L}_{\mathrm{r} 2}$. For a typical design, the following specifications are given: Input voltages $V_{\text {in1 }}$ and $V_{\text {in2 }}$, switching frequency $f$ and output power $\mathrm{P}_{\mathrm{o}}$. The design can be performed by examining only boost mode operation since if the converter can be designed to operate in boost mode, then it can operate in buck mode as well. With this in mind, $\mathrm{V}_{\text {in } 1}$ is actually the lower level voltage and $\mathrm{V}_{\text {in2 }}$ is the higher level voltage.

The following should be considered in designing the values of the key components:

\section{1) Capacitor $C_{r}$}

$\mathrm{C}_{\mathrm{r}}$ affects the peak voltage stress that is placed on the switch when the auxiliary circuit is activated; higher the value of $C_{r}$, smaller the stress would be. $C_{r}$ also affects the amount of time needed for the auxiliary circuit to operate when it is activated to turn off $\mathrm{S}_{1}$ with ZCS. Higher the value of $\mathrm{C}_{\mathrm{r}}$, more time is needed for the auxiliary circuit to operate as the resonant cycle determined by the interaction of $\mathrm{C}_{\mathrm{r}}$ and $\mathrm{L}_{\mathrm{r} 2}$ is increased. The length of time the auxiliary circuit operates should only be a small fraction of the switching cycle so that current stresses are low on the auxiliary circuit components and so that its effect on the operation of the main power converter is minimized (i.e. to minimize the limitations on the duty cycle reduction of the main switches that may need to be considered). 


\section{2) Inductors $L_{r 1}$ and $L_{r 2}$}

$\mathrm{L}_{\mathrm{rl}}$ is placed in series with the main power switch $\mathrm{S}_{1}$ so that it can slow down the rise of current when $S_{1}$ is turned on and slow down the rate of current transfer away from the switch when it is turned off. The same is true of $\mathrm{L}_{\mathrm{r} 2}$ in relation to $\mathrm{S}_{2}$. If $\mathrm{L}_{\mathrm{r} 1}$ and $\mathrm{L}_{\mathrm{r} 2}$ are too small, then the transfer of current to and away from their respective switches will happen too quickly so that these switches will not operate with ZCS. If $\mathrm{L}_{\mathrm{r} 1}$ and $\mathrm{L}_{\mathrm{r} 2}$ are too large, then the transfer of current to and away from their respective switches will happen too slowly and the overall operation of the converter may be affected.

\section{3) Dc voltage conversion ratio and duty cycle}

The dc voltage conversion ratio can be determined to be as flows, based on the equations that were derived in Section 2.2:

$$
\frac{V_{o}}{V_{\text {in }}}=\frac{1}{2 \pi} \frac{f}{f_{o}}\left(\frac{1}{2 V_{i n}} \sqrt{\frac{L_{r 1} \times L_{r 2}}{\left(L_{r 1}+L_{r 2}\right) C_{r}}}\right)+\frac{\Delta t}{T}
$$

where $f$ is the switching frequency and

$$
f_{o}=\frac{1}{2 \pi} \sqrt{\frac{L_{r 1}+L_{r 2}}{L_{r 1} \times L_{r 2} \times C_{r}}}
$$

If $f$ and $f_{o}$ are fixed, then the output voltage can be regulated by variation of $\Delta t / T$ which represents the duty cycle, as in a conventional PWM converter. If $\Delta t / T=0$, then $f / f_{0}$ is

$$
\frac{f}{f_{o}}=\frac{V_{o}}{V_{\text {in }}}
$$

The maximum value of $\Delta t / T$ (duty cycle) is given by: 


$$
\frac{\Delta t}{T}=\frac{V_{o}}{V_{\text {in }}}-\frac{f}{f_{o}}
$$

\section{4) Parameters of resonant circuit}

Switches $\mathrm{S}_{1}$ and $\mathrm{S}_{2}$ can turn-off with ZCS if the following ratio is less than one $(\alpha<1)$ :

$$
\alpha=\frac{I_{\max }}{V_{i n}} \sqrt{\frac{L_{r 1} \times L_{r 2}}{\left(L_{r 1}+L_{r 2}\right) C_{r}}}
$$

where the maximum input inductor $\left(\mathrm{L}_{\text {in }}\right)$ current is

$$
I_{\max }=\frac{P_{\max }}{V_{o}}
$$

for an ideal converter. Equation (28) is simply another way of stating that the auxiliary circuit must be able to divert current away from the main switches when they are about to be turned off. The parameters of resonant circuit can be defined to be

$$
\frac{L_{r 1} \times L_{r 2} \times C_{r}}{L_{r 1}+L_{r 2}}=\frac{1}{\left(2 \alpha f_{o}\right)^{2}}
$$

or

$$
\frac{L_{r 1} \times L_{r 2}}{\left(L_{r 1}+L_{r 2}\right) C_{r}}=\left(\frac{V_{i n} \alpha}{I_{\max }}\right)^{2}
$$

The converter switches should be selected when the above component values are determined. Peak voltage and current values should be noted in selecting the switches. 


\subsection{Design Example}

A procedure for the selection of key converter components is demonstrated in this section with a design example. For the example, the converter is to be designed according to the following specifications: Input voltage $\mathrm{V}_{\mathrm{in}}=100 \mathrm{~V}, \mathrm{~V}_{\mathrm{o}}=400 \mathrm{~V}$, maximum output power $\mathrm{P}_{\mathrm{o}}=500 \mathrm{~W}, \mathrm{~L}_{\text {in }}=500 \mu \mathrm{H}$, switching frequency: $f=80 \mathrm{kHz}$. As stated above, only the design for boost mode operation need be considered.

The maximum input current is

$$
I_{\text {max }}=\frac{P_{\text {max }}}{V_{o}}=\frac{500}{400}=1.25
$$

The resonant frequency of the auxiliary circuit can be determined by considering $f / f_{o}=$ 0.3 and proceeding as follows:

$$
\begin{gathered}
f_{o}=\frac{f}{0.3}=267 \mathrm{kHz} \\
f_{o}=\frac{1}{2 \pi} \sqrt{\frac{L_{r 1}+L_{r 2}}{L_{r 1} \times L_{r 2} \times C_{r}}}=267 \mathrm{kHz} \\
\text { thus } \frac{L_{r 1} \times L_{r 2} \times C_{r}}{L_{r 1}+L_{r 2}}=3.56 \times 10^{-13}
\end{gathered}
$$

The resonant frequency must be considerably smaller than the switching frequency and the ratio of $f / f_{o}=0.3$ can be determined by an iterative process. 
In order to satisfy the ZCS criterion to ensure that the main switches turn off softly a value of $\alpha=0.7$ can be chosen. Such a value is conservative to provide an adequate margin since the presence of inductors in series with switches means that the switches cannot interrupt current without being damaged, due to inductive energy that cannot be made to vanish. As a result,

$$
\begin{gathered}
\alpha=\frac{I_{\max }}{V_{i n}} \sqrt{\frac{L_{r 1} \times L_{r 2}}{\left(L_{r 1}+L_{r 2}\right) C_{r}}}=0.7 \\
\text { thus } \frac{L_{r 1} \times L_{r 2}}{\left(L_{r 1}+L_{r 2}\right) C_{r}}=56 \Omega^{2}
\end{gathered}
$$

Since $\mathrm{L}_{\mathrm{r} 1}=\mathrm{L}_{\mathrm{r} 2}$ there are two equations that relate $\mathrm{L}_{\mathrm{r} 1}, \mathrm{~L}_{\mathrm{r} 2}$ and $\mathrm{C}_{\mathrm{r}}$ and $\mathrm{L}_{\mathrm{r} 1}$, can be set to be equal to $\mathrm{L}_{\mathrm{r} 2}$, the values for the resonant components can be calculated as $\mathrm{L}_{\mathrm{r} 1}=\mathrm{L}_{\mathrm{r} 2}=4.8 \mu \mathrm{H}$ and $\mathrm{C}_{\mathrm{r}}=20.8 \mathrm{nF}$

\subsection{Experimental Results}

An experimental prototype of the proposed bidirectional converter was built to confirm its feasibility - to show that the main converter switches can operate with ZCS regardless of the direction of power flow. The prototype had the following specifications: Input voltage $\mathrm{V}_{\text {in1 }}=100 \mathrm{~V}$, input voltage $\mathrm{V}_{\text {in } 2}=400 \mathrm{~V}$, maximum output power $\mathrm{P}_{\mathrm{o}}=500 \mathrm{~W}, \mathrm{~L}_{\text {in }}=500 \mu \mathrm{H}$, switching frequency: $\mathrm{f}_{\mathrm{sw}}=80 \mathrm{kHz}$. The prototype was implemented using the following components values: Auxiliary circuit inductors $\mathrm{L}_{\mathrm{r} 1}=5 \mu \mathrm{H}$ and $\mathrm{L}_{\mathrm{r} 2}=5 \mu \mathrm{H}$ and auxiliary circuit capacitor $\mathrm{C}_{\mathrm{r}}=22 \mathrm{nF}$, which were close to the values that were calculated in the design 
example. The following devices were used for the semiconductors in the prototype: IRG4IBC30S for $\mathrm{S}_{1}$ and $\mathrm{S}_{2}$, STGF20NB60S for the auxiliary switch $\mathrm{S}_{\text {aux }}$.

Fig. 2.6 shows a typical switch waveform for the converter when it is operating in boost mode. It can be seen that the current in the switch rises gradually when it is turned on and the voltage across the switch begins to rise only when the switch current is zero. The current waveform shows a resonant hump that is the result of the auxiliary circuit.

Fig. 2.7 shows a typical switch waveform for the converter when it is operating in buck mode. Like the switching waveforms shown in Fig. 2.6, current in the switch rises gradually when the switch is turned on and the voltage across the switch rises only after the switch current is zero.

Fig. 2.8 and Fig. 2.9 show efficiency measurements taken from the proposed bidirectional converter in both boost and buck modes of operation, compared to those obtained for a hard-switching bidirectional converter (a converter without the auxiliary circuit). It can be seen that the proposed converter is about $7 \%$ more efficient at full load in the boost mode and about $6 \%$ more efficient at full load in the buck mode compared to the hard-switching bidirectional converter. 


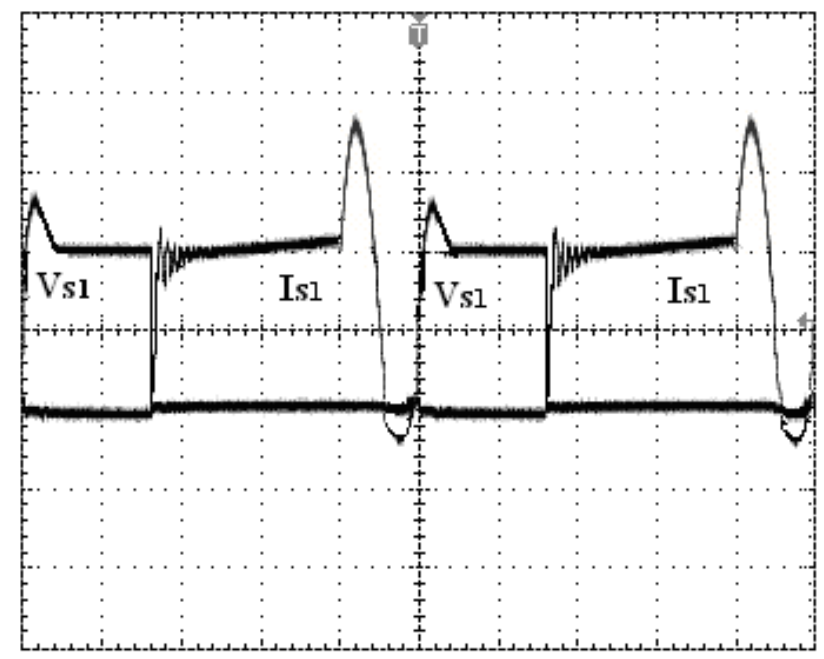

Fig. 2.6 Current and voltage in $\mathrm{S}_{1}$ - Boost mode (V: $200 \mathrm{~V} / \mathrm{div}, \mathrm{I}: 2.5 \mathrm{Amps} / \mathrm{div}, \mathrm{t}: 2.5 \mu \mathrm{s} / \mathrm{div}$ )

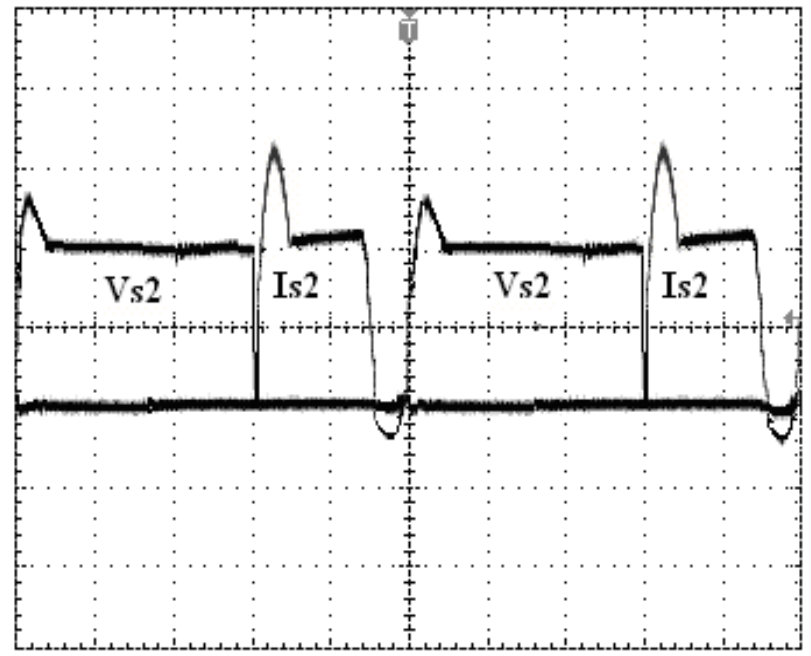

Fig. 2.7 Current and voltage in $\mathrm{S}_{2}$ - Buck mode

(V: 200V/div, I: $2.5 \mathrm{Amps} / \mathrm{div}, \mathrm{t}: 2.5 \mu \mathrm{s} / \mathrm{div}$ ) 


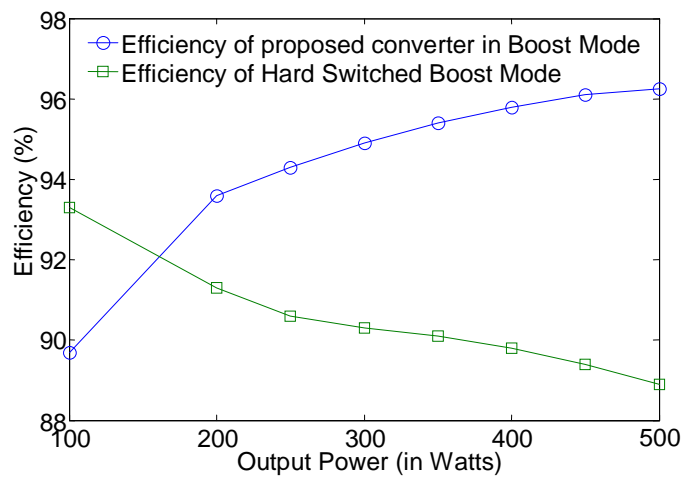

Fig. 2.8 Efficiency comparison for boost mode operation.

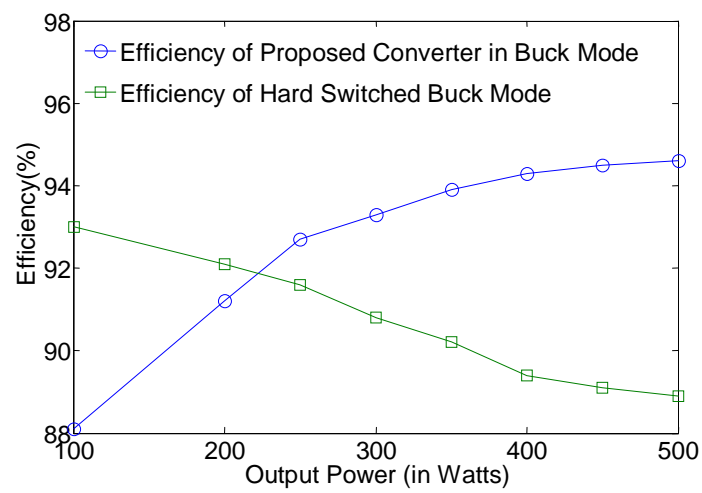

Fig. 2.9 Efficiency comparison for buck mode operation.

\subsection{Conclusion}

A new ZCS PWM bidirectional Dc-Dc converter with only one auxiliary switch was proposed in this chapter. The main advantage of this converter over other previously proposed converters of the same type is the simplicity of the auxiliary circuit, which consists only of a single active switch, an inductor and a capacitor. The proposed converter is the only bidirectional converter that can operate with soft-switching for both main 
switches in both boost and buck modes using only one additional active switch, which can also operate with soft-switching.

In this chapter, the modes of operation of the converter in both boost and buck modes was explained, the design of the converter was discussed, and experimental results obtained from a $500 \mathrm{~W}, 80 \mathrm{kHz}$ prototype that confirmed the feasibility of the converter were presented. It was found that the proposed converter was close to $7 \%$ more efficient than a hard-switched converter for both boost and buck modes at full load. 


\section{Chapter 3}

\section{A New ZCS-PWM Full-Bridge Dc-Dc Converter with Simple Auxiliary Circuits}

\subsection{Introduction}

A new ZCS-PWM full-bridge converter is proposed in this chapter of thesis. The outstanding feature of the new converter is that it allows its main power switches to operate with ZCS and with fewer conduction losses than conventional full-bridge converters. This is achieved by using two very simple active auxiliary circuits - one active with a switch that can turn on and off with ZCS and one passive that consists of a few passive components.

This chapter presents the new converter and then discusses its operation, steady-state characteristics and design. Experimental results obtained from a converter prototype are presented to validate the converter's performance and the concepts presented in this chapter.

\subsection{Converter Operation}

The proposed converter is shown in Fig. 3.1. It operates like a ZVZCS-PWM converter except that the auxiliary circuit is activated whenever the main power switches in the leading leg to which it is attached are about to turn off. It should be noted that in this diagram, as in other circuit diagram present in this paper, the transformer leakage inductance is not shown as a separate element, but is assumed to be a part of the transformer. 

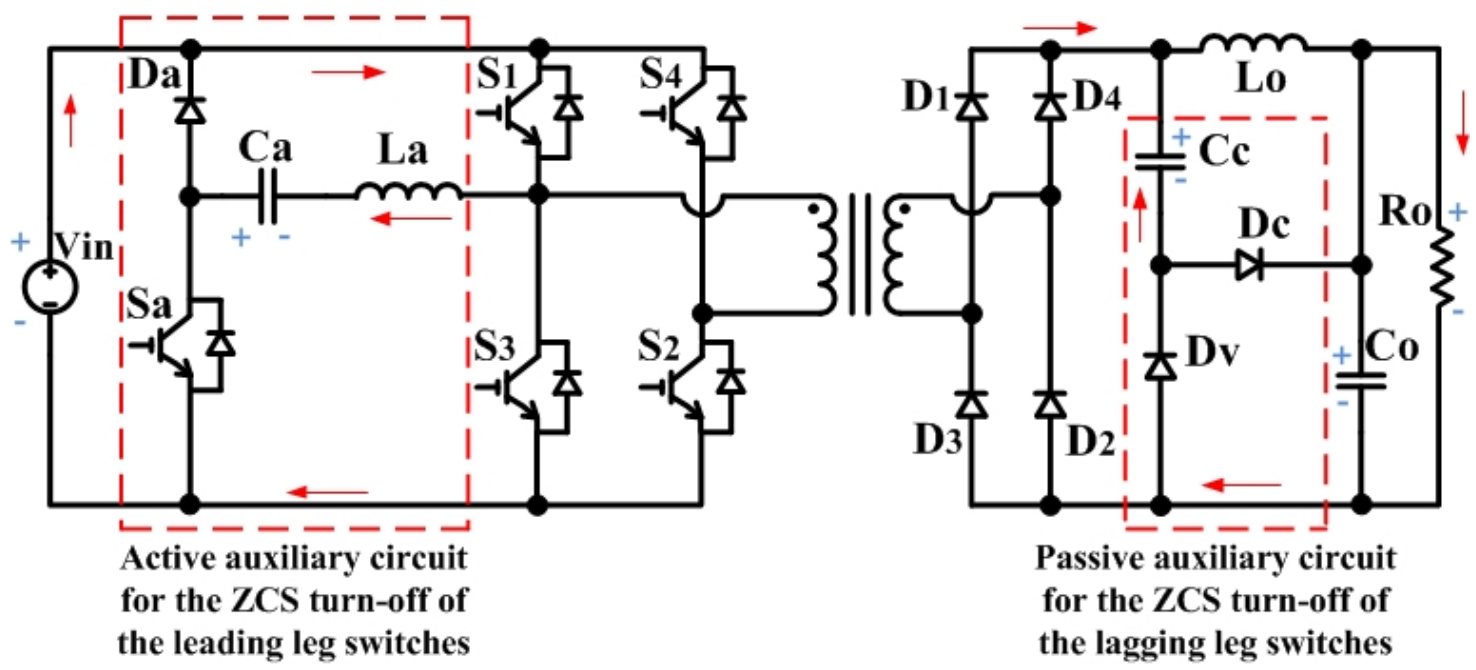

Passive auxiliary circuit for the ZCS turn-off of the lagging leg switches

Fig. 3.1 The proposed ZCS converter

Equivalent circuit diagrams of the modes of operation that the proposed converter goes through during a half switching are shown in Fig. 3.2 and ideal converter waveforms are shown in Fig. 3.3. It should be noted that in Fig. 3.3, a current waveform such as $\mathrm{I}_{\mathrm{S} 1}$ shows the current flowing through a switch (positive part of the waveform) and its body diode (negative part of the waveform). Moreover, the $\mathrm{I}_{\mathrm{Sa}}$ waveform is also the waveform for $\mathrm{I}_{\mathrm{La}}$ and $\mathrm{I}_{\mathrm{Ca}}$ as $\mathrm{I}_{\mathrm{Sa}}=\mathrm{I}_{\mathrm{La}}=\mathrm{I}_{\mathrm{Ca}}$ and $\mathrm{V}_{\mathrm{Ca}}^{\prime}$ on the $\mathrm{V}_{\mathrm{Ca}}$ waveform can be considered to be equal to the input voltage. The converter's modes of operation are as follows:

Mode $1\left(t_{0}<t<t_{1}\right)\left(\right.$ Fig. 3.5(a)): Switches $\mathrm{S}_{1}$ and $\mathrm{S}_{2}$ are on before this mode and the input power is transferred to the output through $\mathrm{D}_{3}$ and $\mathrm{D}_{4}$. At the beginning of this mode, auxiliary switch $\mathrm{S}_{\mathrm{a}}$ is turned on and $\mathrm{C}_{\mathrm{a}}$ starts to discharge, resonating with $\mathrm{L}_{\mathrm{a}}$. This mode ends when the current flowing through $S_{a}$ reaches zero. From the equivalent circuit of Mode 1 shown in Fig. 3.4(a), the primary currents and voltages can be expressed as:

$$
I_{\text {in }}=I_{S 1}=I_{L a}+I_{L I k}
$$




$$
\begin{aligned}
& V_{i n}=L_{a} \frac{d I_{L a}}{d t}+V_{C a} \\
& V_{i n}=L_{I k} \frac{d I_{L k}}{d t}+\frac{V_{o}}{n}
\end{aligned}
$$

where $\mathrm{n}$ is the transformer ratio, $\mathrm{L}_{\mathrm{lk}}$ is the leakage inductance, $\mathrm{I}_{\mathrm{S} 1}$ is the instantaneous current through switch $\mathrm{S}_{1}, \mathrm{I}_{\mathrm{in}}$ is the instantaneous input current, $\mathrm{I}_{\mathrm{La}}$ is the current through inductor $\mathrm{L}_{\mathrm{a}}, \mathrm{I}_{\mathrm{Llk}}$ is the current through the leakage inductance and is equal to the primary current $\mathrm{I}_{\text {primary }}, \mathrm{V}_{\mathrm{Ca}}$ is the voltage across capacitor $\mathrm{C}_{\mathrm{a}}$ and $\mathrm{V}_{\mathrm{o}}$ is the output voltage.

The initial conditions for equations (2) and (3) are $\mathrm{V}_{\mathrm{Ca}}\left(\mathrm{t}_{0}\right)=\mathrm{V}_{\mathrm{in}}, \mathrm{I}_{\mathrm{La}}\left(\mathrm{t}_{0}\right)=0$ and $\mathrm{I}_{\mathrm{LIk}}\left(\mathrm{t}_{0}\right)$ $=\mathrm{nI}_{\mathrm{o}}$ where $\mathrm{n}$ is the transformer turns ratio $\mathrm{n}=\mathrm{n}_{2} / \mathrm{n}_{1}$ and $\mathrm{I}_{\mathrm{o}}$ is the output current. For simplicity, the primary current during this mode is approximated as the reflected primary current $\mathrm{nI}_{\mathrm{o}}$. Solving these equations gives:

$$
\begin{gathered}
I_{L a}(t)=n I_{o}\left(1-\cos \omega_{0}\left(t-t_{0}\right)+\frac{\frac{V_{o}}{n}-V_{i n}}{Z_{0}} \sin \omega_{0}\left(t-t_{0}\right)\right) \\
I_{S 1}(t)=I_{o}-n I_{o}\left(1-\cos \omega_{0}\left(t-t_{0}\right)\right)-\frac{\frac{V_{o}}{n}-V_{i n}}{Z_{0}} \sin \omega_{0}\left(t-t_{0}\right)-\frac{\frac{V_{o}}{n\left(V_{C a}-\frac{V_{o}}{n}\right)}\left(t_{0}-\sin \omega_{0}\left(t-t_{0}\right)\right)}{\omega_{0}^{2} L_{I k}}
\end{gathered}
$$

where $V_{\text {in }}$ is the input voltage and,

$$
\begin{aligned}
& \omega_{0}=\frac{1}{\sqrt{n^{2} C_{a}\left(L_{a}+L_{I k}\right)}} \\
& Z_{0}=\sqrt{\frac{L_{a}+L_{I k}}{C_{a}}}
\end{aligned}
$$


Mode $2\left(t_{1}<t<t_{2}\right)$ (Fig. 3.5(b)): At the beginning of this mode, current in $S_{a}$ starts flowing in the opposite direction from its flow in Mode 1, through the anti-parallel diode of $\mathrm{S}_{\mathrm{a}}, \mathrm{D}_{\mathrm{Sa}}$. $\mathrm{S}_{\mathrm{a}}$ can be turned off softly while current is flowing in $\mathrm{D}_{\mathrm{Sa}}$. Voltage across $\mathrm{C}_{\mathrm{a}}$ starts increasing as $\mathrm{C}_{\mathrm{a}}$ resonates with $\mathrm{L}_{\mathrm{a}}$. Current in $\mathrm{S}_{1}$ starts decreasing in this mode and reaches zero at the end of this mode. The currents $\mathrm{I}_{\mathrm{S} 1}$ and $\mathrm{I}_{\mathrm{Ca}}=\mathrm{I}_{\mathrm{La}}$ follow the same equations as in Mode 1. The equivalent circuit of Mode 2 is shown in Fig. 3.4(b). It is very similar to that of Mode 1except that the direction of $\mathrm{I}_{\mathrm{Ca}}=\mathrm{I}_{\mathrm{La}}$ current is different due to it being the negative portion of a resonant cycle.

Mode $3\left(t_{2}<t<t_{3}\right)$ (Fig. 3.5(c)): At the beginning of this mode, current in $S_{1}$ starts flowing in the reverse direction through the anti-parallel diode of $\mathrm{S}_{1}, \mathrm{D}_{\mathrm{S} 1}$; therefore $\mathrm{S}_{1}$ can be turned off in this mode softly with ZCS. The voltage across $\mathrm{C}_{\mathrm{a}}$ continues to rise as $\mathrm{C}_{\mathrm{a}}$ resonates with $L_{a}$. The current in the auxiliary switch flows in the negative direction, through $\mathrm{D}_{\mathrm{Sa}}$. The equivalent circuit of Mode 3 is shown in Fig. 3.4(c). The voltage across $C_{a}$ and current flowing through $\mathrm{L}_{\mathrm{a}}$ can be expressed according to the following equations:

$$
\begin{gathered}
I_{L a}=n I_{o}+I_{L I k} \\
-\frac{d^{2} V_{C a}(t)}{d t^{2}}=V_{C a}(t) \omega_{1}^{2} \\
V_{L a}(t)=V_{C a}(t)=L_{a} \frac{d i_{L a}(t)}{d t}
\end{gathered}
$$

where:

$$
\omega_{1}=\frac{1}{\sqrt{L_{a} C_{a}}}
$$


The initial conditions for equations $(8)$ to $(10)$ are: $\mathrm{V}_{\mathrm{Ca}}\left(\mathrm{t}_{2}\right)=-\mathrm{nI}_{\mathrm{o}} \mathrm{Z}_{1}$ and $\mathrm{i}_{\mathrm{La}}\left(\mathrm{t}_{2}\right)=\mathrm{nI}_{\mathrm{o}}$. Solving these equations gives:

$$
\begin{gathered}
V_{C a}(t)=-\frac{V_{\text {in }} \sin \omega_{1}\left(t-t_{2}\right)}{\sqrt{1+\frac{L_{a}}{C_{a}}}}+\frac{V_{\text {in }}\left(t_{2}-\cos \omega_{1}\left(t-t_{2}\right)\right)}{\omega_{1}^{2}} \\
I_{L a}(t)=n I_{o}-\frac{L_{a}\left(V_{C a}-V_{i n}\right)\left(1-\cos \omega_{1}\left(t-t_{2}\right)\right)}{Z_{1}}+\frac{V_{i n} \omega_{1}^{2}\left(t_{2}-\sin \omega_{1}\left(t-t_{2}\right)\right)}{\omega_{1}^{2} L_{a}}
\end{gathered}
$$

where

$$
Z_{1}=\sqrt{\frac{L_{a}}{C_{a}}}
$$

Mode $4\left(t_{3}<t<t_{4}\right)$ (Fig. 3.5(d)): At the beginning of this mode, $\mathrm{S}_{3}$ is turned on softly as the rise in switch current is constrained by the presence of $\mathrm{L}_{\mathrm{a}}$ and transformer leakage inductance. During this mode, diode $\mathrm{D}_{\mathrm{v}}$ becomes forward biased and the voltage across $\mathrm{C}_{\mathrm{c}}$ appears across the transformer secondary. This voltage is reflected to the primary as a counter voltage that helps extinguish the primary current and thus the current through $\mathrm{S}_{2} . \mathrm{C}_{\mathrm{c}}$ is discharging throughout this mode.

The voltage and current in auxiliary inductor $\mathrm{L}_{\mathrm{a}}$ can be found from the following equations in this mode:

$$
\begin{gathered}
V_{L a}(t)=V_{L_{l k}}(t)+\frac{V_{o}}{n} \\
L_{a} \frac{d I_{L a}(t)}{d t}=L_{I k} \frac{d I_{L_{i K}}(t)}{d t}+\frac{V_{o}}{n}
\end{gathered}
$$

The initial conditions for equations (15) and (16) are $\mathrm{V}_{\mathrm{Ca}}\left(\mathrm{t}_{3}\right)=0$ and $\mathrm{i}_{\mathrm{La}}\left(\mathrm{t}_{3}\right)=\mathrm{nI}_{\mathrm{o}}$. Solving these equations gives: 


$$
\begin{aligned}
& V_{L a}(t)=\frac{2}{n} V_{o}+\frac{n I_{o}}{\mu_{0}} \sin \mu_{0}\left(t-t_{3}\right) \\
& I_{L a}(t)=n I_{o}\left[1-\frac{1+\cos \mu_{0}\left(t-t_{3}\right)}{\mu_{0}}\right]
\end{aligned}
$$

where

$$
\mu_{0}=\sqrt{\frac{n^{2} C_{c}+C_{a}}{n^{2} L_{l k} C_{c} C_{a}}}
$$

Mode $5\left(t_{4}<t<t_{5}\right)$ (Fig. 3.5(e)): This mode begins when current in $\mathrm{S}_{2}$ has reached zero. $\mathrm{S}_{2}$ can be turned off with ZCS sometime after the start of this mode. During this mode, current continues to flow through the body diode of $\mathrm{S}_{\mathrm{a}}$ and $\mathrm{S}_{3} . \mathrm{C}_{\mathrm{c}}$ supplies the load current and the voltage across it continues to drop.

Mode 6 ( $\left.t_{5}<t<t_{6}\right)$ (Fig. 3.5(f)): Current has stopped flowing through the primary of the converter at the beginning of this mode. $\mathrm{S}_{3}$ can be turned off with $\mathrm{ZCS}$ during this mode as there is no current flowing in the primary side. Capacitor $\mathrm{C}_{\mathrm{c}}$ continues to discharge.

Mode $7\left(\boldsymbol{t}_{6}<\boldsymbol{t}<\boldsymbol{t}_{7}\right)$ (Fig. 3.5(g)): This mode begins when $\mathrm{C}_{\mathrm{c}}$ has been completely discharged. Diodes $\mathrm{D}_{1}-\mathrm{D}_{4}$ start conducting at the beginning of this mode and the load current freewheels through them afterwards. 


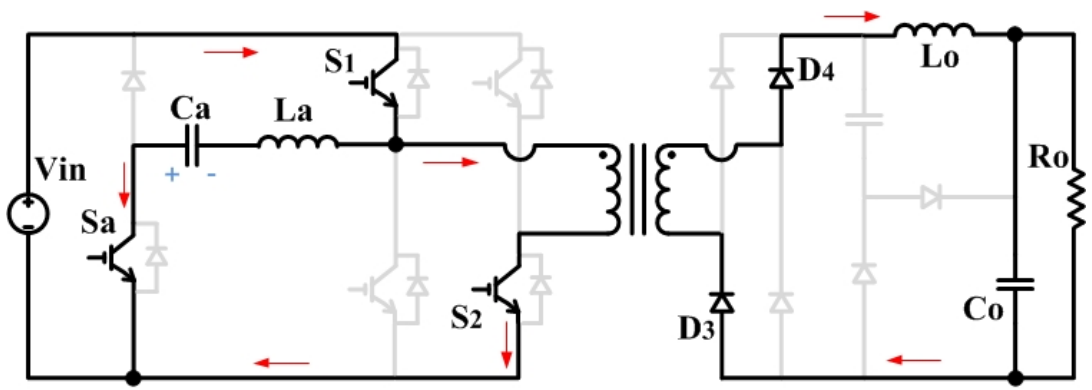

(a)

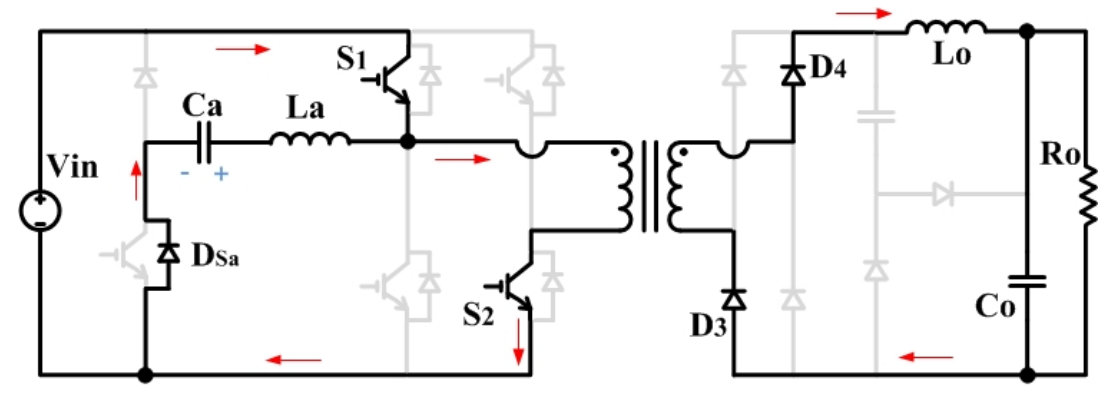

(b)

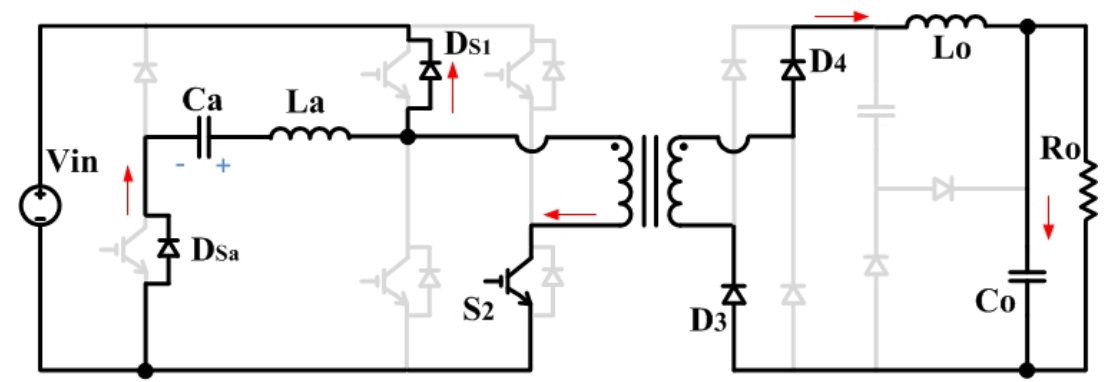

(c)

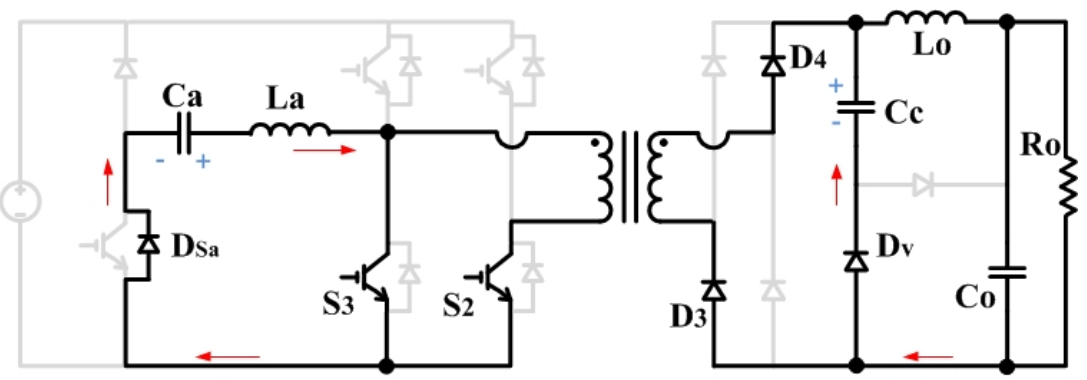

(d)

Fig. 3.2 Equivalent circuit for each mode of operation 


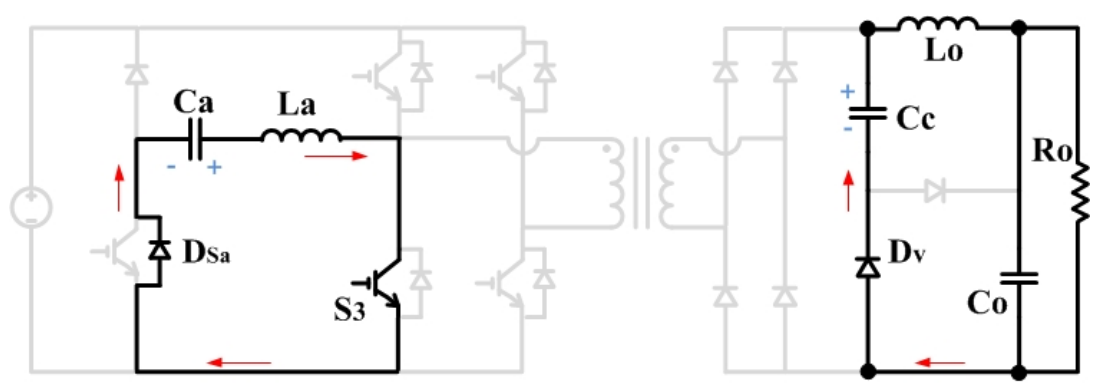

(e)

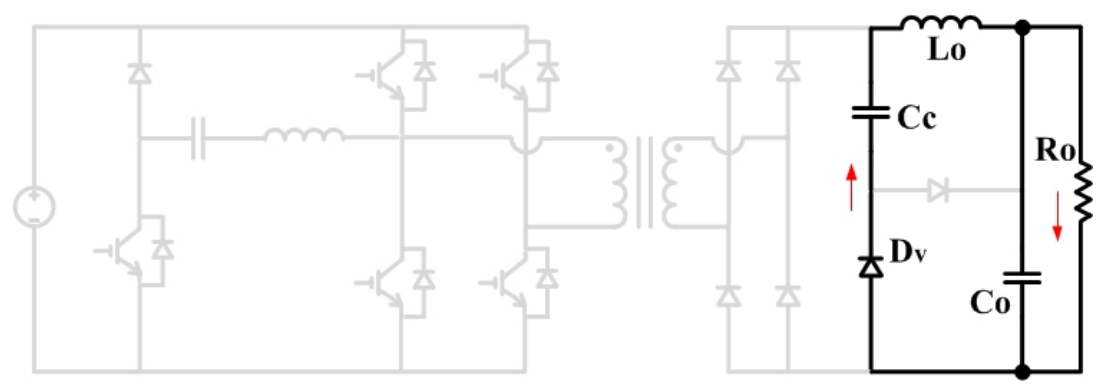

(f)

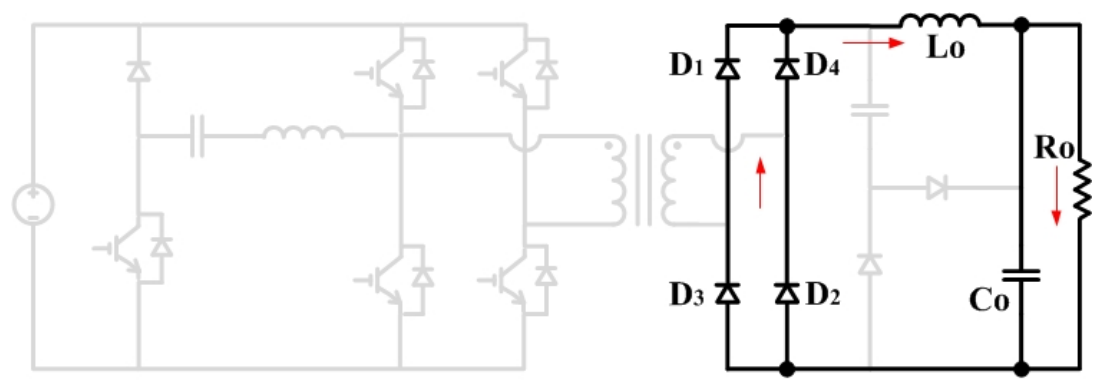

(g)

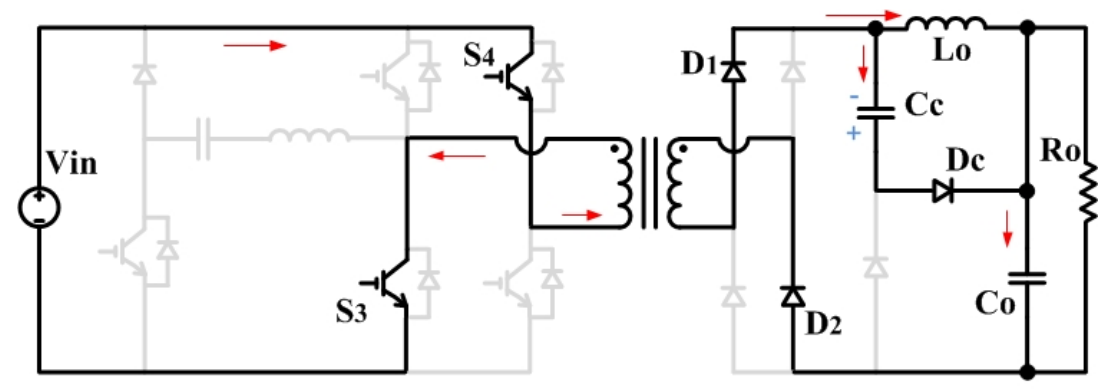

(h)

Fig. 3.2 (cont) Equivalent circuit for each mode of operation 


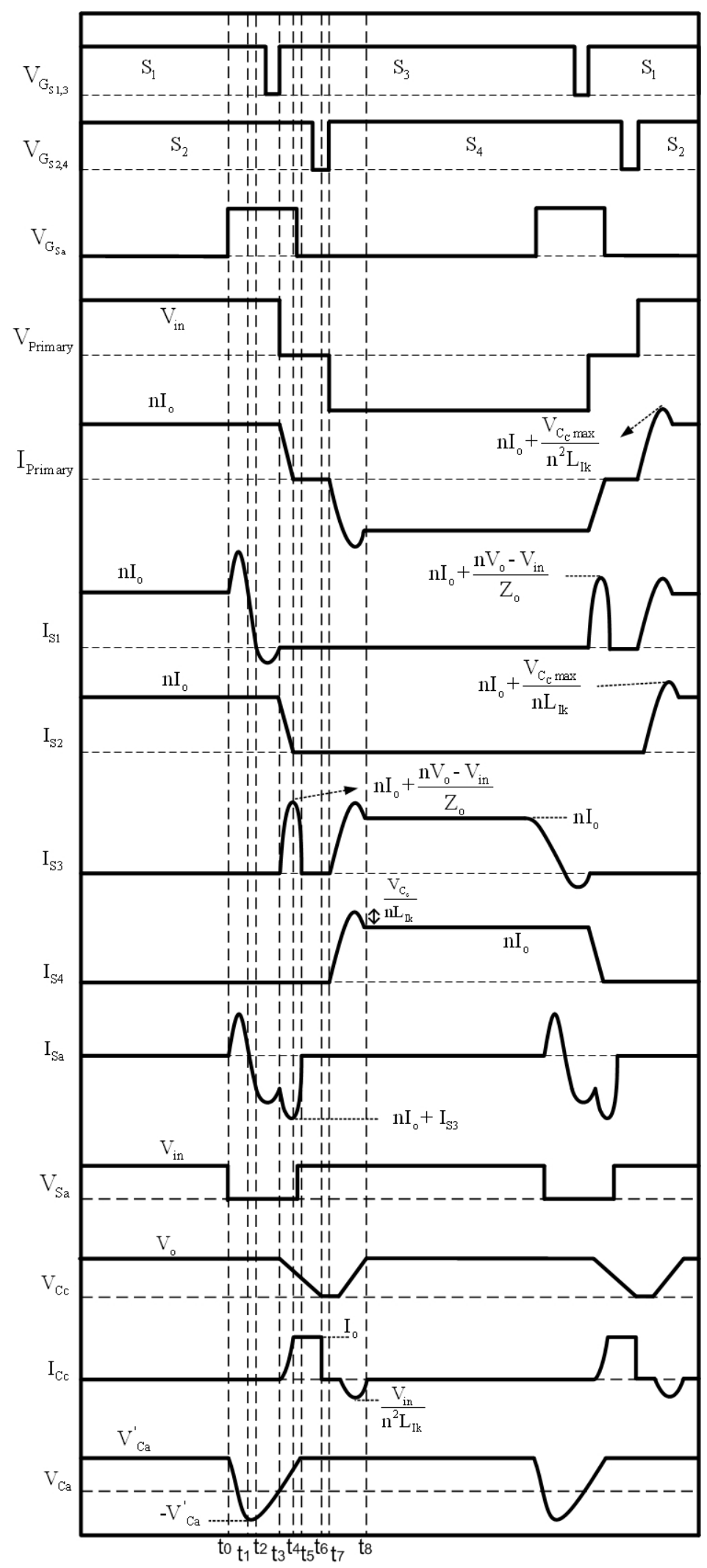

Fig. 3.3 Ideal waveforms 


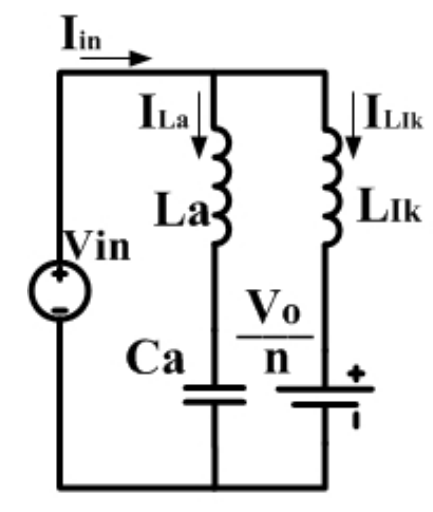

a

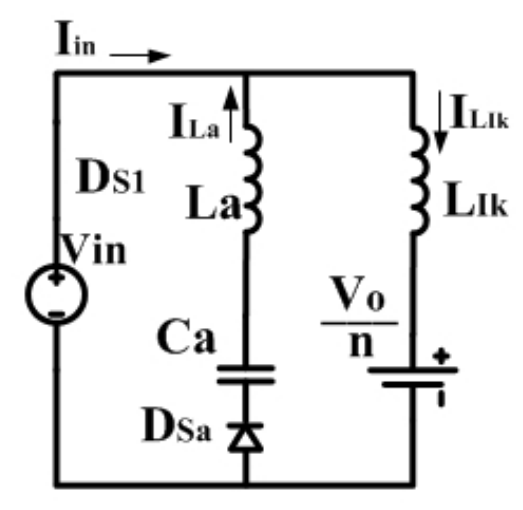

b

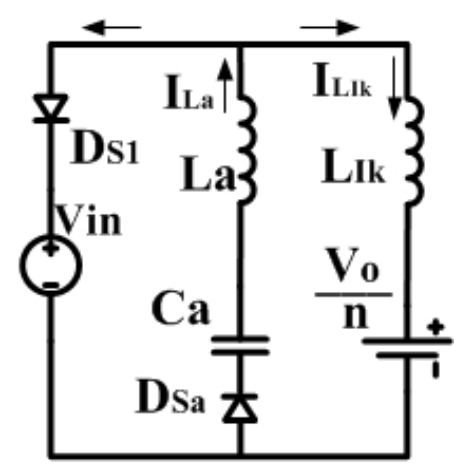

C

Fig. 3.4 Equivalent circuit for (a) Mode 1 (b) Mode 2 (c) Mode 3

Mode $8\left(t_{7}<t<t_{8}\right)$ (Fig. 3.5(h)): At the beginning of this mode, $\mathrm{S}_{4}$ is turned on softly and the current through it rises gradually since the primary current cannot change suddenly due to the transformer leakage inductance. Energy is transferred to the secondary side of the converter through $\mathrm{D}_{1}$ and $\mathrm{D}_{2}$. Voltage across $\mathrm{C}_{\mathrm{c}}$ rises through $\mathrm{D}_{\mathrm{c}}$ resonating with the leakage inductance of the transformer. It should be noted that the proposed converter can be implemented using standard phase-shift PWM.

\subsection{Converter Features}

The proposed converter has the following features:

- The voltage across secondary circuit capacitor $\mathrm{C}_{\mathrm{c}}$ is reflected to the converter primary when the converter is in a freewheeling mode of operation (Mode 4). This is the mechanism that extinguishes the freewheeling current, which reduces conduction losses and allows the lagging leg switches to turn off with ZCS.

- The leading leg switches turn off with ZCS as the primary-side auxiliary circuit 
injects current into their body-diodes before they are turned off. In the case of $\mathrm{S}_{1}$, as seen in Fig. 3.2, this body-diode current is generated by first charging Ca after $\mathrm{S}_{\mathrm{a}}$ is turned on, then having the current through $\mathrm{L}_{\mathrm{a}}$ and $\mathrm{C}_{\mathrm{a}}$ reverse direction and flow through the body-diode of $\mathrm{S}_{1}$ after $\mathrm{C}_{\mathrm{a}}$ has been charged to its peak value. In the case of $\mathrm{S}_{2}$, which is not shown in Fig. 3.2, $\mathrm{C}_{\mathrm{a}}$ has negative voltage across it at the time $\mathrm{S}_{2}$ is to be turned off so that when $S_{a}$ is turned on to initiate the turning off of $S_{2}$, current is diverted away from the switch and into $\mathrm{S}_{\mathrm{a}}$; Eventually current flows through the body-diode of $\mathrm{S}_{2}$.

- $\quad \mathrm{S}_{\mathrm{a}}$ can be turned off with ZCS (Mode 3) as the $\mathrm{C}_{\mathrm{a}}-\mathrm{L}_{\mathrm{a}}$ resonant circuit forces current through the switch to be gradually removed then flow through its body-diode.

- All converter switches turn on with ZCS because they either have an inductor in series with them (main transformer leakage inductance for $\mathrm{S}_{2}$ and $\mathrm{S}_{4}$, La for $\mathrm{S}_{\mathrm{a}}$ ) or the current in the series is constrained by the presence of other inductances in circuit $\left(\mathrm{L}_{\mathrm{a}}\right.$ and the main transformer leakage inductance for $\mathrm{S}_{1}$ and $\mathrm{S}_{3}$ ).

- Due to the gradual rise and fall of the primary current during any switching transition, the secondary diodes turn off softly. Moreover, $\mathrm{C}_{\mathrm{c}}$ acts a clamping capacitor to suppress any voltage ringing that may appear across the secondary diodes. The converter is based on a ZVZCS converter and thus has the features of converters of this type.

It should be noted that neither the active auxiliary circuit nor the passive auxiliary circuit are new individually, by themselves. The active auxiliary circuit can be any one of a number of previously proposed ZCS-PWM converter active auxiliary circuits and the passive auxiliary can also be any one of a number of previously proposed passive auxiliary 
circuits used in previously proposed ZVZCS-PWM converters. The auxiliary circuits chosen for the proposed converter were chosen as they are among the simplest of each type.

What is new and novel about the proposed converter is that the combination of an active ZCS auxiliary circuit and a passive ZVZCS auxiliary circuit has never been previously proposed before to the best of the authors' knowledge. It is this combination that allows the converter to have a very simple topology that can be implemented with IGBTs for all four main power switches and with ZCS turn-on and turn-off for all four switches and the active auxiliary switch as well. These properties cannot be found in previously proposed ZVZCS full-bridge converters, which have leading leg switches that must operate with a ZVS turn-on (which is unsuitable for IGBTs) nor can they be found in previously proposed ZCS full-bridge converters, which require more sophisticated topology, blocking diodes, and/or bulky resonant components.

The proposed converter, however, has the following drawbacks:

- $\quad$ Since it is a ZCS-PWM converter, it is not a suitable topology if the converter is to be implemented with MOSFETs as it is a standard practice to operate MOSFETs with ZVS.

- The current in any given switch in the proposed converter will have a resonant peak so that the converter's peak switch current will be higher than that of a switch in a ZVS-PWM converter.

- The light load efficiency of the converter is worse when the active auxiliary circuit is implemented than when it is not. This is because the turn-off losses of the leading leg switches to which the active auxiliary circuit is attached are fewer than the losses of the active auxiliary circuit when the converter is operating under light load conditions. 
The opposite becomes true at heavier loads.

All the above drawbacks are common to ZCS-PWM converters in general.

\subsection{Design Guidelines}

A procedure for the design of the two auxiliary circuits for the converter - the active circuit at the primary side and the passive circuit at the secondary side - is presented in this section and is demonstrated with an example. For the example, the auxiliary circuits are to be designed for a full-bridge converter operating with output voltage $\mathrm{V}_{\mathrm{o}}=380 \mathrm{~V}$, input voltage $\mathrm{V}_{\text {in }}=400 \mathrm{~V}$, maximum output power $\mathrm{P}_{\mathrm{o}}=3 \mathrm{~kW}$, leakage inductance $\mathrm{L}_{\mathrm{Ik}}=3.2 \mu \mathrm{H}$, transformer ratio is $6: 7$ and switching frequency $\mathrm{f}_{\mathrm{sw}}=80 \mathrm{kHz}$. The design procedure that is presented here is iterative and requires several iterations before the final design can be completed. Only the final iteration will be shown in the example that follows.

The following design objectives should be considered:

I. The auxiliary circuit is attached to the leading converter leg, which is the leg with switches that would normally turn on and off with ZVS in a ZVZCS-PWM fullbridge converter. The auxiliary circuit must be such that that its peak current is greater than the maximum peak current that flows through the main switches in the leg in order for the switches to turn off with ZCS. If this is not the case, then the auxiliary circuit will not be able to divert sufficient current away from the bottom switch of the leg that it is attached to and have it flow in its circuit. It will also not be able to divert current away from the top switch of the leg by reversing the flow of current through the switch so that its body diode conducts. 
II. It has been determined from previous iterations that an auxiliary switch peak current that is about two times the maximum peak switch current allows current to be transferred away from a main switch at a rate that is neither too sudden nor too gradual. If the peak auxiliary circuit is very high, however, say four times the maximum peak current for the main switches in the leg, then the transfer of current away from a main switch is too sudden and the IGBT device will still turn off with a current tail and thus with switching losses. The ratio of peak auxiliary circuit current, to the maximum peak switch current should not be too high or too low, which would make the transfer of current away from a main switch too gradual and would increase the length of time that the auxiliary circuit is active in the converter.

III. An appropriate "ZCS time window" needs to be considered in the design of the auxiliary circuit. The ZCS time window is the amount of time during which a main switch in the leading converter leg can turn on with ZCS. If a main switch is turn off before this window of time, then an insufficient amount of time will have been given to the auxiliary circuit to divert current away from a main switch. If a main switch is turned off after this window of time, current that has been diverted away from a main switch will reappear in the same switch due to the resonant nature of the auxiliary circuit. As with the rate of current transfer, the width of the ZCS time window is dependent on the ratio of peak auxiliary circuit current to maximum peak switch current. If this ratio is too high, then the time window is too narrow; if it is too low, then the time window is too wide and the auxiliary circuit will be on for a considerable fraction of the switching cycle. This should be avoided as it increases the average and RMS current stresses of the auxiliary circuit components and may 
place limits on the duty cycle of the converter as time is needed to reset the auxiliary circuit in preparation for the next switching cycle.

IV. It would be preferable if the voltage across resonant capacitor $C_{a}$ in the auxiliary circuit does not exceed $400 \mathrm{~V}$ so that standard $450 \mathrm{~V}$ capacitors can be used with some voltage margin. This places a constraint on the impedance of the resonant circuit in the auxiliary circuit as it must be such that it allows the peak auxiliary circuit current to be sufficiently high so that the main power switches in the leg can turn off with ZCS. A voltage of $C_{a}$ that is low may result in values of $L_{a}$ and $C_{a}$ that are such that the transfer of current away from the main switches in the leg is too sudden for the current tail in the IGBT to be eliminated.

V. The switches in the lagging converter leg turn off with ZCS due to the secondary side auxiliary circuit. The key component in this circuit is capacitor $\mathrm{C}_{\mathrm{c}}$ as it is the voltage across $\mathrm{C}_{\mathrm{c}}$ that gets reflected to the transformer primary that is the basis of the counter-voltage that extinguishes the current that circulates in the converter when it is in a freewheeling mode of operation. The value of this capacitor should be sufficiently high so that it does not discharge too quickly, before the freewheeling current in the primary side can be extinguished. If the value of this capacitor is too high, however, then $\mathrm{C}_{\mathrm{c}}$ will not discharge and this may interfere with the operation of the converter. Higher values of $\mathrm{C}_{\mathrm{c}}$ require smaller duty cycles during light load conditions to make sure that the $\mathrm{C}_{\mathrm{c}}$ completely discharges during the freewheeling period.

The design of the converter's auxiliary circuit can be done with the following steps: 


\section{Step 1: Active Auxiliary Circuit Component Values}

In this step, preliminary values of $\mathrm{C}_{\mathrm{a}}$ and $\mathrm{L}_{\mathrm{a}}$ are determined based the voltage across $\mathrm{C}_{\mathrm{a}}$. As stated above, it is desired that this voltage be high, but not so high that it exceeds $400 \mathrm{~V}$. Once these preliminary values have been selected, the suitability of these component values based on whether they allow the auxiliary circuit to divert current away from the main switches at a suitable rate can be confirmed in a later step of the procedure.

The maximum voltage across the resonant capacitor $C_{a}$ can be calculated from the following equation:

$$
V_{C a}(t)=\frac{V_{O}}{n}+I_{i n} Z_{o}
$$

where

$$
\mathrm{Z}_{\mathrm{o}}=\sqrt{\frac{\mathrm{L}_{\mathrm{a}}+\mathrm{L}_{\mathrm{Ik}}}{\mathrm{C}_{\mathrm{a}}}}
$$

Eqn. (20) is derived using Kirchhoff's current law in Mode 3 by considering the reflected voltage source from the secondary side $\mathrm{V}_{\mathrm{o}} / \mathrm{n}$ and the transformer leakage inductance. Fig. 3.5 is plotted from Eqn. (20) for different values of $Z_{0}$ versus the maximum voltage across $C_{a}$ for different values of input voltage, when $n=21 / 18$ and $\mathrm{I}_{\mathrm{in}}=7.5 \mathrm{~A}$ (the maximum input current considering $100 \%$ efficiency for a $3 \mathrm{~kW}$ prototype when input voltage is $400 \mathrm{~V})$.

It can be found from this graph that by choosing a larger impedance, the voltage across $\mathrm{C}_{\mathrm{a}}$ will increase. If a smaller impedance is chosen, a larger capacitor must be used for $\mathrm{C}_{\mathrm{a}}$ as there must be enough energy stored in the capacitor at the end of this mode to force the current into the full bridge to reverse direction and create an opportunity for the ZCS turn 
off of switches. Since $V_{\text {in }}=400 \mathrm{~V}$ and it is desired that the voltage across $\mathrm{C}_{\mathrm{a}}, \mathrm{V}_{\mathrm{Ca}}$, be $400 \mathrm{~V}$ as well, the corresponding impedance value from the graph in Fig. 3.5 is $Z_{0}=1.4 \Omega$.

\section{Step 2: Characteristic impedance of the active auxiliary circuit}

The characteristic impedance of the auxiliary circuit, defined by:

$$
Z_{1}=\sqrt{\frac{L_{a}}{C_{a}}}
$$

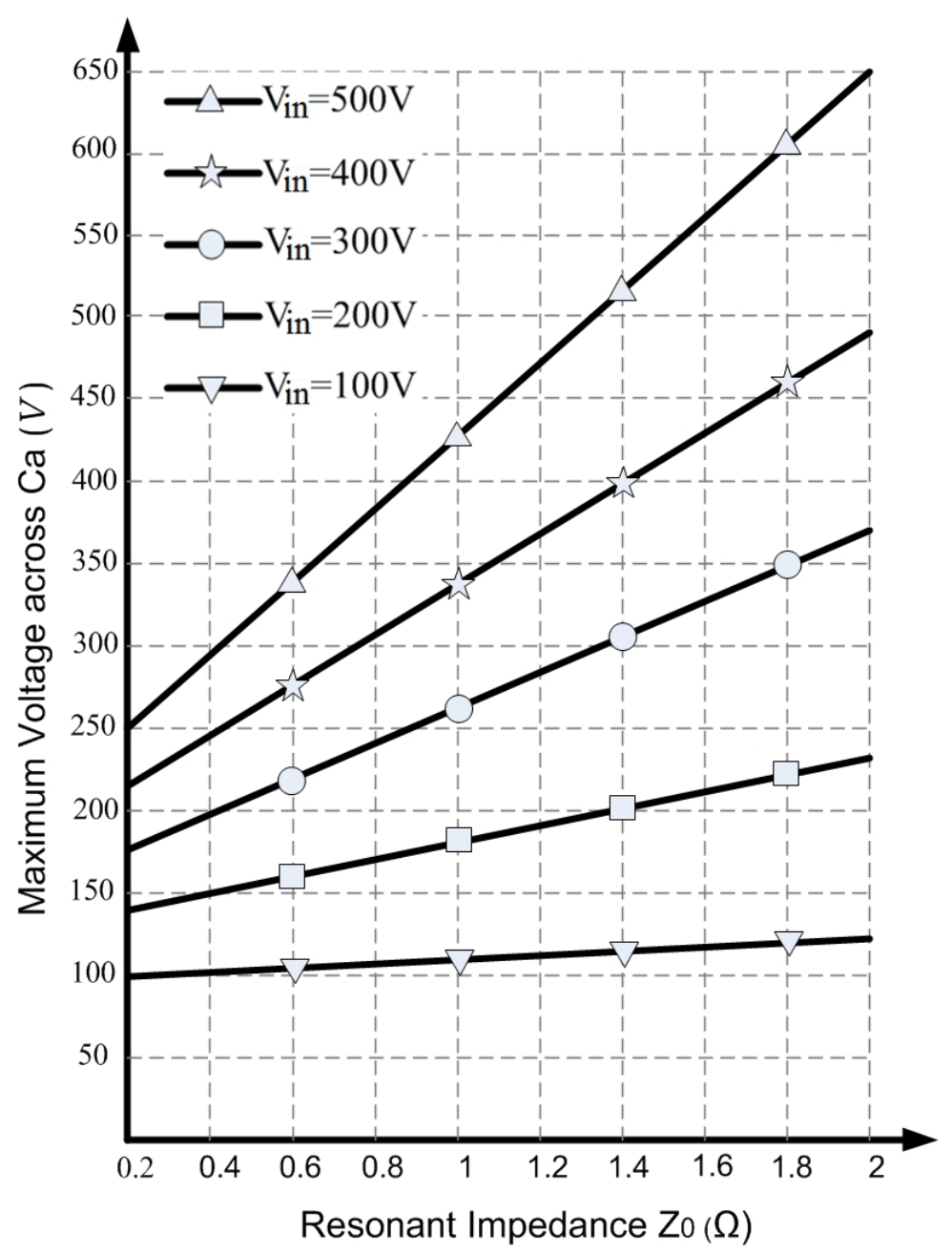

Fig. 3.5 Variation of $C_{a}$ peak voltage for different values of $Z_{0}$ 
that affects the peak current stress of the auxiliary circuit components and the window of time within the leading leg switches can be turned off with ZCS. It should be noted that the peak current in the auxiliary switch must be greater than the full-bridge input current so the bridge current can reverse, reduce to zero, and flow in the opposite direction through the body diodes of the bridge switches, which can then be turned off with ZCS.

Fig. 3.6 is plotted from Eqn. (13) and shows the peak current in the auxiliary inductor $L_{a}$ for different values of $Z_{1}$ in a wide range of input voltage $V_{\text {in. }}$. If $Z_{1}=\sqrt{\frac{L_{a}}{C_{a}}}=0.7 \Omega$ is selected, that gives $I_{\mathrm{Sa}} \approx 16 \mathrm{~A}$ from the graph in Fig. 3.6. This is a reasonable peak current value in the auxiliary circuit as (a) it is about twice the input current instead of four or five times; (b) on the basis of previous iterations, it was seen that this current may be sufficient to result in the ZCS operation of the leading legs switches (whether this is actually the case will be confirmed in the next step of the design procedure).

With $Z_{0}=1.4 \Omega$ and $Z_{1}=0.7 \Omega$ selected, it is possible to determine values for $\mathrm{La}$ and $\mathrm{Ca}$ using equations (21) and (22). From these equations, it can be found that $\mathrm{L}_{\mathrm{a}}=3 \mu \mathrm{H}$ and $\mathrm{C}_{\mathrm{a}}=$ $62 \mathrm{nF}$. The key equation that describes the duty cycle of the of the active auxiliary circuit $\left(t_{c}\right)$ is typically equivalent to 3 times the reverse recovery time of the auxiliary diode, which can be determined from

$$
t_{C}=\frac{\pi}{2 \omega_{0}}
$$

where

$$
\omega_{0}=\frac{1}{\sqrt{n^{2} C_{a}\left(L_{a}+L_{l k}\right)}}
$$


thus

$$
t_{c}=\frac{\pi}{2} \sqrt{n^{2}\left(L_{a}+L_{l k}\right) C_{a}}
$$

As a result of the auxiliary component values, the duty cycle of the auxiliary circuit is $120 \mathrm{~ns}$ or $6 \%$ of the duty cycle in one cycle. The auxiliary switch is activated slightly before $\mathrm{S} 1$ and S3 are to be turned on to pull the current away from the bridge.

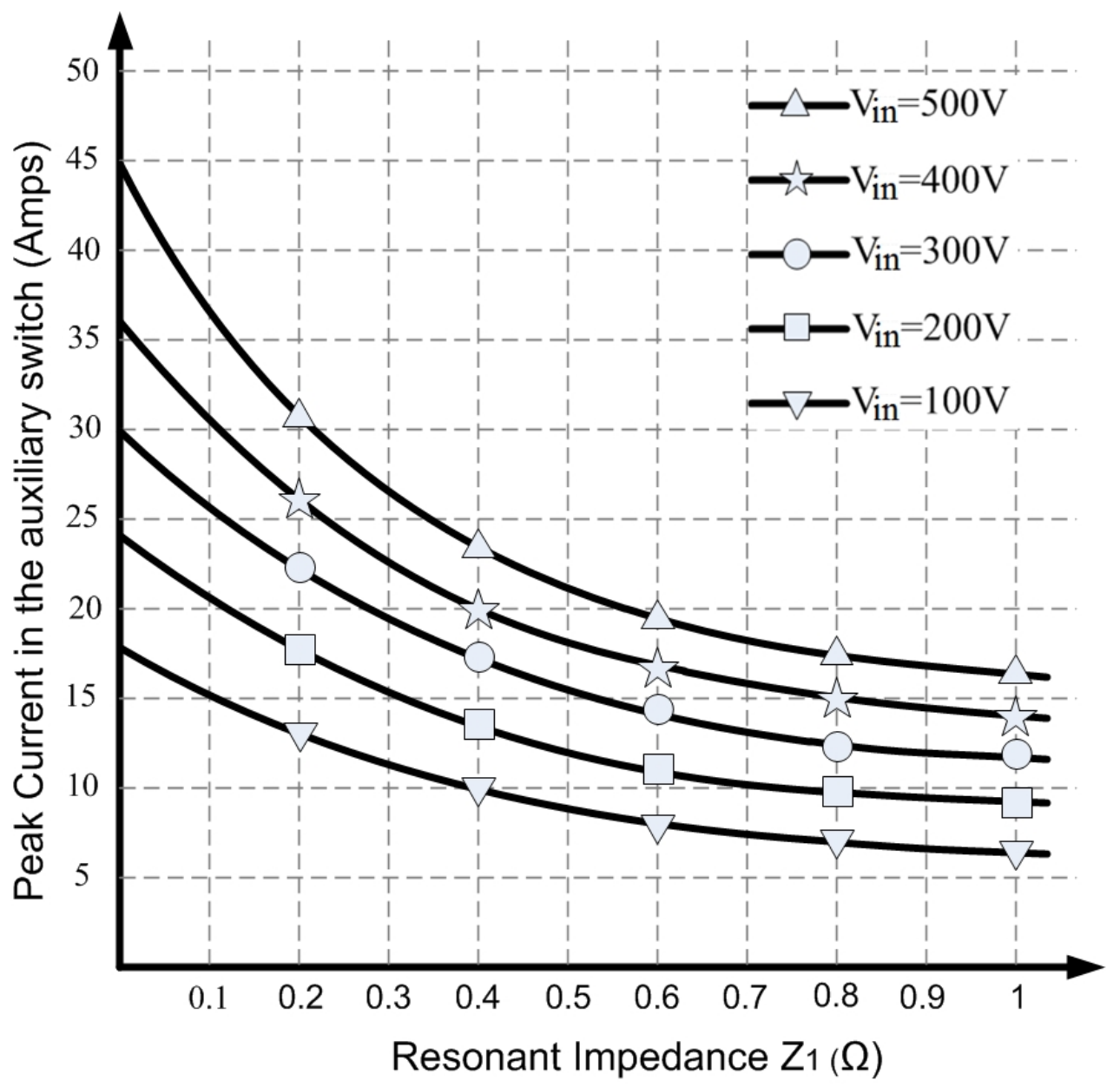

Fig. 3.6 Variation of peak current in auxiliary switch for different values of $Z_{1}$ 


\section{Step 3: ZCS range of leading leg switches}

With the auxiliary circuit values of $L_{a}$ and $C_{a}$ known, the next step is to confirm whether the auxiliary circuit can allow the converter's leading leg switches to operate with ZCS and the auxiliary switch to operate with ZCS. Fig. 3.7 is a graph of curves of the main switch $\left(\mathrm{S}_{1}\right)$ current vs. time that are plotted by using Eqn. (5) for different values of $\mathrm{V}_{\mathrm{Ca}}$, and the values of $\mathrm{L}_{\mathrm{a}}, \mathrm{C}_{\mathrm{a}}$, and $\mathrm{L}_{\mathrm{Ik}}$ that are defined above. The negative portion of each curve indicates the amount of time (ZCS time window) during which the switch can be turned off with ZCS after the current in $\mathrm{S}_{1}$ has dropped to zero. For $\mathrm{V}_{\mathrm{Ca}}=400 \mathrm{~V}$, the width of the $\mathrm{ZCS}$ time window is about $0.9 \mu \mathrm{s}$.

It should be noted that the auxiliary switch $S_{a}$ can be turned off softly when $S_{1}$ is turned off. This is because current in $\mathrm{S}_{\mathrm{a}}$ flows through its body diode, when current is flowing through $\mathrm{D}_{\mathrm{S} 1}$.

\section{Step 4: ZCS turn-off of lagging leg switches}

A very simple passive auxiliary circuit without any additional switch is applied in the secondary side of the converter to achieve ZCS for the lagging leg switches, by resetting the primary current with the energy stored in $C_{c}$. At the end of Mode 8 when $C_{c}$ is charged completely, the voltage across $\mathrm{C}_{\mathrm{c}}$ reaches the output voltage $\mathrm{V}_{\mathrm{o}}$. The voltage across $\mathrm{C}_{\mathrm{c}}$ can be expressed according to the following equations:

$$
\begin{gathered}
V_{C C}(t)=n V_{i n}-L_{I k} \frac{d i_{L_{l k}}(t)}{d t} \\
L_{I k} \frac{d i_{L_{l k}}^{2}(t)}{d t}+\frac{i_{C_{C}}}{C_{C}}=0 \\
i_{L_{I k}}(t)=n\left(I_{o}+i_{C C}(t)\right)
\end{gathered}
$$


where $\mathrm{V}_{\mathrm{Cc}}$ is the voltage across capacitor $\mathrm{C}_{\mathrm{c}}$ and $\mathrm{I}_{\mathrm{Cc}}$ is the current through it. The initial conditions for equations (26) and (27) are $\mathrm{V}_{\mathrm{Cc}}(\mathrm{t} 8)=0$ and $\mathrm{I}_{\mathrm{Llk}}(\mathrm{t} 8)=0$. Solving these equations gives:

$$
\begin{gathered}
V_{C c}(t)=V_{o}-\frac{1}{C_{c} \omega} I_{o}(\cos \omega t)+\frac{I_{o} t}{C_{c}} \\
I_{C c}(t)=\frac{n V_{i n}}{\sqrt{L_{l k} C_{C}}}(\sin \omega t)
\end{gathered}
$$

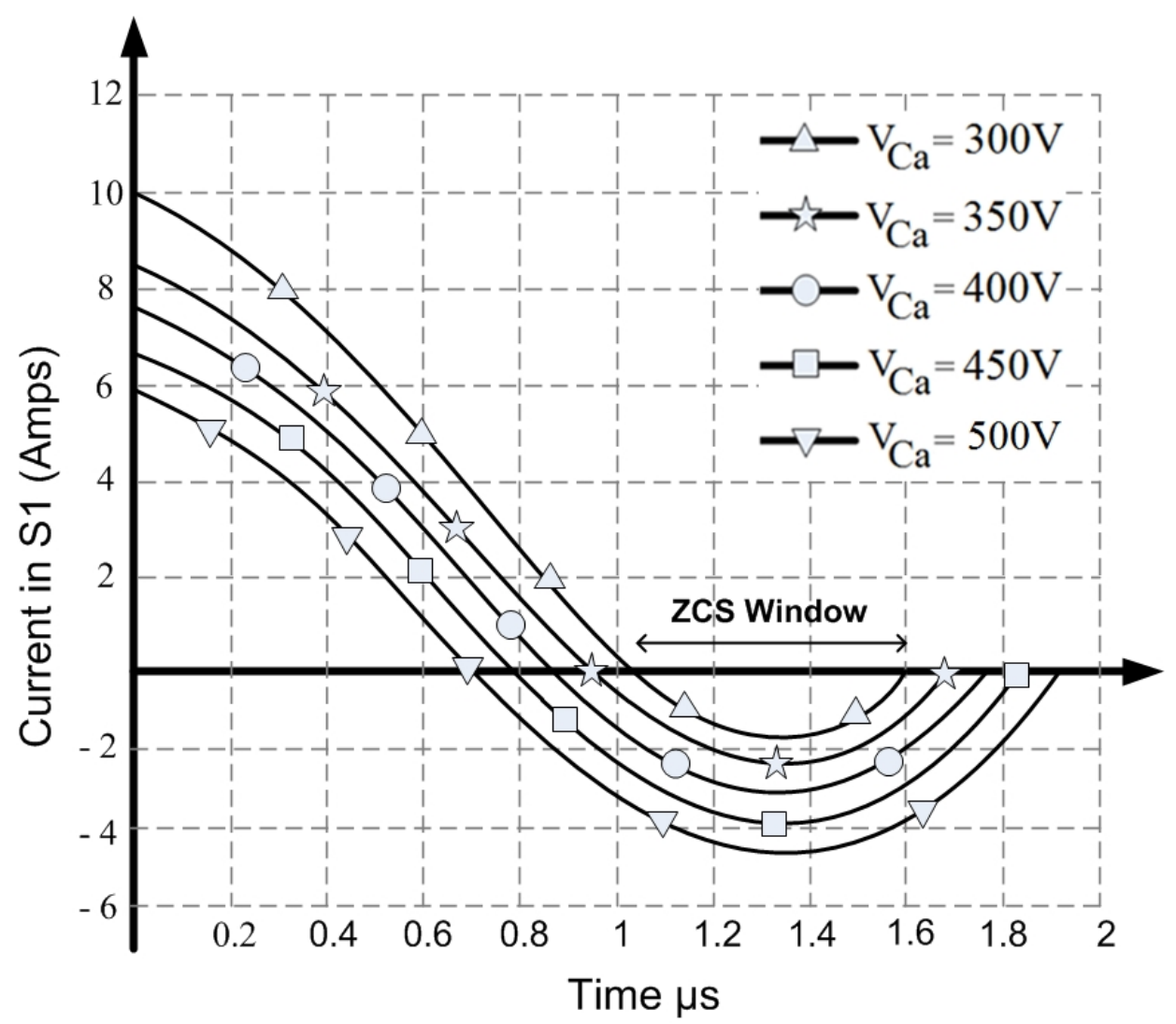

Fig. 3.7 Variation of the duration in which current in $S_{1}$ reduces to zero and goes negative during modes 1-2 for different values of $\mathrm{V}_{\mathrm{Ca}}$

where 


$$
\omega=\frac{n}{\sqrt{L_{l k} C_{C}}}
$$

Solving Eqn. (32) for $\mathrm{Cc}$, the minimal value to ensure the energy stored in $\mathrm{C}_{\mathrm{c}}$ is large enough to reset the primary current and provide a ZCS range for $\mathrm{S}_{2}$ and $\mathrm{S}_{4}$ can be obtained from the following equation where $\mathrm{L}_{\mathrm{lk}}=3.2 \mu \mathrm{H}, \mathrm{I}_{\mathrm{o}}=7.9 \mathrm{~A}=3 \mathrm{~kW} / 380 \mathrm{~V}$ and the efficiency is assumed to be $100 \%$.

$$
C_{C}=\sqrt{\frac{L_{I k} I_{o}^{2}}{V_{o}^{2} n^{2}}}=3.2 \mu \mathrm{F}
$$

Larger values of $\mathrm{C}_{\mathrm{c}}$ require smaller duty cycle during light load conditions to make sure that the holding capacitor completely discharges during the freewheeling period. Therefore Cc should be as small as possible at the same time Eqn. (21) is fulfilled. A value of $\mathrm{C}_{\mathrm{c}} \geq$ $3.2 \mu \mathrm{F}$ can be chosen to ensure the ZCS in the lagging leg switches. $\mathrm{C}_{\mathrm{c}}=3.3 \mu \mathrm{F}$ is chosen for this design example.

\subsection{Experimental Results}

An experimental prototype was built to confirm the feasibility of the proposed converter and to compare the efficiency of the converter with both auxiliary circuits (proposed) and without the active auxiliary circuit at the converter's primary side (just ZVZCS).

The prototype has the following specifications: Input voltage $\mathrm{V}_{\text {in }}=400 \mathrm{~V}$, output voltage $\mathrm{V}_{\mathrm{o}}=380 \mathrm{~V}$, maximum output power $\mathrm{P}_{\mathrm{o}}=3 \mathrm{~kW}$ and switching frequency $\mathrm{f}_{\mathrm{sw}}=80 \mathrm{kHz}$. The prototype was implemented using the following component values: $L_{a}=3 \mu H, C_{a}=62 n F$, $\mathrm{C}_{\mathrm{c}}=3.3 \mu \mathrm{F}$.

The transformer ratio is 21 to 18 with $\mathrm{L}_{\mathrm{Ik}}=3.2 \mu \mathrm{H}$ and the following devices were used 
for the IGBT switches in the prototype: IRG4PC50FD-EPBF for $\mathrm{S}_{1}$ to $\mathrm{S}_{4}$, STGB7NC60HDT4 for the auxiliary switch $\mathrm{S}_{\mathrm{a}}$.

Voltage and current waveforms of the leading leg switches $\left(\mathrm{S}_{1}, \mathrm{~S}_{3}\right)$ are shown in fig. 3.8 and fig. 3.9. The auxiliary circuit forces the current to flow through the anti-parallel diodes of the switches to make the ZCS turn-off possible. It should be noted that the notches in the current waveforms are due to the ZVZCS property of the converter. Voltage and current waveforms of $S_{2}$ are shown in fig. 3.01 to confirm the zero current switching operation in the lagging leg as well. Fig. 3.11 shows the primary voltage across the transformer which is a regular phase shifted wave form. Finally a comparative study was done on the proposed converter with and without the auxiliary circuit and presented in Fig. 3.12. It can be seen that the proposed converter is about $7 \%$ more efficient at full load when it has the auxiliary circuit. It should be noted that the reason for the declining efficiency curve of the ZVZCS converter is that the ZVZCS converter was implemented with IGBTs and two of the switches do not operate with a ZCS turn-off so that the turn-off losses of these switches worsen as the load is increased.

\subsection{Conclusion}

A new ZCS-PWM full-bridge converter was proposed in this chapter of this thesis. The outstanding feature of the new converter is that it allows its main power switches to operate with zero current switching (ZCS) and with fewer conduction losses than conventional fullbridge converters. This is achieved by using a very simple active auxiliary circuit and a ZVZCS technique so that the converter has all the advantageous features of ZVZCS converters but with ZCS operation for all the converter switches so that they can all be 
IGBT devices, which helps reduce component cost. The proposed converter does not have the drawbacks of previously proposed techniques for higher power Dc-Dc full-bridge converters with IGBTs, including resonant techniques, ZCS-PWM techniques with active auxiliary circuits, passive techniques, ZVZCS techniques, and techniques that require the use of reverse blocking diodes.

Experimental results obtained from a $3 \mathrm{~kW}, 80 \mathrm{kHz}$ converter prototype confirm the feasibility of the converter and show that the active auxiliary circuit results in a maximum efficiency improvement of $7 \%$ at full load, compared to the conventional ZVZCS converter due to the elimination of leading leg turn-off losses by the active auxiliary circuit.

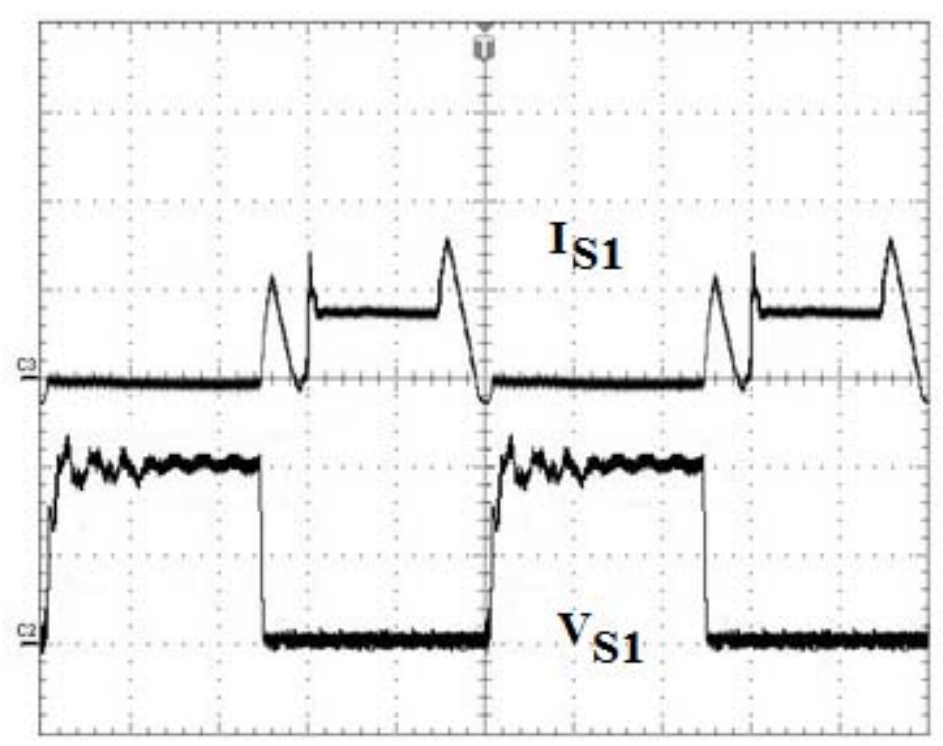

Fig. 3.8 Current and voltage waveforms in $\mathrm{S}_{1}$

(I: $10 \mathrm{Amps} / \mathrm{div}, \mathrm{V}: 200 \mathrm{~V} / \mathrm{div}$, t: $2.5 \mu \mathrm{s} / \mathrm{div}$ ) 


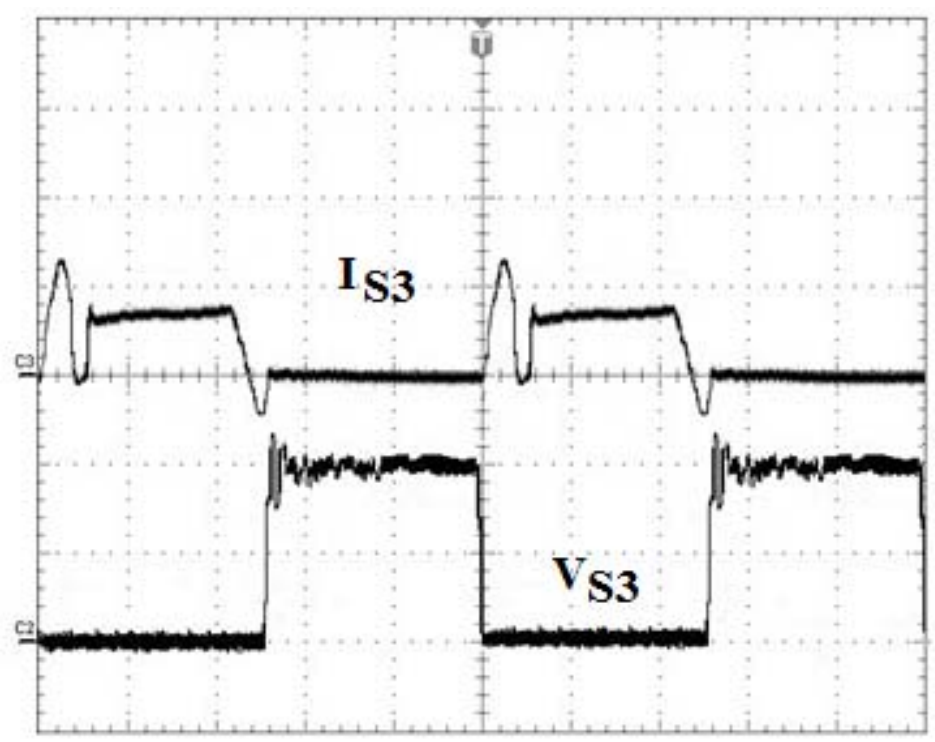

Fig. 3.9 Current and voltage waveforms in $\mathrm{S}_{3}$ (I: $10 \mathrm{Amps} / \mathrm{div}, \mathrm{V}: 200 \mathrm{~V} / \mathrm{div}, \mathrm{t}: 2.5 \mu \mathrm{s} / \mathrm{div}$ )

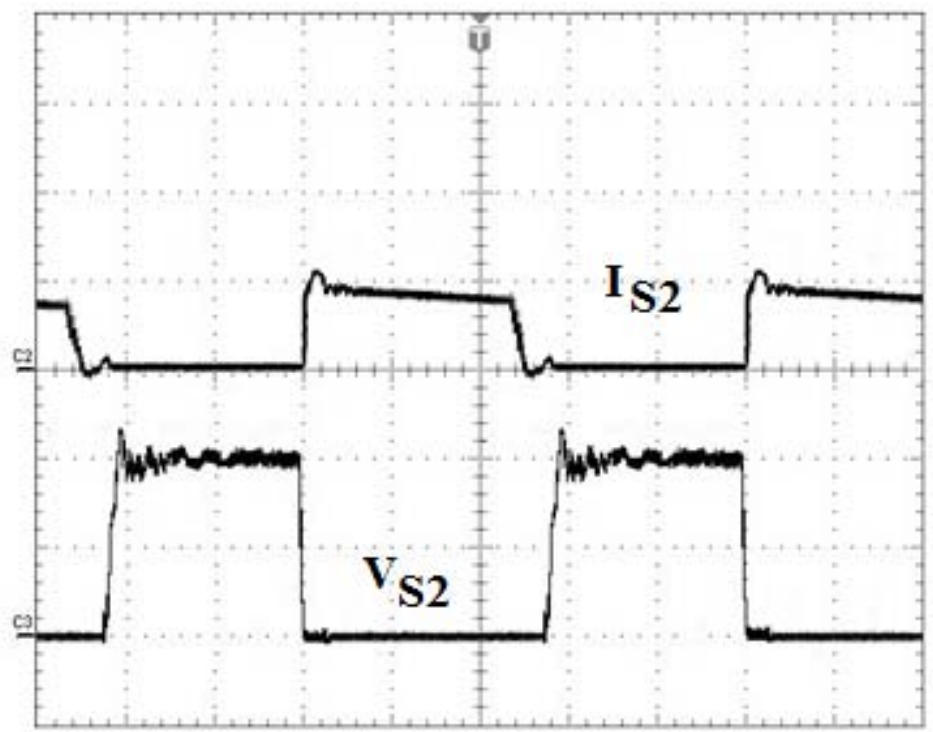

Fig. 3.10 Current and voltage waveforms in $\mathrm{S}_{2}$ (I: $10 \mathrm{Amps} / \mathrm{div}, \mathrm{V}: 200 \mathrm{~V} / \mathrm{div}, \mathrm{t}: 2.5 \mu \mathrm{s} / \mathrm{div}$ ) 


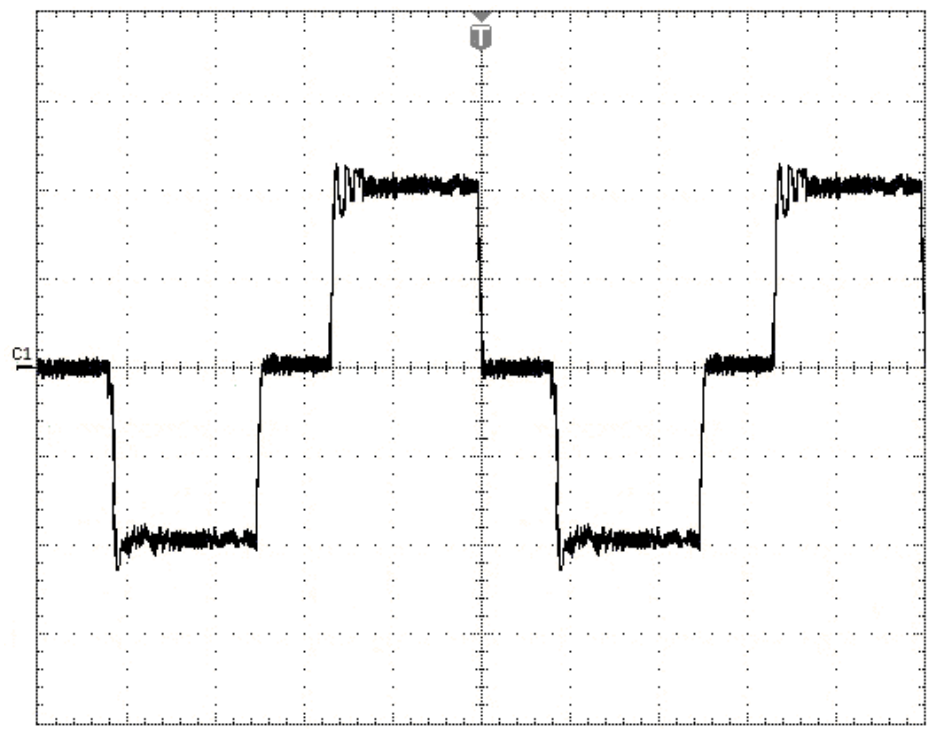

Fig. 3.11 Primary voltage waveform across the transformer (V: $200 \mathrm{~V} / \mathrm{div}, \mathrm{t}: 2.5 \mu \mathrm{s} / \mathrm{div}$ )

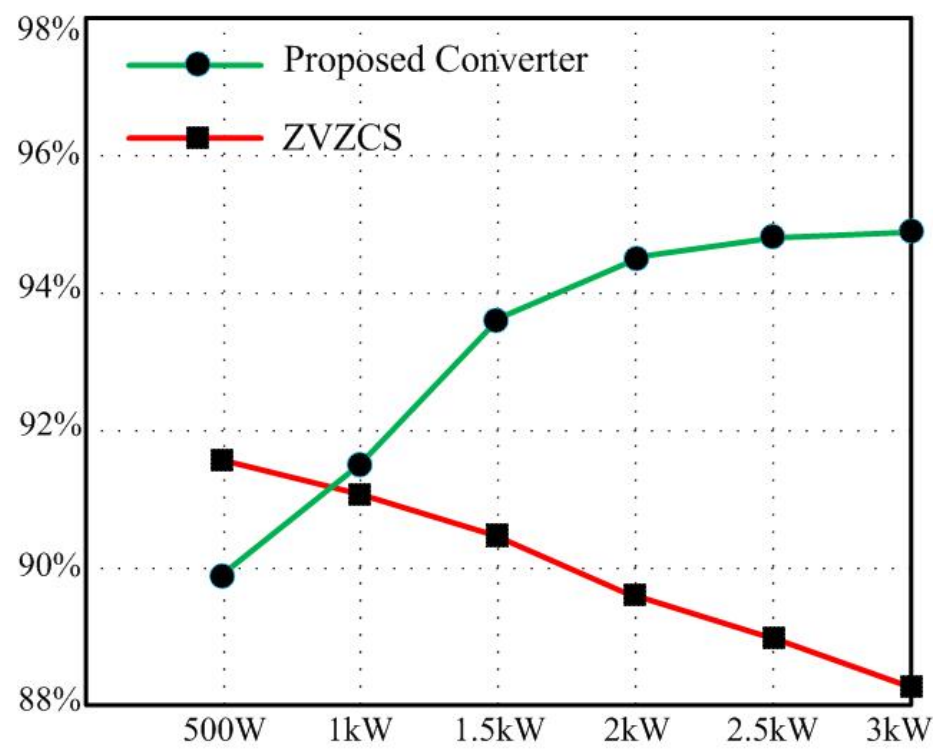

Fig. 3.12 Efficiency comparison results 


\section{Chapter 4}

\section{A Novel Three-Phase ZVS PWM Dc-Dc Boost Converter}

\subsection{Introduction}

So far in this thesis, it has been shown that converter efficiency in two different types of Dc-Dc converters can be improved by the use of simple active auxiliary circuits that allow the main converter switches to operate with ZCS. These auxiliary circuits use only a single active switch and used resonant circuit principles to divert current away from the main switches so that they can be turned off with ZCS. Moreover, the auxiliary switch in each of the two converters can operate with ZVS as well.

Three-phase Dc-Dc converters with transformer isolation that convert low input dc voltages into high output dc voltages (i.e photovoltaic converters, fuel cell converters, etc.) are typically implemented with MOSFETs due to their low voltage input. Since MOSFETs are used in these converters, the preferred method of soft-switching is zero-voltage switching (ZVS) and not ZCS; however, it may be possible to use similar principles as were used in the previous chapters of this thesis to improve converter efficiency.

A new three-phase Dc-Dc PWM boost converter is proposed in this chapter. The proposed converter can operate with ZVS due to a simple auxiliary circuit that consists of just a single active switch and a few passive components. This chapter presents the new converter and then discusses its operation, steady-state characteristics and design. 
Experimental results obtained from a converter prototype are presented to validate the converter's performance.

\subsection{Circuit Description and Modes of Operation}

The proposed converter is shown in Fig. 4.1. It is a three-phase boost converter that consists of three input inductors $\left(\mathrm{L}_{1} \sim \mathrm{L}_{3}\right)$, three main MOSFET switches, $\left(\mathrm{S}_{1} \sim \mathrm{S}_{3}\right)$, a threephase delta-delta wound transformer, a three-phase output diode bridge $\left(D_{1} \sim D_{6}\right)$, and an auxiliary circuit. The auxiliary circuit consists of a switch $S_{a}$, three diodes $\left(D_{a 1} \sim D_{a 3}\right)$, an inductor $\mathrm{L}_{\mathrm{a}}$ and a capacitor $\mathrm{C}_{\mathrm{a}}$.

The basic principle behind the ZVS operation of the converter is that the auxiliary switch, $\mathrm{S}_{\mathrm{a}}$, is turned on just before any one of the three main switches is turned on. Doing so discharges the output capacitance across the main switch that is to be turned on so that when it does so, it turns on with zero voltage across it. This discharge is possible as current is diverted away from the main switches to the auxiliary circuit. The auxiliary switch also operates with soft-switching as inductor $\mathrm{L}_{\mathrm{a}}$ slows down the rate of current rise through $\mathrm{S}_{\mathrm{a}}$ when this switch is turned on and current is not in the switch but flows through its bodydiode instead when it is turned off.

The ideal waveforms are shown in Fig. 4.2 and the equivalent circuit diagrams of modes of operation that are associated with the turning on of $S_{1}$ are shown in Figs. 4.3. The same modes of operation are assumed for the other two main switches. 
Mode 0 [ $\left.\boldsymbol{t}<\mathrm{t}_{\mathbf{0}}\right]: \mathrm{S}_{3}$ is on and current is flowing to the load through the transformer. $\mathrm{S}_{1}, \mathrm{~S}_{2}$ and $\mathrm{S}_{\mathrm{a}}$ are all off. The auxiliary capacitor is charged to a voltage $\left(\mathrm{V}_{\mathrm{Ca} 0}\right)$. Power is transferred to the output through $\mathrm{D}_{1}$ and the return path is through $\mathrm{D}_{6}$ and $\mathrm{S}_{3}$.

Application of the principle of volt-second balance to the primary side gives

$$
V_{\text {prim }}=D V_{\text {in }}+(1-D)\left(-V_{o}\right)
$$

where

$$
V_{\text {in }}=V_{\text {prim }}
$$

The output current can be calculated from the following equation in this mode

$$
I_{o}=D\left(-\frac{V_{o}}{R_{o}}\right)+(1-D)\left(\frac{1}{N}-\frac{V_{o}}{R_{o}}\right)
$$

so that

$$
I_{i n}=\frac{N V_{o}}{(1-D) R_{o}}
$$

Mode $1\left[t_{0}<t<t_{1}\right]$ : At the beginning of this mode, auxiliary switch $\mathrm{S}_{\mathrm{a}}$ is turned on with inductor $\mathrm{L}_{\mathrm{a}}$ limiting the rate of current rise. $\mathrm{C}_{\mathrm{a}}$ discharges until it reaches zero volts at the

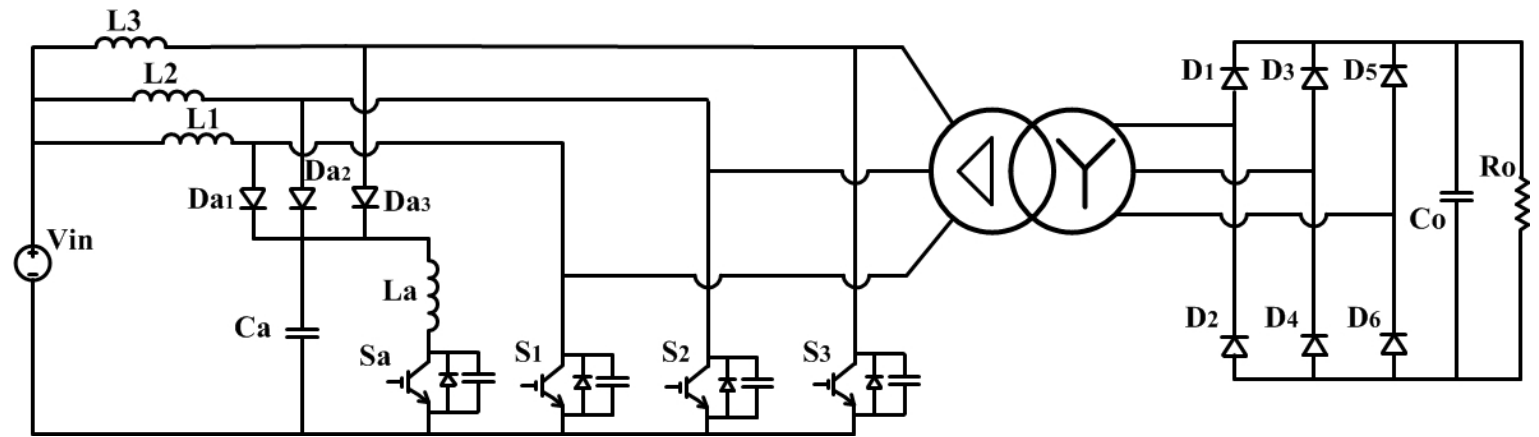

Fig. 4.1. Proposed three-phase ZVS boost converter 
end of this mode. The input current is transferred to the output through $\mathrm{D}_{1}-\mathrm{D}_{6}$. The voltage across $\mathrm{C}_{\mathrm{a}}$ and the current through $\mathrm{L}_{\mathrm{a}}$ can be expressed as

$$
\begin{gathered}
V_{C a}(t)=L_{a} \frac{d i_{L a}(t)}{d t}+V_{C S a} \\
i_{L a}(t)=i_{C a}(t)=-C_{a} \frac{d V_{C a}(t)}{d t}
\end{gathered}
$$

The initial conditions for (4) and (5) are $\mathrm{V}_{\mathrm{Ca}}(0)=\mathrm{V}_{\mathrm{Ca} 0}$ and $\mathrm{i}_{\mathrm{La}}=0$ and these equations can be expressed as

$$
\begin{gathered}
V_{C a}(t)=V_{C S a}+\left(V_{C a 0}-V_{C S a}\right) \operatorname{Cos} \omega_{o} t \\
i_{L a}(t)=\frac{\left(V_{C a 0}-V_{C S a}\right) \operatorname{Sin} \omega_{o} t}{Z_{o}}
\end{gathered}
$$

where

and

$$
\begin{gathered}
\omega_{o}=\sqrt{\frac{1}{L_{a} C_{a}}} \\
Z_{o}=\sqrt{\frac{L_{a}}{C_{a}}}
\end{gathered}
$$

Mode $2\left[t_{1}<t<t_{2}\right]$ : The auxiliary diodes become forward biased when the auxiliary branch voltage drops to zero at the start of this mode. Current starts increasing in the auxiliary switch and decreasing in $S_{3}$. Power is being transferred to the output through $\mathrm{D}_{1}-\mathrm{D}_{6}$ during this mode. The operation of the converter during this mode can be defined as follows:

$$
\begin{gathered}
I_{\text {in }}=i_{L l k}(t)+i_{L a}(t)+i_{C a}(t) \\
-\frac{d^{2} V_{C a}(t)}{d t^{2}}=V_{C a}(t) \omega_{1}-V_{d s} \omega_{o}
\end{gathered}
$$


where

$$
\omega_{1}=\frac{1}{L_{e q} C_{a}}
$$

and

$$
\begin{gathered}
L_{e q}=\frac{L_{a} L_{l k}}{L_{a}+L_{I k}} \\
V_{L a}(t)=V_{C a}(t)=L_{a} \frac{d i_{L a}(t)}{d t}+V_{d s}
\end{gathered}
$$

The initial conditions for (9) and (10) are $\mathrm{V}_{\mathrm{Ca}}(0)=0$ and $\mathrm{i}_{\mathrm{La}}=\mathrm{I}_{\mathrm{in}}$ so that

$$
\begin{gathered}
I_{L a}=\frac{\left(V_{C a}-V_{d s}\right) \operatorname{Sin}\left(\operatorname{Cos}^{-1}\left(\frac{V_{d s}}{V_{d s}-V_{C a}}\right)\right)}{Z_{o}} \\
V_{C a}=-\frac{\left(V_{C a}-V_{d s}\right) \operatorname{Sin}\left(\operatorname{Cos}^{-1}\left(\frac{V_{d s}}{V_{d s}-V_{C a}}\right)\right) \operatorname{Sin} \omega_{1} t}{\sqrt{1+\frac{L_{I k}}{L_{a}}}+\frac{V_{d s} \omega_{o}\left(1-\operatorname{Cos} \omega_{1} t\right)}{\omega_{1}}} \\
I_{L_{l k}}(t)=I_{i n}-\frac{L_{e q}\left(V_{C a}-V_{d s}\right) \operatorname{Sin}\left(\operatorname{Cos}^{-1}\left(\frac{V_{d s}}{V_{d s}-V_{C a}}\right)\left(1-\operatorname{Cos} \omega_{1} t\right)\right)}{Z_{o} L_{l k}}+\frac{V_{d s} \omega_{o}\left(t-\operatorname{Sin} \omega_{1} t\right)}{\omega_{1} L_{I k}} \\
I_{L a}=\frac{\left(V_{C a}-V_{d s}\right) \operatorname{Sin}\left(\operatorname{Cos}^{-1}\left(\frac{V_{d s}}{V_{d s}-V_{C a}}\right)\right)}{Z_{o}}-\frac{L_{e q}\left(V_{C a}-V_{d s}\right) \operatorname{Sin}\left(\operatorname{Cos}^{-1}\left(\frac{V_{d s}}{V_{d s}-V_{C a}}\right)\left(1-\operatorname{Cos} \omega_{1} t\right)\right)}{Z_{o} L_{a}}+\frac{V_{d s} \omega_{o}\left(t-\operatorname{Sin} \omega_{1} t\right)}{\omega_{1} L_{a}}-\frac{V_{d s}}{L_{a}}
\end{gathered}
$$

Mode $3\left[t_{2}<t<t_{3}\right]$ : At the end of this mode, the current that was flowing in the primary of the transformer and $\mathrm{S}_{3}$ reaches zero and the current flowing through the auxiliary circuit in this mode is the same as the input current and continue to rise during the mode. As $\mathrm{I}_{\mathrm{La}}$ continues to rise, the current that exceeds the input current discharges the capacitor across 
$\mathrm{S}_{1}$ and drops the voltage across the switch to zero. There is no power transfer from transformer primary to secondary during this mode.

Mode $4\left[t_{3}<t<t_{4}\right]: \mathrm{S}_{1}$ is turned on with ZVS at the start of this mode as the capacitor across it was discharged in the previous mode. Current starts increasing in $S_{1}$ and $S_{3}$ after $t=t_{3}$. Current flowing through the auxiliary circuit is still positive, but less than the input current and decreasing. The operation of the converter during this mode can be defined as

$$
\begin{gathered}
I_{i n}=C_{a} \frac{d V_{C a}(t)}{d t}+I L_{I k} \\
V_{C a}=L_{I k} \frac{d i_{L l k}(t)}{d t}+\frac{V_{o}}{N}
\end{gathered}
$$

The initial conditions for $(15)$ and $(16)$ are $\mathrm{V}_{\mathrm{Ca}}(0)=\mathrm{V}_{\mathrm{o}} / \mathrm{N}$ and $\mathrm{I}_{\mathrm{La}}(0)=0$ so that

$$
\begin{gathered}
I_{L l k}(t)=I_{\text {in }}\left(1-\operatorname{Cos} \omega_{2} t\right) \\
V_{C a}(t)=\frac{V_{o}}{N}+I_{\text {in }} Z_{1} \operatorname{Sin} \omega_{2} t
\end{gathered}
$$

where

$$
\omega_{2}=\frac{1}{\sqrt{L_{a} C_{a}}} \text { and } Z_{1}=\sqrt{\frac{L_{a}}{C_{a}}}
$$

Mode 5 [ $\left.t_{4}<t<t_{5}\right]$ :_At the start of this mode, current in $\mathrm{L}_{\mathrm{a}}$ reaches zero and the auxiliary switch is turned off softly. $\mathrm{C}_{\mathrm{a}}$ starts charging and power is transferred to the output through $\mathrm{D}_{3}$ and $\mathrm{D}_{2}$.

Mode 6 [ $\left.t_{5}<t<t_{6}\right]$ : At the start of this mode, Current in the auxiliary circuit has reached zero after $\mathrm{Ca}$ was fully charged to the primary voltage at the end of the previous mode. All the input current is flowing through the main switches $S_{1}$ and $S_{3}$. 
Mode 7 [ $\left.\mathbf{t}_{6}<\boldsymbol{t}<\mathbf{t}_{7}\right]: \mathrm{S}_{3}$ is turned off at the start of this mode and the capacitor across it begins to charge. Since this capacitor limits the rate of voltage rise, the switch turns off with ZVS. The switch capacitor is charged until the voltage across it is equal to the output voltage. All the input current then starts flowing through $S_{1}$. The converter operates exactly like a standard PWM boost converter during this mode.

\subsection{Converter Features}

The proposed converter has the following features:

- An increased power rating through employing a three-phase power transfer in the DcDc converter.

- Reduction in conduction loss through the distribution of rms current among per-phase switches and transformer windings, when compared to a single-phase converter for the same power ratings

- Reduction in the size of the input de inductors and elimination of the output filter by increased effective switching frequency

- Only one active switch is used in the auxiliary circuit, which is an advantage over the previously proposed converters that use multiple active auxiliary switches.

All converter switches, including the auxiliary switch operate with soft-switching. The main power switches operate with ZVS while the auxiliary switch operates with ZCS. 


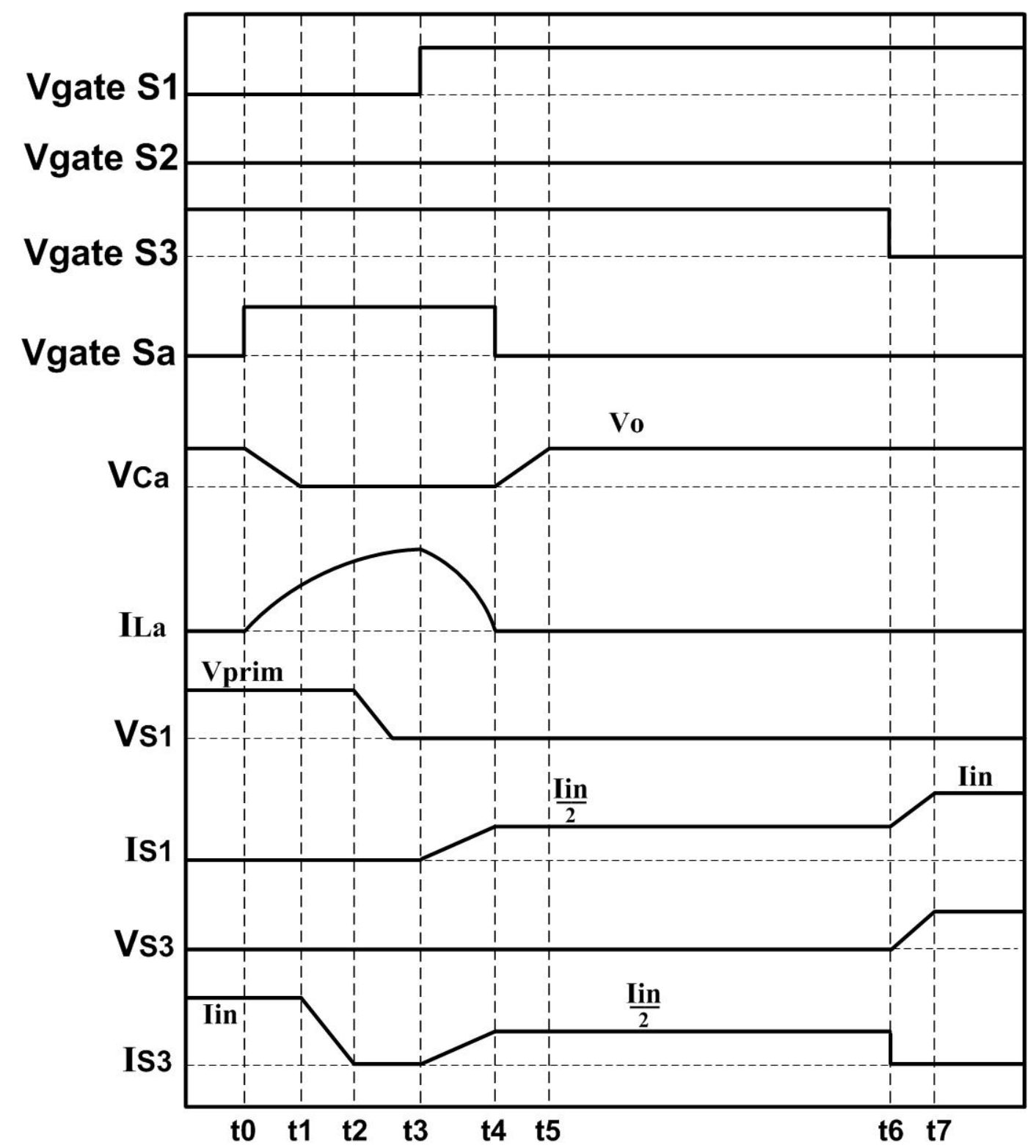

Fig. 4.2. Typical converter waveforms 


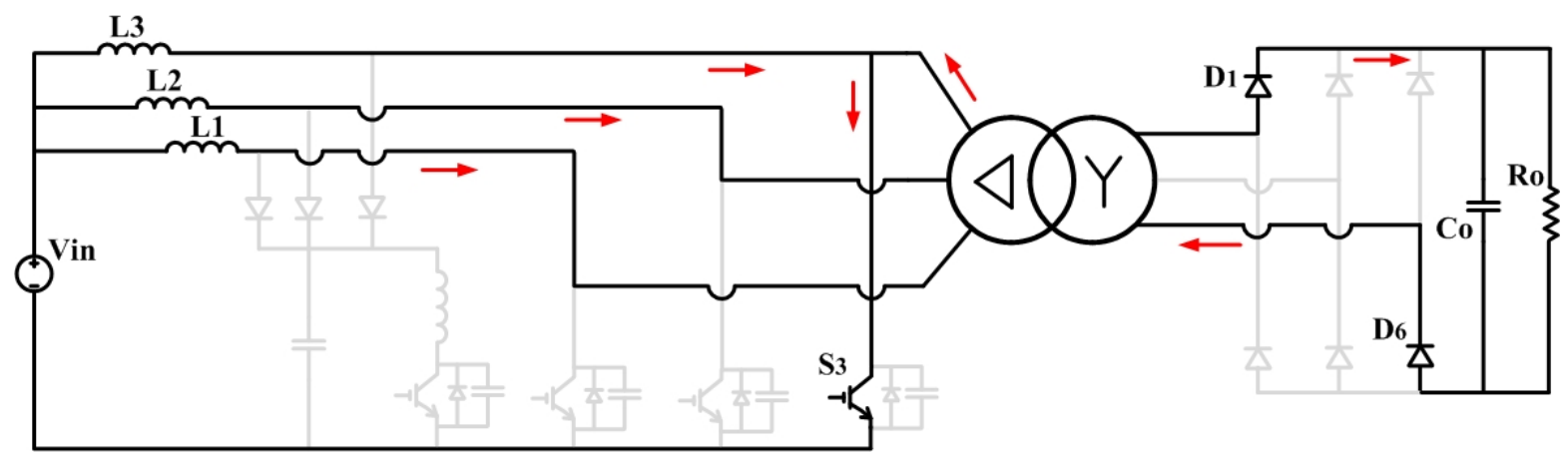

Mode 0

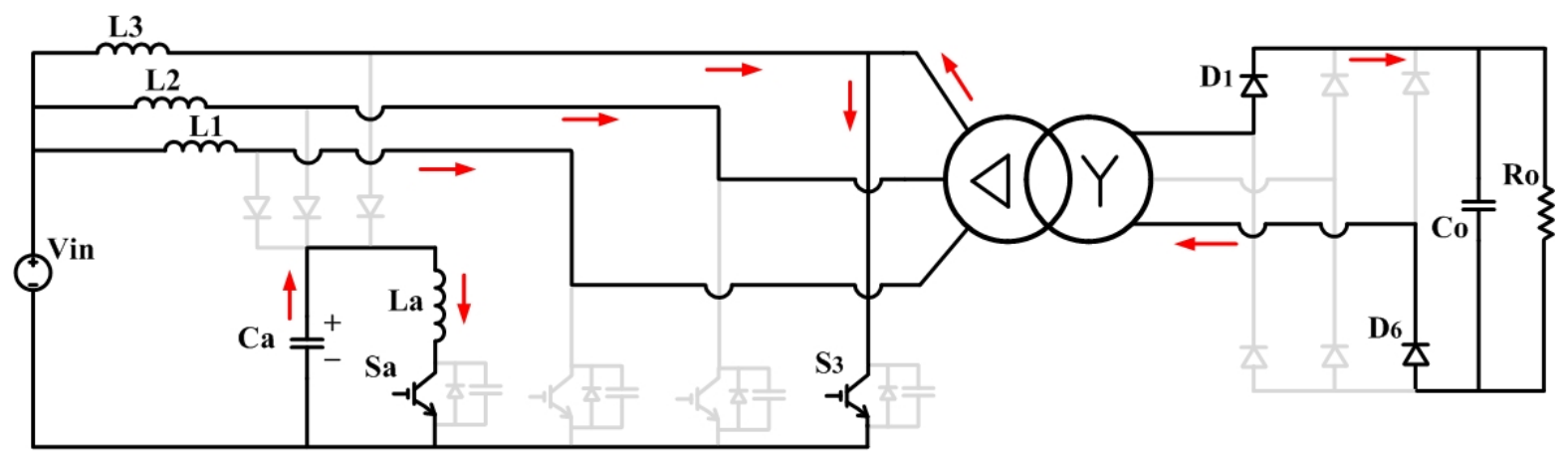

Mode 1

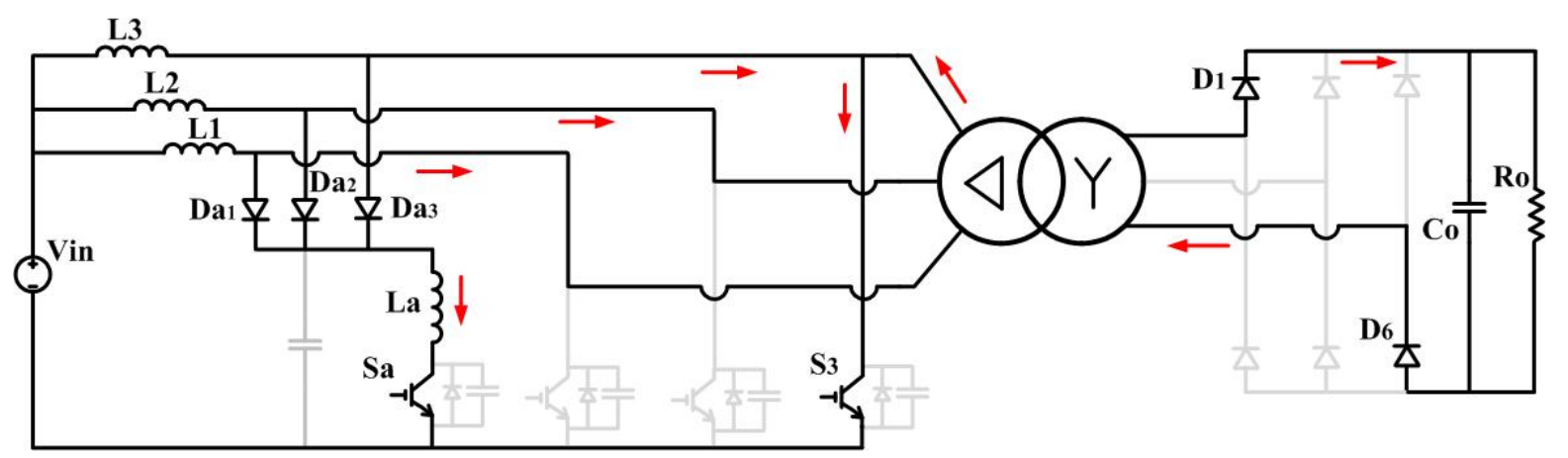

Mode 2

Fig.4.3. Equivalent circuit diagrams of modes of operation 


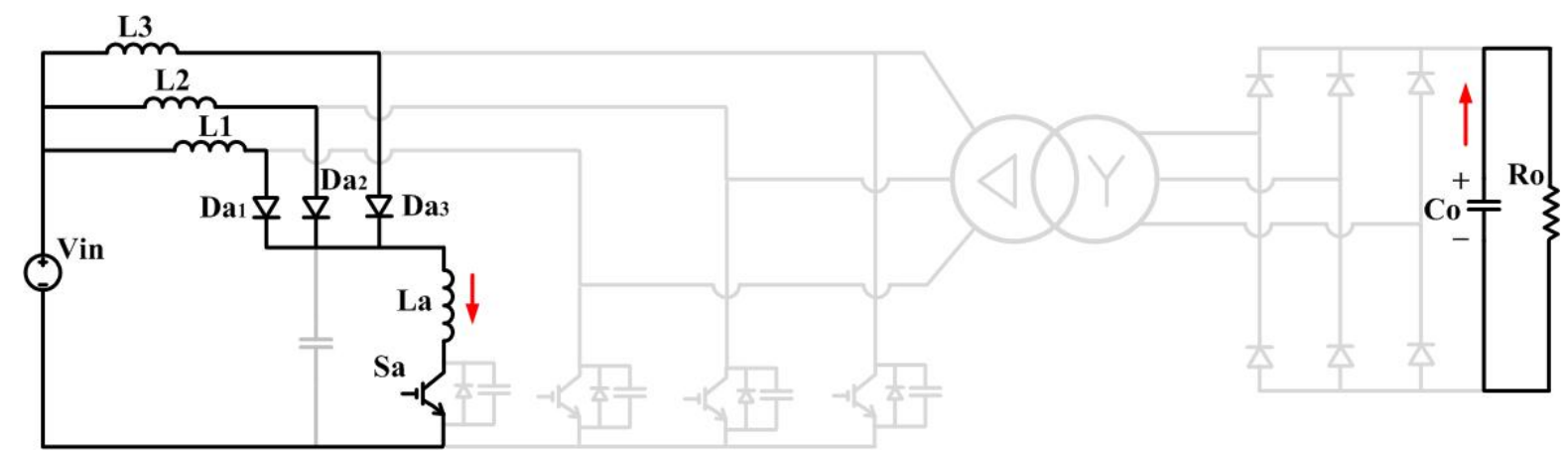

Mode 3

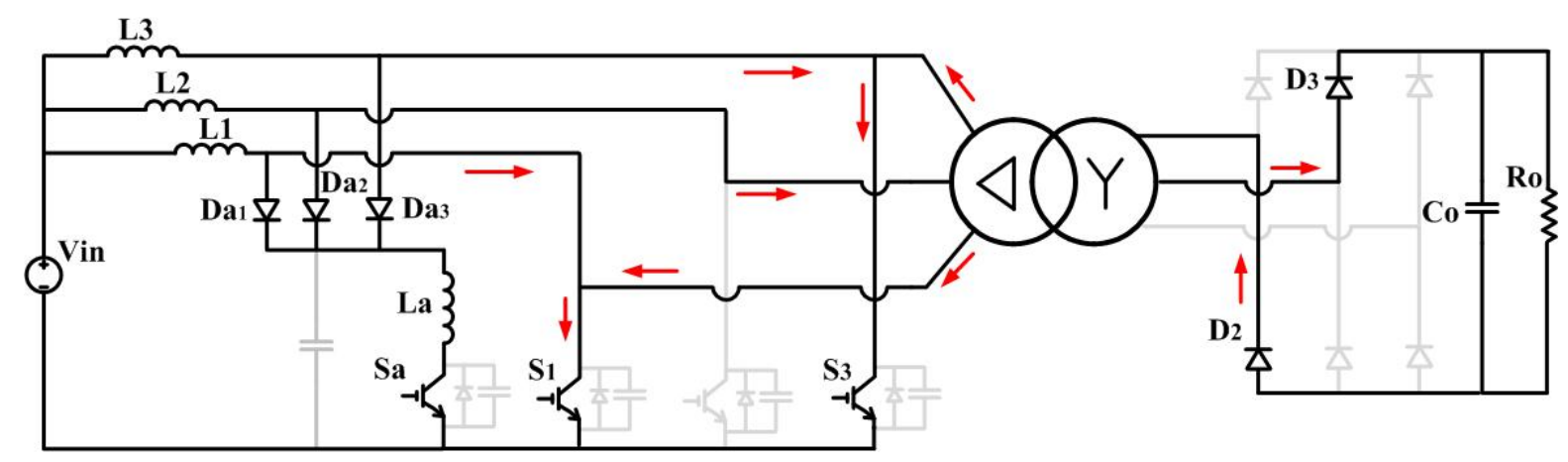

Mode 4

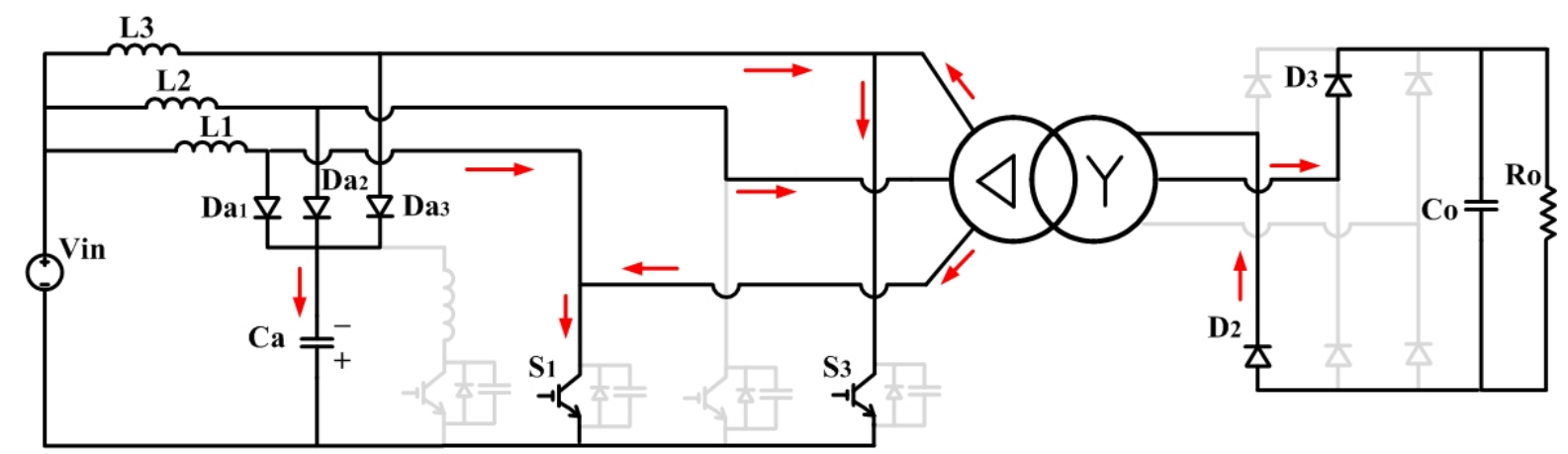

Mode 5

Fig.4.3(Cont). Equivalent circuit diagrams of modes of operation 


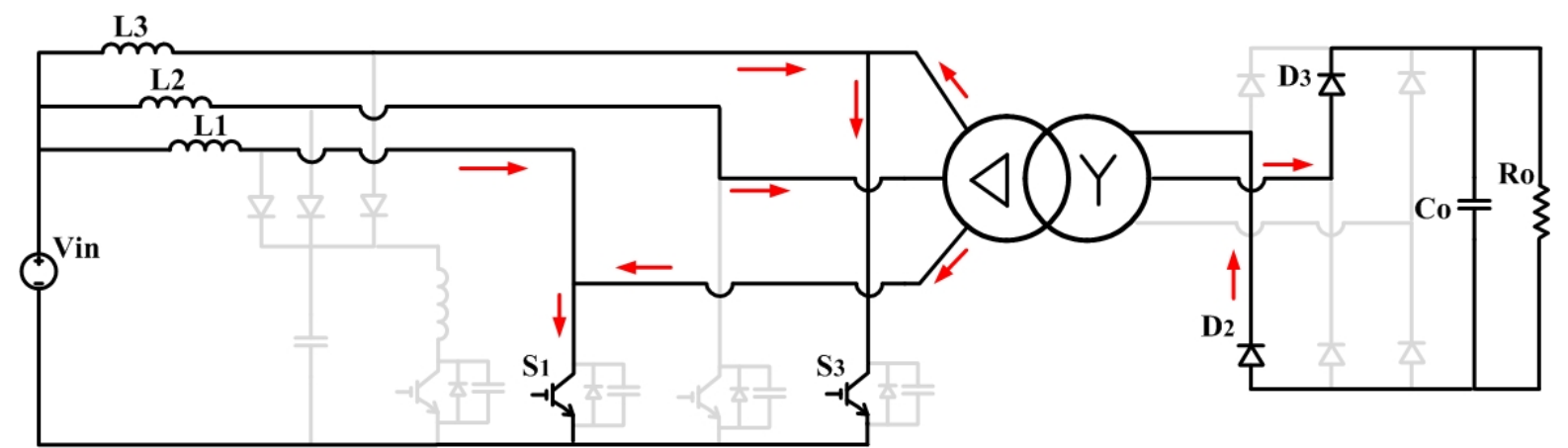

Mode 6

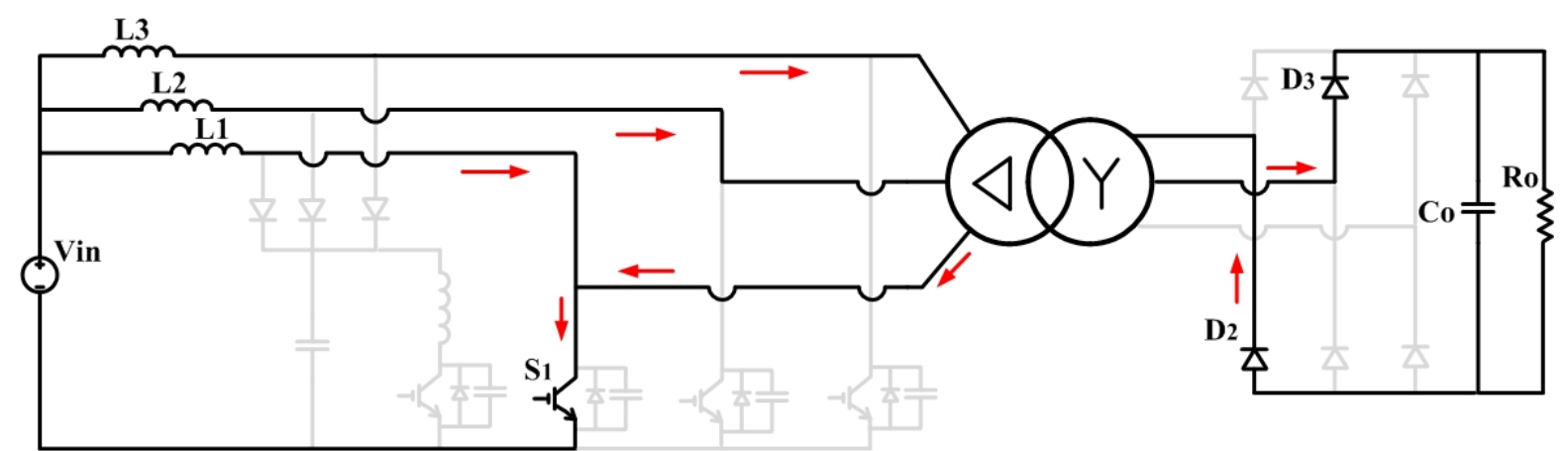

Mode 7

Fig.4.3(Cont). Equivalent circuit diagrams of modes of operation

\subsection{Design Procedure}

\section{a) Calculation of Maximum Input Current}

The maximum input current $\mathrm{I}_{\mathrm{in}-\mathrm{max}}$ can be calculated from $I_{\text {in }}=\frac{P_{o}}{V_{\text {in }}}$ for an ideal converter operating with maximum load. If the input current peak value is assumed typically at $20 \%$ of the input current, then the maximum input current can be expressed as 


$$
I_{\text {in-Max }}=\frac{P_{o}}{V_{\text {in }}}+0.2 I_{\text {in }}
$$

\section{b) Input Inductor Design}

The value of the input boost inductor is determined by the amount of peak-to-peak ripple current $\mathrm{I}_{\text {in-Max }}$ to be tolerated. This should be limited by the worst case peak input current when happens when the input voltage is at its minimum rms value. The worst case peak input current can be calculated from the following equation:

$$
I_{P k-\operatorname{Max}}=\frac{P_{o}}{\eta V_{\text {in-Min }}}+\frac{I_{\text {in-Max }}}{2}
$$

The higher the inductor value, the higher is the maximum output current because of the reduced ripple current. The following equation is a good estimation for the right inductor.

$$
L_{1}=L_{2}=L_{3}=\frac{V_{o}}{f_{s w} D N^{2} I_{o}}
$$

where

$$
N=\frac{V_{o}}{V_{\text {in }}}(1-D)
$$

and

$$
D=\frac{V_{o}-V_{i n-\operatorname{Min}}}{V_{o}}
$$

where $V_{\text {in }}=$ typical input voltage, $V_{\mathrm{o}}=$ desired output voltage, $\mathrm{f}_{\mathrm{sw}}=$ switching frequency of the converter. 


\section{c) Minimizing Reverse Recovery Losses in the Auxiliary Diode}

The duration of Mode 5 in which the input current gets diverted from the auxiliary capacitor $\mathrm{C}_{\mathrm{a}}$ to the main switches, $\mathrm{t}_{\mathrm{c}}$, should be greater than $3 \mathrm{t}_{\mathrm{rr}}$ (three times the reverse recovery time of the auxiliary diode):

$$
\begin{gathered}
t_{c}=\frac{\pi}{2} \sqrt{L_{a} C_{a}} \\
t_{c} \geq 3 t_{r r}
\end{gathered}
$$

For fast recovery diodes, the value of $t_{c}$ should be at least $240 \mu$ s [16]. Selecting such a value can ensure that any auxiliary diode reverse recovery current can be eliminated and thus so too can the losses that are associated with such current.

\section{d) Auxiliary Inductor $L_{a}$}

The auxiliary inductor is selected to allow for its current to be able to rise to the maximum input current to within three times the nominal reverse recovery time of the auxiliary diode (3trr). This can be defined as

$$
\frac{V_{o}}{L_{a}} 3 t_{r r} \leq I_{\text {in-Max }}
$$

The larger the value of $L_{a}$, the less likely that there will be recovery current, but there will also be more auxiliary circuit conduction losses as the length of the resonant cycle is increased. $\mathrm{L}_{\mathrm{a}}$ is thus designed so that the auxiliary circuit current is allowed to ramp up to within three times the auxiliary diode's specified reverse recovery time, as suggested in [54]. 


\section{e) Auxiliary Capacitor $\mathrm{C}_{\mathrm{a}}$}

The value of the auxiliary capacitor $\mathrm{Ca}$ should be selected to be as low as possible to keep the length of the resonant cycle small. If, however, the value of $\mathrm{C}_{\mathrm{a}}$ is too low, then this will result in excessive current and voltage values in the auxiliary switch. As a compromise, the value of $C_{a}$ should be selected so that it is small, but does not allow the voltage to exceed some specified limit.

At the end of Mode 4, the voltage across $C_{a}$ rises to a peak voltage that can be determined from the following equation:

$$
V_{C a}(t)=\frac{V_{o}}{N}+I_{i n} Z_{o} \operatorname{Sin} \omega_{2}(t)
$$

where

$$
\omega_{2}=\frac{1}{\sqrt{L_{a} C_{a}}} \text { and } Z_{o}=\sqrt{\frac{L_{a}}{C_{a}}}
$$

Fig. 4.4 shows the voltage across $C_{a}$ for different values of $Z_{o}$ when the input voltage varies. It can be found from this graph that by choosing a larger impedance, the voltage across $\mathrm{C}_{\mathrm{a}}$ will increase. However, if a smaller impedance is chosen, a larger capacitor must be used to store enough energy for the soft switching operation (as described in the modes). By choosing a larger capacitor, the resonant cycle time will increase in the circuit, which will increase the length of time that the auxiliary switch is on and thus cause more losses in this switch. The graph in Fig. 4.5 is plotted from equation (14) and shows the current peak in the auxiliary circuit versus different values of $Z_{o}$ for different peak values of auxiliary capacitor voltage. By considering these graphs, a value for $\mathrm{C}_{\mathrm{a}}$ can be chosen to satisfy all constraints in the circuit. 


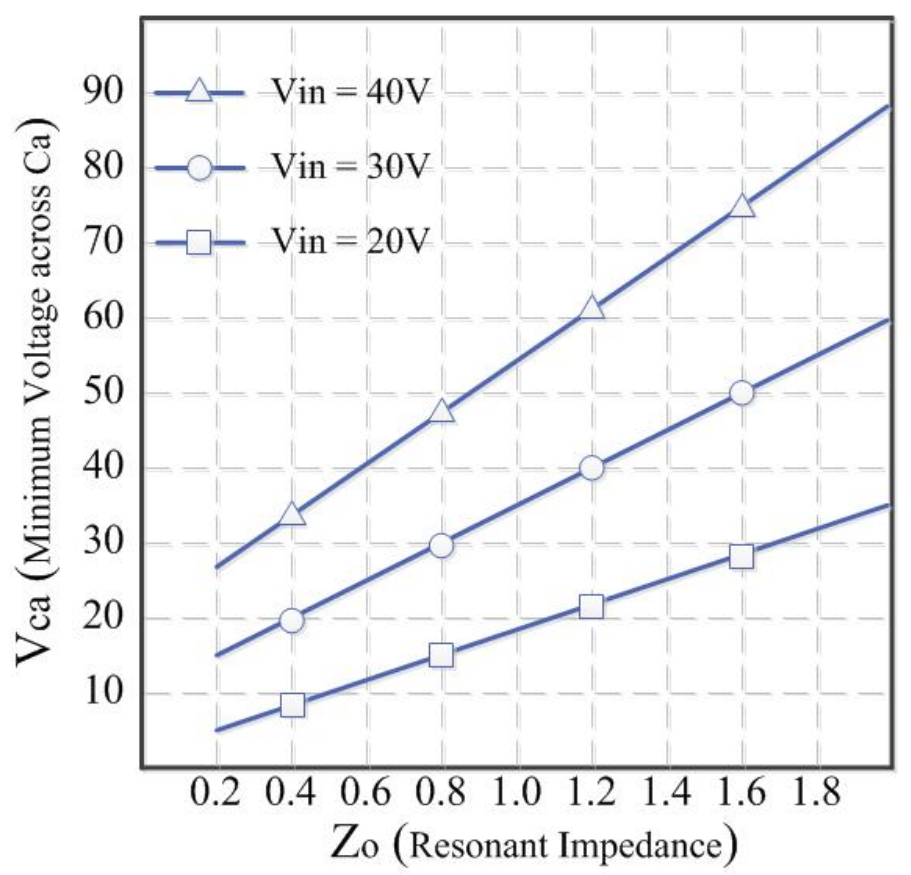

Fig.4.4. Voltage across $\mathrm{Ca}$ for different values of $Z_{\mathrm{o}}$

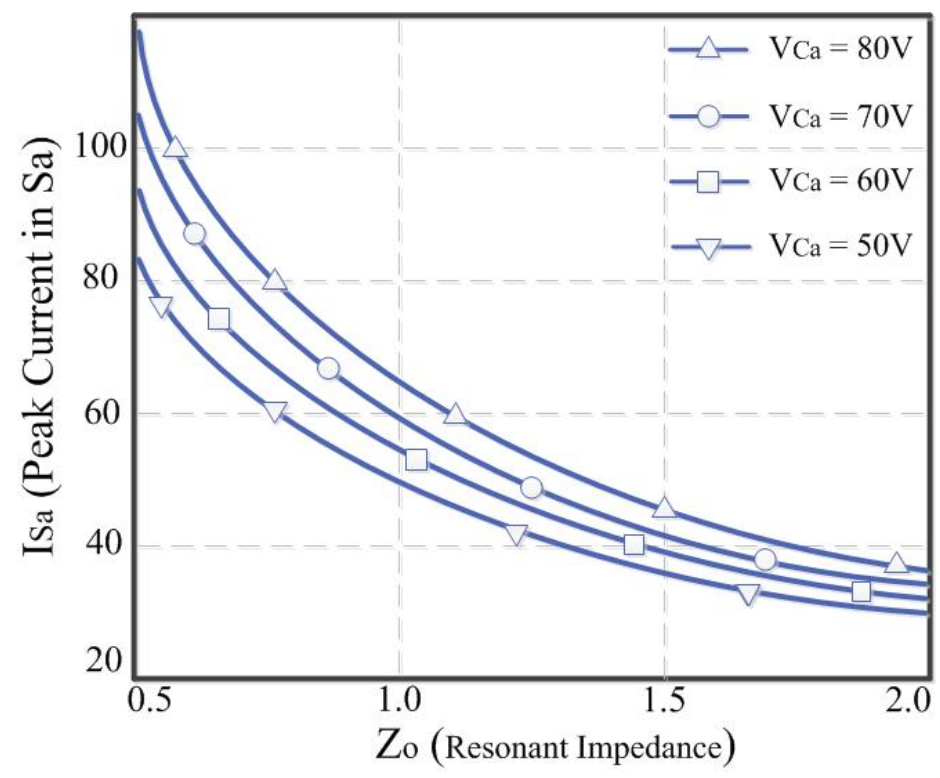

Fig.4.5. current peak in the auxiliary switch versus different values of $Z_{o}$ 


\subsection{Experimental Results}

An experimental prototype of the proposed converter was built to confirm its feasibility and to compare its efficiency to that of a hard-switched three-phase boost converter. The prototype had the following specifications: Input voltage $V_{\text {in }}=40 \mathrm{~V}$, output voltage $V_{0}=$ $400 \mathrm{~V}$, maximum output power $\mathrm{P}_{\mathrm{o}}=1 \mathrm{~kW}$, switching frequency: $\mathrm{f}_{\mathrm{sw}}=50 \mathrm{kHz}$.

The prototype was implemented using the following component values: $\mathrm{L}_{1}=\mathrm{L}_{2}=\mathrm{L}_{3}$ $=330 \mu \mathrm{H}$ auxiliary inductor $\mathrm{L}_{\mathrm{a}}=2.5 \mu \mathrm{H}$ and auxiliary capacitor $\mathrm{C}_{\mathrm{a}}=60 \mathrm{nF}$. The following devices were used for the semiconductors in the prototype: STD70N10F4 $\left(\mathrm{R}_{\mathrm{ds}, \mathrm{on}}=15 \mathrm{~m} \Omega\right.$, $\left.\mathrm{C}_{\text {oss }}=300 \mathrm{pF}\right)$ for $\mathrm{S}_{1}$ to $\mathrm{S}_{3}, \mathrm{STD} 25 \mathrm{NF} 10\left(\mathrm{R}_{\mathrm{ds}, o n}=33 \mathrm{~m} \Omega, \mathrm{C}_{\mathrm{oss}}=220 \mathrm{pF}\right)$ for the auxiliary switch $\mathrm{S}_{\mathrm{a}}$, HFA16PA60C for the output diodes, and FR802 for the auxiliary circuit diodes $D_{a 1} \sim D_{a 3}$.

Fig. 4.6 and 4.7 shows the current and voltage in $S_{1}$ and $S_{2}$ during turn-on. It can be seen that the switch is turned on with zero voltage across it and thus it has no switching losses during turn on. Fig. 4.8 shows the transformer winding voltage of the low voltage side, which is a regular phase-shifted waveform. Efficiency measurements that were taken from the proposed converter and compared to the same converter prototype without the auxiliary circuit, implemented as a hard switching three-phase boost converter (Fig.4.9). The proposed converter is about $5 \%$ more efficient at full load compared to the conventional three-phase boost converter. 


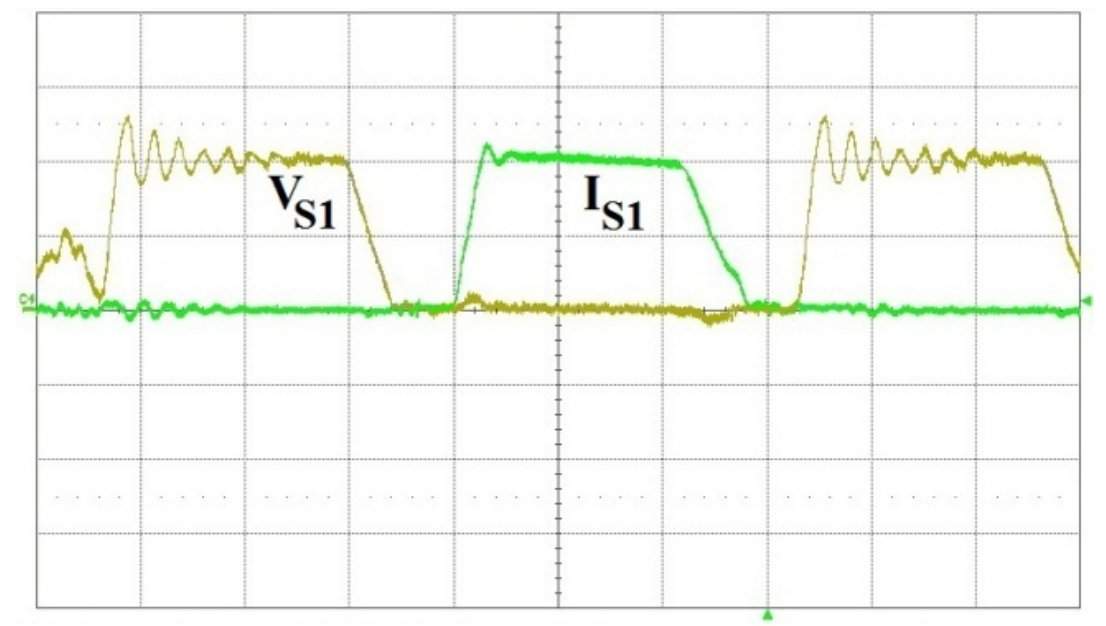

Fig. 4.6. Current and voltage waveforms in $\mathrm{S}_{1}$ (I: $10 \mathrm{Amps} / \mathrm{div}, \mathrm{V}: 30 \mathrm{~V} / \mathrm{div}$, t: $2.5 \mu \mathrm{s} / \mathrm{div}$ )

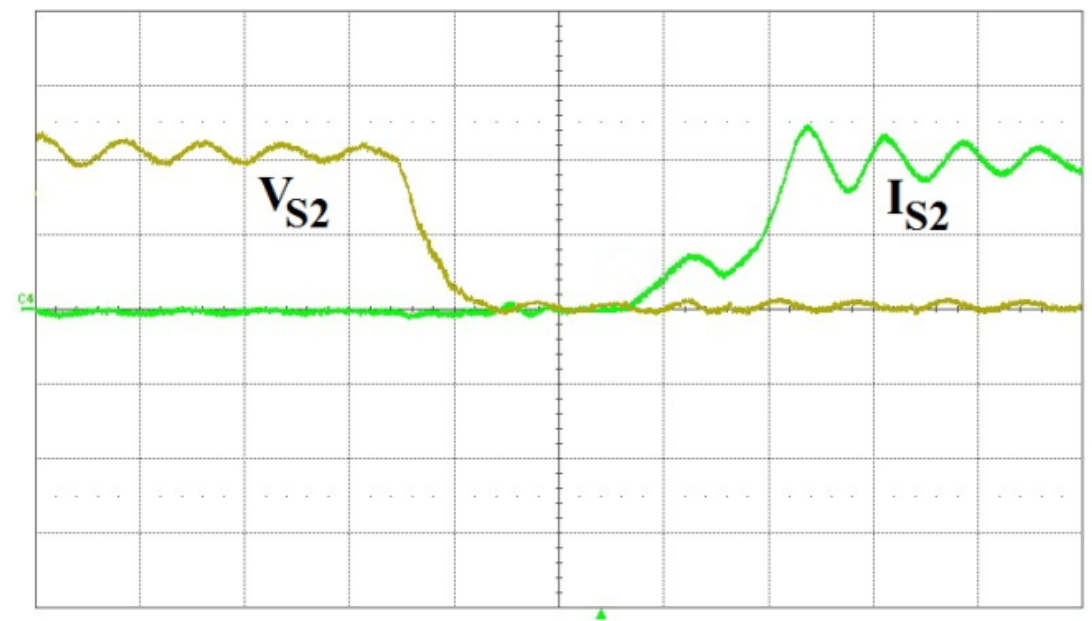

Fig.4.7. Current and voltage waveforms in $\mathrm{S}_{2}$ (I: $10 \mathrm{Amps} / \mathrm{div}, \mathrm{V}: 30 \mathrm{~V} / \mathrm{div}, \mathrm{t}: 1 \mu \mathrm{s} / \mathrm{div}$ )

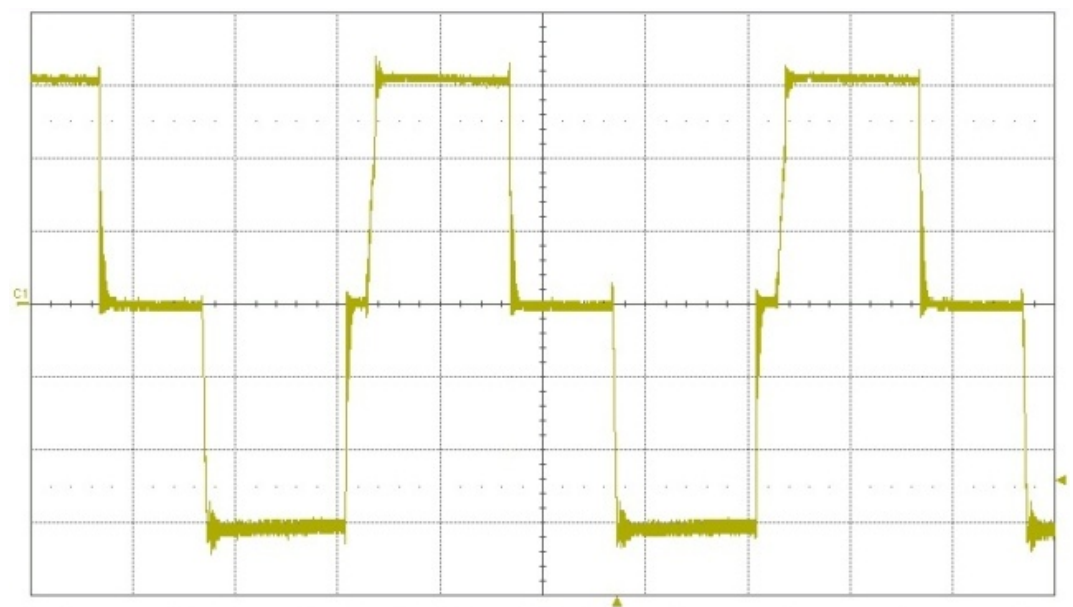

Fig. 4.8. Primary voltage waveform across the transformer (V: $20 \mathrm{~V} / \mathrm{div}, \mathrm{t}: 5 \mu \mathrm{s} / \mathrm{div}$ ) 


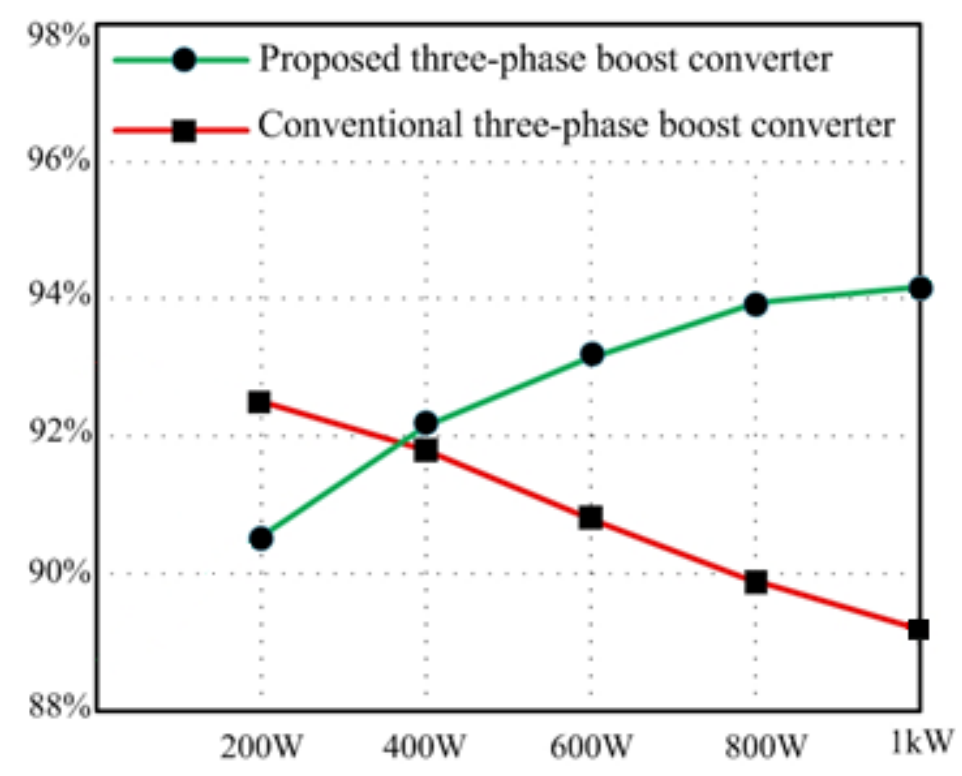

Fig. 4.9. Efficiency results

\subsection{Conclusion}

A novel three-phase dc/dc ZVS-PWM boost converter was proposed in this chapter. The three phase concept enables the converter to be used in higher power applications than a single phase converter. The outstanding feature of the proposed converter is that it allows its main switches to operate with ZVS using a simple auxiliary circuit that has one active switch that can also operate with soft-switching.

In this chapter, the proposed converter was introduced, its operation was explained in general and in detail, and its features and design were discussed. Experimental results obtained from a $1 \mathrm{~kW}$ prototype that confirmed its feasibility and demonstrated its efficiency improvement over a hard-switching three phase boost converter were presented. 


\section{Chapter 5}

\section{Conclusion}

\subsection{Introduction}

In this chapter, the contents of the thesis are summarized, conclusions resulting from the thesis work are presented, the contributions of the thesis to the power electronics literature are stated, and suggestions for future work are given.

\subsection{Summary}

The main focus of this thesis has been on addressing certain issues related to softswitching Dc-Dc converters. The term "soft-switching" refers to a way of operating a power converter so that its switching devices turn on and off gradually instead of "hard". The benefits of soft-switching techniques include a reduction of the switching losses that are caused by the overlap of switch voltage and switch current during a switching transition (from on to off and vice versa) and the reduction of EMI noise; this thesis focused on the former and ignored the latter.

Since switching losses are related to the product of switch voltage and switch current during a switching transition, making either one zero during a switching transition ensures a significant reduction in switching losses. There are, therefore, two types of soft-switching zero-voltage switching (ZVS) and zero-current switching (ZCS). ZVS is the preferred option if MOSFET switching devices are used and ZCS is the preferred option if IGBT 
switching devices are used; this is due to the nature of these devices, as explained in Chapter 1.

Soft-switching methods are typically implemented in power converters by adding additional auxiliary circuitry that is not in the main power paths of the converter. As such, they handle only a fraction of the power that is handled by the main switching devices so that these auxiliary circuits can be implemented with cheaper and smaller devices than the main power devices. Although it has been established in the power electronics literature that the use of auxiliary circuits does in fact result in improved converter efficiencies, they do increase the overall cost of the main power converters. Given the sheer number of power converters that are manufactured each year, any reduction in cost - even one that may seem insignificant on a unit level - can result in considerable savings for power converter manufacturers.

The main objective of this thesis has been to propose new soft-switching converters that improve efficiency by using auxiliary circuits that are simple and relatively inexpensive. The soft-switching of the types of power converters - simple bidirectional converters based on fundamental non-isolated Dc-Dc converters, full-bridge Dc-Dc converters and threephase Dc-Dc converters - was investigated. These three types were chosen because it was possible to develop a soft-switching solution for each type that was simpler than what had been previously proposed and because there were some similarities among the three different solutions. Although the proposed solutions were simple and may even appear to be trivial, they had not been previously proposed or investigated and more sophisticated solutions continued to be used. 
The contents of this thesis can be summarized as follows:

In Chapter 1, certain basic concepts relating to the main focus of the thesis were introduced, a literature review was performed and the thesis objectives and outline were stated.

In Chapter 2, a new ZCS-PWM bidirectional converter was proposed. The main advantage of the proposed converter over other previously proposed converters of the same type is its simple auxiliary circuit, which has only one active switch instead of two and a few passive components. In the chapter, the operation of the new converter was explained, its modes of operation were reviewed, guidelines for the design of the converter were given and their use was demonstrated with a design example. Experimental results obtained from a prototype converter confirmed that the proposed soft-switching converter can generally operate with greater efficiency than a conventional hard-switching converter, regardless of the direction of power flow (power flowing from a higher voltage to a lower voltage or vice versa).

In Chapter 3, a new ZCS-PWM full-bridge Dc-Dc converter was proposed. The main advantage of this converter over other previously proposed converters of the same type is that all its main power switches can turn on and off with ZCS using simple auxiliary circuitry and without adding additional components such as blocking diodes to the main power path. This can be achieved by using two auxiliary circuits - one passive and one active. The passive auxiliary circuit consists of a few passive components and allows the switches in one of the converter legs to turn off with ZCS. It does so by extinguishing the current that would otherwise just circulate in the converter and create conduction losses; as 
a result, not only does the passive auxiliary circuit help reduce the switching losses of the switches in one leg, it also help reduce conduction losses. The active auxiliary circuit consists of two diodes, a capacitor, an inductor and an active auxiliary switch and helps the switches in the other converter leg turn off with soft-switching. Although two auxiliary circuits are used, both are simple and the proposed soft-switching solution is still less expensive than other previously proposed approaches that require the use of two active auxiliary switches.

In the chapter, the operation of the proposed converter was explained in detail, its modes of operation were reviewed and analyzed and the results of the analysis were used to develop a design procedure for the selection of key components. The design procedure was demonstrated with an example that was used in the design of an experimental prototype converter from which experimental results were obtained. These results confirmed that proposed converter can generally operate with higher efficiency than the conventional DcDc PWM full-bridge converter.

In Chapter 4, a new three-phase Dc-Dc converter was proposed. Three-phase Dc-Dc converters are typically used in applications where the input voltage is low and the input current is high. Since the input current is high, it is distributed between three circuit branches or "phase" and the overall converter is operated in a way that helps reduce the input current ripple; such a reduction allows for a reduction in the size of the input inductance and places less stress on the source itself. Since the input voltage is low, low voltage-rated MOSFETs are the preferred device of choice in these converters; since these converters use MOSFETs, ZVS is the preferred method of soft-switching. 
Although the converter proposed in this chapter was a ZVS converter and the converters proposed in Chapters 2 and 3 were ZCS converters, there were similarities in the operation of the active auxiliary circuit that was used to help the main power switches operate with soft-switching. For all three cases, the active auxiliary circuit was a one-switch circuit that had few components and was based on basic principles of resonance between inductors and capacitors. The main advantage of the converter proposed in this chapter over previously proposed converters of the same type is the simplicity of its auxiliary circuit. Moreover, the operation of the auxiliary circuit in this converter does not add to the peak current stress of the main power switches.

Like the converters proposed in Chapters 2 and 3, the operation of the three-phase converter proposed in Chapter 4 was explained in detail, its modes of operation were reviewed and analyzed and the results of the analysis were used to develop a design procedure for the selection of key components. The design procedure was demonstrated with an example that was used in the design of an experimental prototype converter from which experimental results were obtained. These results confirmed that proposed converter can generally operate with higher efficiency than a hard-switching converter of the same type.

\subsection{Conclusions}

The following conclusions can be made based on the work performed in this thesis:

- It is possible to implement ZCS in a bidirectional PWM boost/buck converter using an auxiliary circuit with just one active auxiliary switch. 
- Doing so, however, results in the main power switches having to operate with higher peak current stresses than those of the switches in the conventional hard-switched converter.

- Although the efficiency of the hard-switched bidirectional converter was found to be approximately the same regardless of whether it was operated in boost mode (power flow from the higher level voltage source to the lower level source) or in buck mode (power flow from the lower level voltage source to the higher level source), it was found that the proposed converter operated with greater efficiency in boost mode than in buck mode.

- If the auxiliary circuit of the proposed bidirectional converter is designed for the case when the converter is operating in boost mode, then it can work properly if the converter is operated in buck mode.

- The efficiency of the proposed converter when it is operating under light load conditions is actually less than that of the hard-switching converter. This is also true for all the other converters that were proposed in this thesis. This is because under light load conditions, there is no need for auxiliary circuits as the losses that they are supposed to minimize are few, given the small amount of current that is flowing in the converter. All auxiliary circuits have some losses and under light load operation, these losses are greater than the switching losses. It is only when the load is increased that the switching losses in the hard-switching converters are greater than the auxiliary circuit losses in the soft-switching converters. 
- For the proposed ZCS-PWM Dc-Dc full-bridge converter, there is a relation between the ZCS time window (the time window of opportunity that exists during which switches in the inverter leg that is attached to the active auxiliary circuit) and the peak current stress of these switches - the longer the time window is, the greater the peak current stress is.

- For the proposed three-phase Dc-Dc converter, the key parameter that needs to be considered in the design of the auxiliary circuit is the value of the auxiliary capacitor $\mathrm{C}_{\mathrm{a}}$. $\mathrm{C}_{\mathrm{a}}$ should be selected to be as low as possible to keep the length of the resonant cycle small. If, however, the value of $C_{a}$ is too low, then this will result in excessive current and voltage values in the auxiliary switch. As a compromise, the value of $\mathrm{C}_{\mathrm{a}}$ should be selected so that it is small, but does not allow the voltage to exceed some specified limit.

\subsection{Contributions}

The main contributions of this thesis to the power electronics literature are as follows:

- A new ZCS-PWM bidirectional Dc-Dc boost/buck converter with a very simple auxiliary circuit that has only a single active switch was proposed.

- A new ZCS-PWM full-bridge Dc-Dc converter that allows all its main power switches to operate with ZCS without placing components such as blocking diodes in its main power path or using more sophisticated two-switch active auxiliary circuits was proposed. 
- A new three-phase ZVS-PWM Dc-Dc converter that allows all its main power switches to operate with ZVS using a very simple auxiliary circuit was proposed.

- In total, three new soft-switching Dc-Dc converters were presented in this thesis. For each of these converters, its steady-state operation was analyzed mathematically, a procedure for the selection of key converter components was developed and its operation was confirmed with experimental results.

\subsection{Future Work}

The following future work can be performed based on the research that was done for this thesis:

- It was found for all three proposed converters that their efficiency under light load conditions was actually less than that of the hard-switched converters and therefore these converters are best suited for heavy load conditions. Future work can be done on improving the light load efficiency of all three proposed converters.

- The proposed three-phase ZVS converter was implemented with MOSFETs because of its low input voltage. If the input voltage is increased, then it may be better to implement the converter with IGBTs, for which ZCS would be the preferred method of soft-switching. Future work can be done to see whether the converter can be adapted so that it can operate with ZCS instead of ZVS. 


\section{References}

[1] M. Ahmadi, E. Galvan, E. Adib, and H. Farzanehfard; "New fully soft switched bidirectional converter for Hybrid Electric Vehicles: Analysis and control," IEEE IECON 2010, pp.2340-2345, 7-10 Nov. 2010.

[2] H. Bodur, and A.F. Bakan; "An improved ZCT-PWM Dc-Dc converter for highpower and frequency applications," IEEE Trans. on Industrial Electronics, vol.51, no.1, pp. 89- 95, Feb. 2004.

[3] S.Y. Hui, K.W. Cheng and S.R. Prakash; "A fully soft-switched extended-period quasi-resonant power-factor correction circuit," IEEE Trans. on Power Electronics, vol.12, no.5, pp.922-930, Sep 1997.

[4] H. Bodur, A.F. Bakan; “A new ZVT-PWM Dc-Dc converter," IEEE Trans. on Power Electronics, vol.17, no.1, pp.40-47, Jan 2002.

[5] H. Guichao, L. Ching-Shan, J. Yimin, F.C. Lee; "Novel zero-voltage-transition PWM converters," IEEE Trans. on Power Electronics, vol.9, no.2, pp.213-219, Mar 1994.

[6] I. Barbi, J.C. Bolacell, D.C Martins and F.B. Libano; "Buck quasi-resonant converter operating at constant frequency: analysis, design, and experimentation," IEEE Trans. on Power Electronics, vol.5, no.3, pp.276-283, Jul 1990.

[7] P. Das, A. Mousavi and G. Moschopoulos; "Analysis and design of a nonisolated bidirectional ZVS-PWM Dc-Dc converter with coupled inductors," IEEE Trans. on Power Electronics, vol.25, no.10, pp.2630-2641, Jul 2010.

[8] E. Sanchis-Kilders, A. Ferreres, E. Maset, J. B. Ejea, J. Jordan, A. Garrigos, and J. Calvente, "Soft switching bidirectional converter for battery discharging-charging," in Proc. IEEE APEC Conf. Rec., 2006, pp. 603-609.

[9] X. Yan; A. Seckold and D. Patterson; "Development of a zero-voltage-transition bidirectional Dc-Dc converter for a brushless DC machine EV propulsion system," PIEEE PESC Conf, 2002. Vol.4, no., pp. 1661- 1666.

[10] P. Das, B. Laan, A. Mousavi and G. Moschopoulos; "A nonisolated bidirectional ZVS-PWM active clamped DC-DC converter," IEEE Trans. on Power Electronics, vol.25, no.10, pp.2630-2641, Feb 2009.

[11] J. Zhang, R.-Y. Kim, and J.-S. Lai,"High-power density design of a soft-switching high-power bidirectional Dc-Dc converter," IEEE PESC Conf. Rec., 2006, pp. 1-7

[12] P. Das; A. Mousavi and G. Moschopoulos, "A novel ZVS-PWM Dc-Dc converter for bidirectional applications with steep conversion ratio," IEEE ECCE Conf. Rec., 2009, pp.2030-2036.

[13] B. P. McGrath, D. G. Holmes, P. J. McGoldrick, and A. D. McIve, "Design of a softwitched 6-kW battery charger for traction applications," IEEE Trans. on Power Electronics, vol. 22, no. 4, pp. 1136- 1144, Jul. 2007. 
[14] K. Jin, Y. Sun, M. Xu, D. Sterk, and F.C. Lee, "Integrated magnetic self-driven ZVS nonisolated full-bridge converter," IEEE Trans. on Industrial Electronics, vol. 57, no. 5, pp. 1615-1623, May. 2010.

[15] X. Zhang, W. Chen, X. Ruan, and K. Yao, "A novel ZVS PWM phase-shifted fullbridge converter with controlled auxiliary circuit," in Proc. IEEE APEC, 2009, pp. 1067-1072.

[16] M. Xu, Y. Ren, J. Zhou, and F.C. Lee, "1-MHz self-driven ZVS full-bridge converter for 48-V power pod and dc/dc brick," IEEE Trans. on Power Electronics, vol. 20, no.5, pp. 997-1006, Sept. 2005.

[17] W. Chen, X. Ruan, and J. Ge, "A novel full-bridge converter achieving ZVS over wide load range with a passive auxiliary circuit," in Proc. IEEE ECCE, 2010, pp. $1110-1115$.

[18] D. Sterk, M. Xu, and F.C. Lee, "High frequency ZVS self-driven full-bridge using full integration of magnetics," in Proc. IEEE APEC, 2010, pp. 1210-1216.

[19] Z. Chen, M. Chen, F. Ji, and J. Li, "Analysis and implementation of a novel fullbridge ZVS converter with adaptive auxiliary circuit," in Proc. IEEE IECON, 2010, pp. 358-363.

[20] P. Meng, X. Wu, C. Zhao, and Z. Qian, "Integrated magnetic ZVS full-bridge converter with phase shifted control," in Proc. IEEE APEC, 2009, pp. 1434-1439.

[21] W. Huai, S. Qian, H. Chung, S. Tapuchi and A. Ioinovici, "A ZCS current-fed fullbridge PWM converter with self-adaptable soft-switching snubber energy," IEEE Trans. on Power Electronics, vol. 24, no.8, pp. 1977 - 1991, Aug. 2009.

[22] K. Fathy, T. Doi, K. Morimoto, H. Lee, and M. Nakaoka, "A novel soft-switching PWM full-bridge DC/DC converter with DC busline series switch-parallel capacitor edge resonant snubber assisted by high-frequency transformer leakage inductor," in Proc. IEEE IPEMC, 2006, pp. 1-5.

[23] K. Suzuoka, S. Moisseev, L. Gamage, K. Soshin, K. Nishida, and M. Nakaoka, "Boost transformer linked full bridge soft-commutation Dc-Dc power converter with secondary-side phase-shifted PWM rectifier switches," in Proc. IEEE IECON, 2003, pp. 49-54.

[24] K. Jin, and X. Ruan, "Hybrid full-bridge three-level LLC resonant converter-A novel Dc-Dc converter suitable for fuel-cell power system," IEEE Trans. on Industrial Electronics, vol. 53, no.5, pp. 1492-1503, Oct. 2006.

[25] X. Sun, J. Liu, X. Jin, and W. Wu, "High power high frequency zero current transition full bridge Dc-Dc converter," in Proc. IEEE APEC, 1998, pp. 823-828.

[26] Z. Zhang, H. Chung, Z. Ruan and A. Ioinovici, "A ZCS full-bridge converter without voltage overstress on the switches," IEEE Trans. on Power Electronics, vol. 25, no.3, pp. 686-698, Mar. 2010. 
[27] Y. Huang, C. Liu, and Y. Konishi, "Soft-switching PWM full-bridge Dc-Dc converter with energy recovery transformer and auxiliary passive lossless snubbers," in Proc. IEEE INTELEC, 2007, pp. 622-627.

[28] J. Cho, C. Jeong, and F.C. Lee, "Zero-voltage and zero-current-switching full-bridge PWM converter using secondary active clamp," IEEE Trans. on Power Electronics, vol. 13, no.4, pp. 601 - 607, July 1998.

[29] F. Liu, J. Yan, and X. Ruan, "Zero-voltage and zero-current-switching PWM combined three-level dc/dc converter," IEEE Trans. on Industrial Electronics, vol. 57, no. 5, pp. 1644-1654, May. 2010.

[30] K. Seok, and B. Kwon, "An improved zero-voltage and zero-current-switching fullbridge PWM converter using a simple resonant circuit," IEEE Trans. on Industrial Electronics, vol. 48, no. 6, pp. 1205-1209, Dec 2001.

[31] X. Feng, X. Guo, and L. Xiu, "A novel zero-voltage and zero-current-switching fullbridge PWM converter," in Proc. IEEE IECON, 2003, pp. 383-390.

[32] I. H. Cho, D. Y. Kim and G. W Moon, "Zero-voltage zero-current switching full bridge PWM converter with reduced filter size," in Proc. IEEE ICPE, 2011, pp. 15851590.

[33] J. Cho, J. Baek, C. Jeong, D. Yoo, K. Joe, "Novel zero-voltage and zero-currentswitching full bridge PWM converter using transformer auxiliary winding," IEEE Trans. on Power Electronics, vol. 15, no.2, pp. 250-257, March 2000.

[34] X. Wu, X. Xie, C. Zhao, Z. Qian, and R. Zhao, "Low voltage and current stress ZVZCS full bridge DC-DC converter using center tapped rectifier reset," IEEE Trans. on Industrial Electronics, vol. 55, no. 3, pp. 1470-1477, March 2008.

[35] T. Song, and N. Huang, "A novel zero-voltage and zero-current-switching full-bridge PWM converter," IEEE Trans. on Power Electronics, vol. 20, no.2, pp. 286-291, March 2005.

[36] Y. Bao, S. Li, J. Jiang, and W. Zhang, "Research and improvement of a zero-voltage zero-current switching full-bridge converter," in Proc. IEEE PESC, 2010, pp. 825829.

[37] Y. Ma, X. Wu, J. Zhang, and Z.Qian, "ZVZCS full bridge Dc-Dc converter with reduced circulating loss and filter requirement," in Proc. IEEE Industry Applications Conference, 2007, pp. 1988-1992.

[38] J. Cho, J. Baek, C. Jeong, G. Rim, "Novel zero-voltage and zero-current-switching full-bridge PWM converter using a simple auxiliary circuit," IEEE Trans. on Industrial Applications, vol. 35, 1, pp. 15-20, Feb 1999.

[39] L. Zhu; "A novel soft-commutating isolated boost full-bridge ZVS-PWM Dc-Dc converter for bidirectional high power applications," IEEE Trans. on Power Electronics, Vol. 21, No. 2, pp. 422-429, March 2006. 
[40] A. Vázquez, C. Aguilar, F. Canales, and M. Ponce, "Integrated power conditioner topology for fuel cell based power supply systems," in Proc. IEEE Power Electronics Specialists Conf. (PESC), 2008, pp. 223-229.

[41] W. Song, B. Lehman; "Current-fed dual-bridge Dc-Dc converter," IEEE Trans. on Power Electronics, Vol. 22, No. 2, pp. 422-429, March 2007.

[42] H. Xiao and S. Xie, "A ZVS bidirectional Dc-Dc converter with phase-shift plus PWM control scheme," IEEE Trans. on Power Electronics, vol. 23, no. 2, pp. 813823, March 2008.

[43] J. Cho, C. Jeong, H. Lee, G. Rim; "Novel zero-voltage-transition current-fed fullbridge PWM converter for single-stage power factor correction," IEEE Trans. on Power Electronics, Vol. 13, No. 6, pp. 1005-1012, Nov 2008.

[44] M. Mohr and F. W. Fuchs," Clamping for current-fed de/dc converters with recovery of clamping energy in fuel cell inverter systems," in Proc. Euro. Conf. on Power Elec. and Appl., 2007 pp.1-10.

[45] W. Li, J. Liu, J. Wu, and X. He, "Design and analysis of isolated ZVT boost converters for high-efficiency and high-step-up applications," IEEE Trans. on Power Electronics, vol. 22, no. 6, pp. 2363-2374, Nov. 2007.

[46] P. D. Ziogas, A. R. Prasad, and S. Manias, "A three phase resonant PWM dc/dc converter," in Proc. IEEE 22nd Annul. Power Electronics Specialists Conf. (PESC '91), Cambridge, MA, Jun. 24-27, 1991, pp. 463-473.

[47] H. Cha, J. Choi, W. Kim, V. Blasko; " A New Bi-directional three-phase interleaved isolated converter with active clamp," in Proc IEEE APEC Conf, 2009. pp. 17661772 .

[48] C. Liu, A. Johnson, and J. Lai, "A novel three-phase high-power soft-switched Dc-Dc converter for low-voltage fuel cell applications," IEEE Trans. on Industry Applications, vol. 41, pp. 1691-1697, Nov.-Dec. 2008.

[49] G. Franceschini, E. Lorenzani, M. Cavatorta, and A. Bellini, "3boost: A high-power three-phase step-up full-bridge converter for automotive applications," IEEE Trans. on Industrial Electronics., vol. 55, no. 1, pp. 173-183, Jan. 2008.

[50] H. Cha, J. Choi, P. N. Enjeti, "A three-phase current-fed dc/dc converter with active clamp for low-dc renewable energy sources," IEEE Trans. on Power Electronics, vol. 23, no.6, pp. 2784-2793, Nov. 2008.

[51] A. Bhat and L. Zheng, "Analysis and design of a three phase LCC type resonant converter," IEEE Trans. on Aerospace and Electronic Systems, vol. 34, no.2, pp. 508519, Nov. 1998.

[52] H. Cha, S. Choi; "Comparison of PWM strategies for three-phase current-fed Dc-Dc converter," in Proc. IEEE Power Electronics ICPE. $7^{\text {th }}$ International Conference, Oct. 2007, pp. 895-899. 
[53] C. Dick, A. Konig, R. Doncker; "Comparison of three-phase Dc-Dc converters vs. single-phase Dc-Dc converters," in Proc. Power Electronics and Drive Systems, (PEDS) Conference, Nov 2007, pp. 217-224.

[54] J. Bazinet and J. O'Connor, "Analysis and design of a zero-voltage transition power factor correction circuit," in IEEE Applications Power Electronics Conf. Rec., 1994, pp. 591-600. 


\section{Curriculum Vitae}

\section{Name:}

Ahmad Mousavi

\section{Education:}

Ph.D in Electrical Engineering - Power Electronics

University of Western Ontario, London, Ontario

Thesis: Soft-Switching Dc-Dc Converters

Masters of Science in Electrical Engineering- Power Electronics

University of Western Ontario, London, Ontario

Thesis: A novel ZCS PWM full-bridge Dc-Dc converter for fuel cell applications

Certificate - Electro Mechanical Design

Seneca College, Toronto, Ontario

Bachelor of Science in Electrical Engineering- Power Electronics

Tehran University of Technology, Tehran, Iran

\section{Professional Experience:}

Research Assistant

2007-2013

University of Western Ontario, London, Ontario

- Soft-switching techniques, Converter topologies, Green and renewable energy

- New methods of soft-switching in fuel-cell applications applied in Hybrid vehicles.

The objective of improving the efficiency was achieved by reducing the switching losses in the converters

Power Electronics design Engineer

2004-2007

LG Electronics, Mississauga, Ontario

- Power System Design and Analysis and power supply design

- Coordinating with Marketing and Customers to identify and implement new requirements and features

Electrical Engineer

2002-2004

Gital Company, Tehran, Iran

- Providing technical support in the design of Electrical distribution systems

- Designing Pre-fabricated Pre-cabled Systems (BUSDUCTS) 


\section{Publications:}

- A.Mousavi, and G.Moschopoulos, "A New ZCS-PWM Full-Bridge Dc-Dc Converter with Simple Auxiliary Circuits," in IEEE Trans. on Power Electronics, Early Access

- A.Mousavi, P.Das, and G.Moschopoulos, "A Comparative Study of a New ZCS DC-DC FullBridge Boost Converter With a ZVS Active-Clamp Converter," in IEEE Trans. on Power Electronics, March.2012, vol.27,no.3, pp.1347-1358

- P.Das, A.Mousavi, and G.Moschopoulos, "Analysis and Design of a Nonisolated Bidirectional ZVS-PWM DC-DC Converter With Coupled Inductors," in IEEE Trans. on Power Electronics, Oct.2010, vol.25,no.10, pp.553-558

- P.Das, B.Laan, A.Mousavi , and G.Moschopoulos, "A Non-isolated Bidirectional ZVS-PWM Active Clamped DC-DC Converter," in IEEE Trans. on Industrial Electronics, Feb.2009, vol.24, no.2, pp.553-558

- A.Mousavi, P.Das, and G.Moschopoulos, "A novel three-phase ZVS PWM DC-DC boost converter", in IEEE APEC Conf. 2013, pp. 50-54.

- A.Mousavi, P.Das, and G.Moschopoulos, "A Novel ZCS-PWM Full-Bridge Converter with a Simple Active Auxiliary Circuit", in IEEE APEC Conf. 2012, pp. 459-464.

- A.Mousavi, M. Pahlevaninezhad, P.Das, and P. Jain, "ZCS PWM bidirectional converter with one auxiliary switch," in IEEE ECCE Conf.2011, pp. 1175-1180

- A.Mousavi, P.Das, and G.Moschopoulos, "ZVS and ZCS Dc-Dc PWM full-bridge fuel cell converters," in IEEE APEC Conf. 2010, pp. 564-570.

- P.Das, A.Mousavi, and G.Moschopoulos, "Analysis and design of a novel ZVS-PWM Dc-Dc converter for bidirectional applications with steep conversion ratio," in IEEE APEC Conf. 2010, pp. 1222-1229.

- P.Das, A.Mousavi, G.Moschopoulos, and P.Jain "A Study of AC-DC ZVS-PWM Boost Converters with Silicon Carbide Diodes," in IEEE APEC Conf. 2009, pp. 1158-1164.

- A.Mousavi, P.Das, and G.Moschopoulos, "A ZCS-PWM Full-Bridge Boost Converter for Fuel-Cell Applications," in IEEE APEC Conf. 2009, pp. 459-464.

- A.Mousavi, P.Das, and G.Moschopoulos, "Analysis and Design of a New ZCS-PWM FullBridge Fuel Cell Converter”, IEEE ECCE Conf.2009, pp.2037-2042

- P.Das, A.Mousavi, and G.Moschopoulos, "A novel ZVS-PWM Dc-Dc converter for bidirectional applications with steep conversion ratio" in IEEE ECCE Conf.2009, pp. 2030 2036

- P.Das, A.Mousavi, and G.Moschopoulos, “An ac-dc single-stage full-bridge PWM converter with bridgeless input," in IEEE ECCE Conf.2009, pp. 1347-1352

- B.Laan, P.Das, A.Mousavi, and G.Moschopoulos, "A novel bidirectional PWM Dc-Dc converter," in IEEE CCECE Conf.2008, pp. 313-316 